
March 1942

\title{
TENSILE ELASTIC PROPERTIES OF NICKEL, COPPER, OPEN-HEARTH IRON, AND TYPICAL STEELS
}

\author{
By Dunlap J. McAdam, Jr., and Russell W. Mebs
}

\section{ABSTRACT}

From stress-set curves are derived proof stresses for five values of permanent set. From corrected stress-strain curves are derived values of the modulus at zero stress and its stress coefficient. The diagrams show the influence of prior plastic extension on these indices.

The curves of variation of the proof stresses with plastic extension are affected by the rate of work-hardening, by variation of internal stresses of two kinds, and by the rest interval. The curves of variation of the modulus of elasticity with plastic extension are affected by variation of crystal orientation, internal stress, and lattice expansion, and by rest. The curves of variation of the stress coefficients of the modulus are affected by all these factors except possibly the reorientation factor.

\section{CONTENTS}

Page

I. Introduction

II. Materials, specimens, and apparatus

1. Materials and specimens _._. 313

2. Apparatus

III. Measurement of stress, strain, and permanent set

1. Method of test

2. Plotting of results

3 . Accuracy of determination of set and strain values _...... 316

IV. Tensile elastic properties of nickel

1. Influence of plastic extension on the elastic strength of annealed nickel

2. Internal stresses and their effects on the proof stresses..... 319

3. General description of the stress-deviation curves for nickel and their relation to the stress-set curves

4. Influence of stress on the modulus of elasticity of nickel

5 . Indices of variation of the modulus of elasticity with stress

6. Form of the corrected stress-strain curve for nickel ......... 323

7. Influence of plastic extension of annealed nickel on the modulus of elasticity and on its linear stress coefficient _......... 324

8. Influence of prior plastic extension of nickel on the quadratic stress coefficient, $C^{\prime}$, of the modulus of elasticity _..._. 325

9. Elastic properties of severely cold-drawn nickel as affected by further plastic extension and by annealing for relief of internal stress

10. The secant modulus at any stress 
V. Tensile modulus of elasticity of 18:8 chromium-nickel steel and of copper as affected by stress and by plastic extension.

1. Influence of prior plastic extension of $18: 8$ alloy on the modulus of elasticity and on its linear stress coefficient, $C_{0} \ldots \ldots \ldots$

2. Influence of prior plastic extension of copper on the stressmodulus line

3. Influence of prior plastic extension of copper on the modulus of elasticity and on its linear stress coefficient, $C_{0} \ldots$

4. Influence of prior plastic extension of 18:8 alloy and of copper on the quadratic stress coefficient, $C$, of the modulus of elasticity.

VI. Tensile elastic properties of open-hearth iron and some carbon steels
1. Age-hardening of open-hearth iron during intermittent plastic

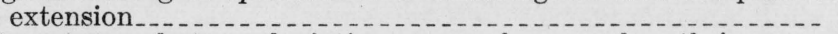

2. Stress-set and stress-deviation curves for open-hearth iron . - 331

3. Stress-modulus lines for open-hearth iron ............... 332

4. Influence of prior plastic extension of open-hearth iron on the modulus of elasticity and on its linear stress coefficient, $C_{0 \ldots}-332$

5. Influence of prior plastic extension of three carbon steels on the modulus of elasticity and on its linear stress coefficient, $C_{0-\ldots} 333$

6. Influence of prior plastic extension of three carbon steels on the quadratic stress coefficient, $C^{\prime}$, of the modulus of elasticity _- 333

VII. Crystal orientation and its influence on elastic properties _... . .

1. Directional variation of the modulus of elasticity of single

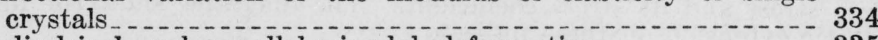

2. Cylindrical and parallelopipedal deformation

3 . Influence of plastic extension on the crystal orientation of facecentered cubic metals.

4. Influence of plastic extension on the crystal orientation of body-centered cubic metals .

5. Effect of annealing on erystal orientation.

6. Directional variation of the elastic strength of a single crystal_- 339

VIII. Some important factors associated with plastic extension; their effects

on the modulus of elasticity and on its stress coefficients
1. Results obtained by other investigators of the influence of

plastic extension on the tensile modulus of elasticity
2. Factors affecting the variations of $C_{0}$ and $C^{\prime}$ with prior plastic

3. Factors affecting the variations of $E_{0}$ with prior plastic extension

4. The secant modulus at the yield stress

IX. Conclusions

X. References_... 347

\section{INTRODUCTION}

The elastic properties to be considered in this paper comprise the elastic strength and modulus of elasticity. By "elastic strength" is meant the stress necessary to deform the metal to the boundary between elastic and inelastic strain. As shown in a previous paper by the authors [22], ${ }^{1}$ this boundary generally is not definite. For practical purposes, therefore, the elastic strength is generally expressed in terms of one or more indices which represent the stress that causes a specified slight permanent extension. In the previous paper, the tensile elastic strength and yield strength of 18:8 chromium-nickel steel are expressed in terms of five indices termed "proof stresses." These are the stresses necessary to cause permanent extensions of $0.001,0.003,0.01,0.03$, and 0.1 percent. The same indices will be used in this paper.

As the stress-strain line for 18: 8 chromium-nickel steel and for many other metals is curved, the modulus of elasticity cannot be expressed

1 Figures in brackets indicate the literature references at the end of this paper. Additional references pertaining to the elastic properties of metals but not specifically referred to in this paper are also included. 
by a single numerical value. In the previous paper [22], the modulus of elasticity is expressed in terms of two indices: the modulus at zero stress, $E_{0}$, which is determined by extrapolating the stress-modulus line to zero stress; and the stress coefficient of the modulus. In the previous paper, the linear stress coefficient is designated $C_{1}$. In this paper, it will be designated $C_{0}$, and the quadratic stress coefficient will be designated $C^{\prime}$. When $E_{0}, C_{0}, C^{\prime}$, and the five proof stresses are known, a fairly good picture is available of the elastic properties of a metal.

Even at stresses below the 0.001-percent proof stress, deformation may increase with time at constant load. A prevalent designation for such an increase of deformation is "drift." After release of the load, moreover, deformation generally continues for a time in the reverse direction to that of the loading. Such deformation is often termed "elastic aftereffect", although this term is not generally appropriate. After a fairly rapid increase or removal of the load, a considerable part of the change in dimensions may be due to "thermal creep", a purely elastic effect first described and explained by Kelvin. The changes of dimension under constant load or after removal of the load, however, are not due entirely to thermal creep. They frequently consist almost entirely in a slower change, which may continue for days or even weeks. As the slow deformation after release of the load is a type of inelastic action, it is not properly termed "elastic aftereffect."

A general term is needed to designate any type of continuing deformation that does not require a continuing change of the load. The word "creep", frequently used with this meaning, will be so used in this paper. The change occurring after removal of the load will be termed "negative creep." A fairly sharp distinction can be made between thermal creep and the slower creep. If there is a real difference between the so-called drift and other types of slow creep referred to in the literature, however, the authors are not able to make such a distinction in discussion of the data to be presented.

The modulus of elasticity, its stress coefficients, and the elastic strength of a metal are affected by three important factors associated with plastic extension. In order to distinguish the effects of these factors, a comparison has been made of the effects of plastic deformation on the elastic properties of a variety of metals, including nickel, copper, and typical steels.

\section{MATERIALS, SPECIMENS, AND APPARATUS}

\section{MATERIALS AND SPECIMENS}

The materials included in this investigation are nickel, oxygenfree copper, open-hearth iron, 0.20-percent carbon steel (SAE 1020), 0.42 -percent carbon steel (SAE 1040), and 0.73-percent carbon steel (SAE 1075). Comparison is made between the results obtained with these metals and with some 18:8 chromium-nickel steels, discussed in a previous paper [22].

The nickel was supplied by The International Nickel Co. through the cooperation of W. A. Mudge and the Washington representatives of the company. The oxygen-free copper was supplied by the Scomet Engineering Co. through the cooperation of Sidney Rolle, Assistant Manager. Acknowledgment is made to these companies and to their 


\section{Journal of Research of the National Bureau of Standards}

representatives for their generous cooperation. The elastic properties of this copper were discussed in another publication [23] and are included in this paper with the permission of the National Advisory Committee for Aeronautics. The open-hearth iron and the three SAE steels were purchased in the open market.

All these metals were supplied in the form of round rods. The nickel had been given a reduction in area of 60 percent by cold-drawing without intermediate anneal. The copper had been given a reduction in area of 75 percent by cold-rolling without intermediate anneal. The three SAE steels had been hot-rolled. The open-hearth iron as received had been cold-drawn from 1 in. in diameter to $15 / 16$ in. in diameter. It was cold-drawn further at this Bureau, without intermediate anneal, to a total reduction in area of about 50 percent. (The exact amount is indicated in table 1). A description of the metals is given in table 1. Details of heat treatment are given in table 2, and the tensile properties are given in table 3. The serial designations of the specimens are given in the tables.

Only tension test specimens were used in this investigation. The diameters of these specimens over their gage length are given in table 3 and the corresponding rod diameters in table 1. As the error (in pounds) in estimating the load is practically independent of the load, the percentage error decreases with increase in the load. The percentage error, therefore, decreases with increase in the cross section of the specimen, because an increase in specimen size will require an increase in load to produce an equivalent stress.

The dimensions of the specimens were according to the standard for the American Society for Testing Materials with threaded ends and 2-in. gage, except for specimens of nickel and open-hearth iron. As the rod diameters of these materials were smaller than standard $3 / 4$-in. thread diameters, their diameters over the gage length were 0.417 in., nominal. The ratio of gage length to diameter was unimportant in this investigation, because the investigation of elastic properties never required extension beyond the beginning of local contraction.

\section{APPARATUS}

A pendulum hydraulic testing machine of $50,000-1 \mathrm{~b}$ capacity was used. The specimens were held in grips with spherical seats. In the earlier experiments [22] upon 18:8 Cr-Ni steel, a Ewing extensometer with ratio 5:1 was used. The smallest scale division on this instrument corresponds to a change of length of 0.00008 in., and readings could be estimated to about \pm 0.000008 in.; this sensitivity corresponds to a strain sensitivity of $\pm 4.0 \times 10^{-4}$ percent for the 2 -in. gage length used. In the remaining experiments, a pair of Tuckerman optical strain gages was used; the gages were attached to the opposite sides of the specimens. The smallest scale division on this extensometer corresponds to a change in length of 0.00004 in. By means of a vernier on this instrument, it is possible to estimate changes in length to within about 0.000002 in.; this sensitivity corresponds to a strain sensitivity of $1.0 \times 10^{-4}$ percent for the 2 -in. gage length used. 


\section{MEASUREMENT OF STRESS, STRAIN, AND PERMANENT SET}

\section{METHOD OF TEST}

In order to investigate the relationship between stress, strain, and permanent set, for a metal in a given state, a stress-set curve and a correlated stress-strain curve were determined. For this purpose the specimen was loaded and unloaded cyclically to successively greater values of load until it had been plastically extended about 0.1 percent. The minimum value of the load in each cycle was $200 \mathrm{lb}$. By plotting each stress at the top of a cycle against the corresponding total strain, a stress-strain curve was obtained. By plotting each stress at the top of a cycle against the corresponding value of total permanent set after reduction of the load to $200 \mathrm{lb}$, a stress-set curve was obtained. A detailed discussion of such a series of loading cycles is given in a previous paper [22].

In obtaining such correlated stress-strain and stress-set curves, it is important to adhere to a carefully arranged time schedule. In a series of loading cycles, the rates of loading and unloading were about the same for all the cycles. The load was held for a period of 2 minutes at the upper and lower values in each cycle. Extensometer readings were obtained at the beginning of the test and the end of each 2-minute holding period.

The total set at the end of any cycle (at 200-lb load) was measured as the difference between that extensometer reading and the reading at the beginning of the series of loading cycles. The permanent set obtained during a single cycle is equivalent to the difference between the positive and negative creep occurring during the cycle. Positive creep will occur while approaching and holding the upper load; negative creep will occur while approaching and holding the 200-lb load. The total strain for any load was measured as the difference between the extensometer readings at that load and the beginning of the series.

In order to investigate the influence of prior plastic extension on the stress-set and stress-deviation curves, some specimens were extended plastically by numerous increments to about the point of beginning local contraction. Correlated stress-strain and stress-set curves were obtained upon the unextended specimen and after each increment of extension. Some of these extension increments were large; others were equivalent only to the extension obtained in determining the previous stress-set curve. Between increments of extension, the specimen was allowed to rest before determining the stress-strain and stress-set curves. The duration of such a "rest interval" will have a pronounced influence upon the form of the stress-set and stressdeviation curves derived from subsequent measurements.

Certain changes will occur in the test specimen during a rest interval, as evidenced by negative creep during this period. As shown in a preceding report [22], these changes may be greatly accelerated by slightly elevating the temperature of the specimen during the rest interval. In order to study further the influence of slightly elevated temperature upon subsequently measured values of total strain and set, some few specimens were tested in which the rest intervals consisted of 1-hour periods with the specimens immersed in boiling water. The intervening plastic extensions for these tests were all large. 
The prior plastic extension for any one series of cycles will be defined as the difference in strain, as observed at $200 \mathrm{lb}$, at the beginning of that series, and at the beginning of the first series upon the specimen. The terms "prior plastic extension," "prior extension," and "plastic extension" are synonomous in this report. Since the extensometer was reset after each series of cycles, the prior extension was actually measured as the sum of the total sets given the specimen prior to that series.

For any given series of cycles, the cross-sectional area of the specimen upon which the stress is based will be equal to the original crosssectional area, divided by the quantity 1 plus the prior extension, the extension being expressed as fractional change in gage length.

\section{PLOTTING OF RESULTS}

Stress-set curves were plotted from calculated values of stress and total set, as described earlier.

The stress-strain relationship is better studied by means of the stress-deviation curve. Such a curve is obtained by plotting against the stress, the difference between the total strain for each upper load and a strain computed on the basis of an assumed constant value of the modulus of elasticity, corresponding to the same load. These differences represent deviations of the actual stress-strain curve from a straight stress-strain line whose slope represents the chosen value of the modulus. By a suitable choice of the assumed value of the modulus, the stress-deviation curve gives a very sensitive representation of the variation of strain with stress.

The derivations of the several elastic properties from stress-set and stress-deviation curves are described in section IV.

\section{ACCURACY OF DETERMINATION OF SET AND STRAIN VALUES}

Values of set were not determined from strain readings at zero load, but at $200 \mathrm{lb}$. Because of the change in elastic strain with the load, any deviation in the actual load from the nominal value of 200 $\mathrm{lb}$, while reading, will introduce an error in the test. This deviation will depend upon the sensibility of reading the scale of the testing machine, the drift in zero position of the scale, and the ability of the testing-machine operator to adjust and maintain the load during extensometer readings.

By allowing the testing machine to attain temperature equilibrium under operating conditions, before beginning the test, the drift of the zero scale position over the time necessary to make several load cycles will be negligible.

The combined influence of sensibility of the scale reading, drift in zero position of the scale, and ability to set the load was determined by the following empirical test: A specimen with a gage diameter of $3 / 4$ in. was secured of a material to which a high value of stress could be applied without producing measurable set. This specimen was loaded cyclically several times to $10,000 \mathrm{lb}$. (slightly less than the load necessary to produce measurable set). The specimen was then allowed to rest long enough to permit all the thermal creep to occur. Tuckerman strain gages were then attached to opposite sides of the specimen. The load was varied between 200 and $500 \mathrm{lb}$ cyclically five times by each of four separate operators. A rest period of 
1 minute was given at each 200 -lb. load, before measuring the strain. The 25,000-lb. scale range of the testing machine was employed during these tests.

For an assumed modulus of 30 million pounds per square inch, and with the area of the specimen being calculated from its gage diameter, the variation in strain readings was expressed in terms of the load change on the specimen. In the case of any one operator this change was not greater than $6 \mathrm{lb}$., for successive cycles; in general, it was somewhat less. Over any five cycles for one operator, the maximum change was slightly greater, about $8 \mathrm{lb}$., which indicates a small value for drift in zero-position of the load scale. For the specimens with a gage diameter of 0.505 and 0.417 inch used in this investigation, an error of $6 \mathrm{lb}$. corresponds to stress errors of 30 and $45 \mathrm{lb} . / \mathrm{in} .^{2}$, respectively. These stress errors correspond to strain errors of 0.001 and 0.0015 percent, for an assumed modulus of 30 million pounds per square inch. These errors will be most important in determining total sets at the lower values of stress. As proof stresses (defined later) are based on total sets ranging from 0.001 to 0.1 percent, the corresponding errors in these proof stresses will range from about 10 percent to 0.1 percent for 0.505 -in. specimens, and from about 15 to 0.15 percent for 0.417 -in. specimens.

Such errors will be minimized when a number of experimental points are used in fairing the stress-set curves. The 10- or 15-percent errors noted above for the proof stress corresponding to 0.001-percent total set, though large, will be shown later to be insufficient to invalidate the conclusions drawn from the tests.

The error in the strain measurement at the upper load will be greater, owing to the greater difficulty in setting and maintaining the load, and to the variation in the calibration error over the employed scale range of the testing machine. Although no direct measurement of this error is possible, it is probably small, as evidenced by the nearness of the points to the smooth stress-deviation curves obtained in this report.

\section{TENSILE ELASTIC PROPERTIES OF NICKEL}

\section{INFLUENCE OF PLASTIC EXTENSION ON THE ELASTIC STRENGTH OF ANNEALED NICKEL}

In studying the elastic properties of nickel, attention will be given first to the elastic strength of fully annealed nickel, as affected by plastic extension, and second to the modulus of elasticity and its stress coefficients.

The recrystallization range for cold-worked nickel is about $1,150^{\circ} \mathrm{F}$, but depends considerably on the degree of cold work. For the investigation of the elastic properties of fully annealed nickel, a specimen was annealed at $1,400^{\circ} \mathrm{F}$. Correlated stress-deviation and stress-set curves obtained with this specimen are shown in figure 1 . The stress-set curves are in the lower row of the figure. Directly above the origin of each stress-set curve is the origin of a corresponding pair of stress-deviation curves. The stress-set curves are used in the following study of the elastic strength of nickel.

The origin of each stress-set curve is shifted to the right a constant distance from the origin of the preceding curve. Each curve thus has its own scale of abscissas. Distances between the origins have no relation to the scale of abscissas. The curves were obtained con- 
secutively from left to right, in pairs, by methods described in saction III, and with intervening (varying) amounts of prior plastic extension.

The prior extensions for individual curves are not indicated in figure 1. The curves are numbered consecutively, however, and the percentages of prior extension may be found by referring to the correspondingly numbered experimentally determined points in figure 3 , which is derived from the stress-set curves in figure 1.

The rest intervals between two series of cycles, from which a pair of stress-set curves was determined, range from 31 to 37 minutes; between separate pairs of curves, the rest interval was somewhat longer. The rest interval preceding each series of cycles from which a stress-set curve is obtained is indicated in figure 1 by the symbol placed at one or more experimentally determined points on the curve.

From each stress-set curve are derived five proof stress values corresponding to total sets of $0.001,0.003,0.01,0.03$, and 0.1 percent. These will be designated by the letter $P$ with subscripts indicating the percentages of permanent set. In figure 3, these proof stresses are plotted against the corresponding percentages of prior plastic extension. The five curves thus obtained are separated by using five different indicated scales of ordinates. The ordinates represent stress, based on the sectional area at the beginning of the series of load cycles used in determining each stress-set curve. The method of calculating this area is given in section III.

In each curve of figure 3 , the points derived from experiment are distributed along the prior extension axis, in pairs, which are separated by relatively long intervening plastic extensions. Each pair of points is derived from a pair of stress-set curves determined with no intervening plastic extension. The difference in plastic extension for the curves of a pair, therefore, is merely the total set obtained in determining the first curve of the pair. The alternate long and short extensions, as in the investigation described in the previous paper [22], were made in order to reveal the influence of the amount of intervening plastic extension on the form of the stress-set curve and on the derived proof stresses. The distribution of these extensions over the range of prior extensions shown is termed "extension spacing."

The stress-set relationship, as affected by plastic extension, rest interval, and extension spacing, may best be studied by considering both the stress-set curves and the derived curves of variation of the proof stresses with prior plastic extension. The steeper the stress-set curve, the higher are the derived proof stresses. As indices of elastic strength, the proof stresses based on 0.001- and 0.003-percent permanent set probably should receive more consideration than the proof stresses based on larger percentages of permanent set. The 0.1-percent proof stress should be viewed as an index of yield strength rather than as an index of elastic strength.

The oscillations in the curves for 0.001-percent proof stress are usually large and parallel to those for greater values of set. They are due principally, therefore, to variations in properties of the test specimen, not to any lack of sensitivity of the testing apparatus.

The first stress-set curve of each pair (figure 1) generally is less steep than the second. This relationship is illustrated also by the relative heights of the experimentally derived points in the diagram (fig. 3); the first point of each pair, with few exceptions, is lower than the 
second. As shown in the previous paper [22], such differences in height are due partly to differences in the duration of the rest interval. The longer the rest interval, the lower generally is the corresponding point in the diagram. This influence of duration is most prominent for short rest intervals, and is slight after the first day. The generally higher position of the second point of a pair, however, is due partly to the influence of the extension spacing. The evidence in figures 1 and 3 , consequently, indicates that the influence of the rest interval and of the extension spacing is qualitatively the same for nickel as for 18:8 chromium-nickel steel [22]

The oscillations due to the influence of the rest interval and of the extension spacing are superposed on curves of variation of the proof stresses due to prior plastic extension alone. These latter curves, hereafter termed basic curves, are smooth in form, but cannot be determined independently. The basic curves would be nearly parallel, however, to curves drawn through the mean position of the oscillations. If the basic curves were drawn in figure 3 , all but the lowest curve would rise continuously, at a gradually decreasing rate. The basic curve for the 0.001 -percent proof stress would not rise continuously, but would have several minima and maxima. With 18:8 chromium-nickel steel [22], such minima and maxima are found in the basic curves for $0.001-$ and 0.003 -percent proof stresses. These curves for the 18:8 alloy generally have an initial rise, whereas the basic 0.001 -percent proof-stress curve in figure 1 possibly has a slight initial descent. This is illustrated by the fact that point 3 is lower than point 1 .

\section{INTERNAL STRESSES AND THEIR EFFECTS ON THE PROOF STRESSES}

The oscillations in proof-stress extension curves may be attributed to variations of one or more kinds of internal stress caused by the extension spacing and by variations in the rest interval. As shown by Heyn and Bauer [16] and by Masing [25], the internal stresses induced by plastic deformation are of three kinds. The first is caused by nonuniformity of plastic deformation in different parts of a cross section. Internal stress of this kind may be measured approximately by Heyn's method. Such internal stress tends to lower the observed elastic strength. The second kind of internal stress is due to initial differences in the resistance to plastic deformation of variously oriented grains of a polycrystalline aggregate, and to differences in the strength of different microconstituents. This condition exists in metal that has been stressed beyond its yield strength; it varies from grain to grain of a polycrystalline aggregate. According to Masing [27] and others, this is the cause of the Bauschinger effect and of the "elastic aftereffect," better designated as negative creep. It tends to strengthen the metal in the direction of the previous loading beyond the yield strength and to weaken the metal in the opposite direction. The range between the tensile and compressive yield stresses is not increased by the Bauschinger effect, but the range increases with workhardening.

The third kind of internal stress, as described by Heyn and by Masing, is associated with the space lattice changes involved in workhardening. A recent paper by Smith and Wood [37] has shown that 
plastic extension of iron causes three-dimensional expansion of the space lattice to exist after removal of the external stress. The directional variation of the expansion was not determined; it seems probable, however, that the expansion is greatest in the direction of the prior tensile extension. The investigators are of the opinion that the lattice expansion diminishes with rest at room temperature. It is also believed to be completely removed by annealing at a temperature considerably below the recrystallization range, although the evidence. presented does not give conclusive support to this view. Moreover, there is considerable scattered evidence that the lattice expansion, like internal stress of the first kind, cannot be completely removed by heating at temperatures below the recrystallization range. Examples of such evidence were given by Sachs in discussing a paper by Masing. [26]. He referred to an experiment by Heyn, in which the recrystallization of a bar of cold-drawn iron caused a decrease of volume. He. also mentioned other evidence of negative creep induced by recrystallization. The lattice expansion, therefore, probably is essentially associated with work-hardening.

In future discussion, the unqualified term "internal stress" will be confined to internal stresses of either the first or the second kind. The first kind will be termed "macroscopic internal stress," the second will be termed "microstructural stress." The term, "internal stress," will not be applied to the stresses due to space lattice changes, but attention will be focused on one of these changes, lattice expansion.

The effect of rest after tensile plastic extension cannot be viewed as a relief of macroscopic internal stress. Although negative creep occurs during rest without load [22], the stress-set curve generally becomes less steep and the proof stresses decrease, with increase in the rest interval. The effect, therefore, is opposite to that of relief of macroscopic internal stress. It might be at least partly due to a reduction of the unsymmetry of the range between the tensile and compressive yield stresses (the Bauschinger effect). Such a reduction of the Bauschinger effect might be caused by relief of microstructural stresses. The negative creep during rest, however, may be largely due to a decrease of the lattice expansion, especially the expansion in the direction of the previous loading. ${ }^{2}$ The effect of rest after plastic extension thus is the resultant of the effects of reduction of macroscopic internal stress, of mierostructural stress, and of the lattice expansion, all of these effects being associated with negative creep. In the rest intervals after tensile plastic extension, the dominant effect probably was a reduction of the lattice expansion and a resultant decrease in the proof stresses.

Oscillations in a curve of the type shown in figure 3, however, are found even when both rest intervals are long [22]. A rise of the curve at such an oscillation could be due either to a decrease of macroscopic internal stress, to an increase of the Bauschinger effect, or to an increase of the lattice expansion. Variations in the relative magnitude of these factors cause temporary maxima and minima in the proof-stress extension curves, especially in the curves for 0.001and 0.003 -percent proof stresses.

Curves of variation of the tensile and compressive yield stresses (0.2-percent offset) with prior plastic extension by tensile loading

\footnotetext{
2 Such a cause for negative creep is suggested by Smith and Wood [37]. A directional variation of the expansion would account also, at least partly, for the Bauschinger effect.
} 
are shown in a paper by Templin and Sturm [39]. With prior plastic extension, the curve of tensile yield stresses rises far above the curve of compressive yield stresses. The relationship evidently is an illustration of the influence of prior tensile extension on the Bauschinger effect. Cold-drawn metals, however, showed equality between the tensile and compressive yield stresses. Such a relationship implies that the curves showing the influence of plastic extension on the tensile and compressive yield stresses would practically coincide when the extension is produced by cold-drawing.

It is of interest, therefore, to compare the proof-stress extension curves with the corresponding proof stresses obtained with nickel, $R$, that had been cold-drawn to a reduction of about 60 percent and not afterward annealed. Such a comparison may be made in figure 3 by reference to the right boundary, where the short horizontal lines represent the five proof stresses. ${ }^{3}$ The comparison leads to the conclusion that the unsymmetry of the range between the tensile and compressive yield stresses was little, if any, greater for the metal that had been extended by intermittent tension than for the metal that had been extended by cold-drawing. The intermittent stressing used in the determination of the curves in figure 3 may have had a sufficiently mobilizing influence to free the curves from the Bauschinger effect.

\section{GENERAL DESCRIPTION OF THE STRESS-DEVIATION CURVES FOR NICKEL AND THEIR RELATION TO THE STRESS-SET CURVES}

An incomplete view of the elastic properties of a metal is obtained by considering only the relation between stress and the deformation that remains after the stress has been removed. Consideration should be given also to the influence of stress on the accompanying total strain and on the elastic strain. These relations are revealed by the stress-deviation curves for nickel and by derived curves and indices.

Stress-deviation curves for annealed nickel are shown in the upper row of figure 1 . The value $E_{A}$ given in each of the diagrams is the assumed modulus used in obtaining the deviations, as described in section III. The initial backward tilt of some of the stress-deviation curves is due to the selection of a slightly too small value for $E_{A}$. Each broken curve represents the influence of stress on the total deviation. Each solid curve, termed "corrected stress-deviation curve," in the upper row of figure 1 was obtained from the corresponding broken curve by deducting values of permanent set obtained from the stress-set curve directly below.

As the stress-deviation curves, like the stress-set curves, are affected by the extension spacing and by the duration of the rest interval [22], it is of interest to observe whether these variables have similar or opposite effects on the slopes of the stress-deviation and stress-set curves. As previously shown [22], the first stress-set curve of a pair, because of the extension spacing and of the variations of the rest interval, tends to be less steep than the second curve. Numerous illustrations of this tendency are found in figure 3, which is derived from the stress-set curves of figure 1. The corrected stress-deviation curves of the same pairs, however, generally show the opposite relation-

\footnotetext{
3 The short horizontal lines at the right border of figure 3 indicate values obtained with cold unannealed nickel.
} 
ship. There is a tendency for the first curve of a pair to be steeper than the second. This relationship is revealed better by a study of a derived diagram (fig. 4), which will be considered later.

\section{INFLUENCE OF STRESS ON THE MODULUS OF ELASTICITY OF NICKEL}

As the corrected stress-deviation lines curve continuously forward, the modulus of elasticity of nickel evidently decreases continuously with increase in stress. The secant modulus, ${ }^{4}$ given by the ratio of stress to elastic strain, has been used in the previous paper [22] and in this paper to study the variation of the modulus with stress and with prior plastic extension.

Graphs of variation of the secant modulus of elasticity with stress have been derived from all the corrected stress-deviation curves in figure 1 and are shown in figure 2. The graphs are numbered consecutively in each figure to correspond to the stress-deviation curves from which they are derived. Each stress-modulus line has been shifted to the right from the preceding line, and has been given a separate abscissa scale. Abscissas reading from left to right represent values of the secant modulus of elasticity; the scale of abscissas is indicated. Ordinates represent stress, based on the sectional area at the beginning of the series of load cycles used in the curve.

In deriving a stress-modulus line from a corrected stress-deviation curve, values of the secant modulus were calculated for various points on that stress-deviation curve. These points in figure 2, therefore, correspond to selected points on the stress-deviation curve, not to stresses at which strains were observed.

The prior plastic extension corresponding to each stress-modulus line is indicated in the derived diagram (fig. 4), which shows the influence of plastic extension on indices calculated from the stressmodulus lines. The experimentally derived points in figure 4 are numbered to correspond to the stress-modulus lines from which they are derived.

In the consecutive series of stress-modulus lines for fully annealed nickel $R-14$ (fig. 2), lines $1,4,5,6,7$, and 8 are curved throughout their extent. Lines 2 and 3 are curved only at the higher values of stress. The other lines in this figure are practically straight. The prior plastic extension beyond which all the stress-modulus lines are straight is about 5 percent (fig. 4). The evidence indicates that the stress-modulus line for nickel tends to be practically straight when the prior plastic extension, whether by tension or by cold drawing, is more than 5 percent.

In this respect, nickel is similar to the $18: 8$ chromium-nickel steels discussed in the previous paper [22]. The stress-modulus line for annealed 18:8 alloy was found to be straight when the prior plastic extension was more than about 12 percent. Unannealed cold-drawn 18:8 alloys (half-hard and hard) generally give straight stress-modulus lines.

\section{INDICES OF VARIATION OF THE MODULUS OF ELASTICITY WITH STRESS}

The modulus of elasticity at zero stress $\left(E_{0}\right)$ may be determined directly from a stress-modulus line by extrapolating the line to zero

${ }^{4}$ It should be noted that this modulus differs from a frequently used secant modulus based on the variation of total strain with stress. 
stress [22]. When the stress-modulus line is straight, the variation of the secant modulus $(E)$ with stress $(S)$ may be represented by

$$
E=E_{0}-k S \text {. }
$$

The constant $k$ is the cotangent of the angle of slope of the stressmodulus line. As shown in the previous paper [22], however, it is sometimes more convenient to change eq 1 to the form

$$
E=E_{0}\left(1-C_{0} S\right)
$$

where $C_{0}=k / E_{0}$ represents the stress coefficient of the secant modulus.

When the stress-modulus line is curved from its origin, as are some lines in figure 2, the stress coefficient of the modulus is not constant but varies with the stress. The variation of the modulus with the stress, then, cannot be represented by $C_{0}$ alone. The curved stressmodulus line may be represented approximately by adding another term to eq 2 and thus obtaining

$$
E=E_{0}\left(1-C_{0} S-C^{\prime} S^{2}\right),
$$

where $C^{\prime}$ is an index of the curvature of the stress-modulus line. ${ }^{5}$

The second constant $\left(C^{\prime}\right)$, which may be viewed as a quadratic stress coefficient of the modulus, is needed for use with nickel that has been fully annealed and afterward not extended more than about 5 percent. For sufficiently work-hardened nickel, the stress coefficient of the modulus is practically constant and is represented by the linear coefficient $C_{0}$.

Values of $C_{0}$ are indicated (fig. 2) by a number adjacent to each stress-modulus line. The value of $E_{0}$ for each stress-modulus line is indicated by the intersection of the line with the axis of abscissas.

\section{FORM OF THE CORRECTED STRESS-STRAIN CURVE FOR NICKEL}

The variations of $C_{0}$ and $C^{\prime}$ with plastic extension evidently are due to variations in the form of the corrected stress-strain curve. The general equation for the corrected stress-strain curve is derived from eq 3:

$$
\epsilon=S / E=S / E_{0}\left(1-C_{0} S-C^{\prime} S^{2}\right),
$$

where $\epsilon$ is the corrected strain. As the linear and quadratic correction terms are small compared with 1 , eq 4 may be written

$$
\epsilon=\left(1 / E_{0}\right)\left(S+C_{0} S^{2}+C^{\prime} S^{3}\right) .
$$

As the strain corresponding to the tangent to the stress-strain line at the origin is $S / E_{0}$, the deviation $\left(\epsilon_{d}\right)$ from this tangent is

$$
\epsilon_{d}=\epsilon-S / E_{0}=\left(1 / E_{0}\right)\left(C_{0} S^{2}+C^{\prime} S^{3}\right) .
$$

When the stress-modulus line is straight, $C^{\prime}$ is zero and the last term of eq 6 disappears. The stress-deviation relationship corresponding to a straight stress-modulus line, therefore, is represented by

$$
\epsilon_{d}=C_{0} S^{2} / E_{0},
$$

which is the equation for a quadratic parabola. When $C_{0}$ is zero, $C_{0} S^{2}$ of eq 6 disappears. The corrected stress-deviation line corresponding to this relationship is represented by

$$
\epsilon_{d}=C^{\prime} S^{3} / E_{0}
$$

which is the equation for a cubic parabola.

\footnotetext{
' In the earlier paper [22], the constants $C_{1}$ and $C_{2}$ were used. $C_{0}=C_{1}$ and $C^{\prime}=C_{1} \cdot C_{3}$.
} 
The stress-deviation curve for nickel that has been extended more than about $4 \frac{1}{2}$ percent is a quadratic parabola. When the curved stress-modulus lines for annealed nickel (fig. 2) are vertical at the zero stress axis, $C_{0}$ is zero, and the corresponding stress-deviation curves are cubic parabolas.

\section{INFLUENCE OF PLASTIC EXTENSION OF ANNEALED NICKEL ON THE MODULUS OF ELASTICITY AND ON ITS LINEAR STRESS COEFFICIEN'T}

The values of $E_{0}$ and $C_{0}$ given in figure 2 have been used in deriving the diagram in figure 4 , which shows the variation of these indices with prior plastic extension. The abscissas represent the percentages of prior plastic extension. Ordinates of two of the curves represent values of the modulus of elasticity; the ordinate scale for these curves is at the left of the figure. Ordinates of the other curve represent values of the stress coefficient $C_{0}$; the ordinate scale for this curve is at the right of the figure.

The experimentally determined points in figure 4 have been numbered to correspond to the consecutively numbered stress-modulus lines in figure 2. Before the general trend of the curves in figure 4 is considered, attention will be given to the superposed oscillations due to the influence of the extension spacing and the variation of the rest interval. The oscillations superposed on the curve for $C_{0}$ generally are qualitatively similar to the corresponding oscillations in the curve for $E_{0}$. Each abrupt rise or drop in the curve for $E_{0}$ is accompanied by a similar change of direction in the curve for $C_{0}$. In this respect, the curves for nickel are similar to curves of the same type for 18:8 chromium-nickel steel [22].

The abrupt oscillations in the curves for $E_{0}$ and $C_{0}$ (fig. 4), however, generally are associated with opposite oscillations in the proof stressextension curves (fig. 3). This relationship is in accordance with the previously mentioned fact that a difference in steepness of the stress-deviation curves of a pair generally is associated with the opposite difference in steepness of the corresponding stress-set curves. (A similar inverse relationship was also found for the 18:8 chromiumnickel steels discussed in the previous paper [22]). The magnitude of such oscillations is affected by the duration of the rest interval. Increase in the rest interval tends to decrease the slope of the stressset curve and to increase the initial slope $\left(E_{0}\right)$ and the curvature $\left(C_{0}\right)$ of the corrected stress-deviation curve.

A basic curve of variation of $E_{0}$ or $C_{0}$ with prior plastic extension would follow the general course of the corresponding series of experimental points. The basic curve for $E_{0}$ is indicated qualitatively in figure 4 by the dotted curve. The basic $C_{0}$ curve is so clearly indicated by the sequence of experimentally determined points that no dotted curve is needed.

The basic $E_{0}$ curve (fig. 4 ) first descends rapidly at a decreasing rate and reaches a minimum at slight plastic extension. With further extension, the curve rises rapidly above the value at zero plastic extension and continues to rise at a gradually decreasing rate. At the beginning of local contraction (35-percent extension), the $E_{0}$ curve is still rising slowly, and is considerably higher than at zero plastic extension. As would be expected, the value of $E_{0}$ at the beginning of local contraction is about the same as that for the severely cold-drawn 
nickel, $R$ (fig. 4). ${ }^{6}$ The basic $C_{0}$ curve for annealed nickel differs in important respects from the $E_{0}$ curve (fig. 4). Between points 7 and 9 , the $C_{0}$ curve rises rapidly, as does the $E_{0}$ curve. Beyond point 9 , however, the $C_{0}$ curve descends at a decreasing rate.

The general rise of the $E_{0}$ curve is due to the dominant influence of a change of crystal orientation. The initial rise of the $C_{0}$ curve is due to the dominant influence of increasing internal stress. The descent of these two curves is due to the dominant influence of another factor associated with plastic extension. The influence of these three factors on the curves for various metals is discussed in section VIII.

\section{INFLUENCE OF PRIOR PLASTIC EXTENSION OF NICKEL ON THE QUADRATIC STRESS COEFFICIENT, $\mathbf{C}^{\prime}$, OF THE MODULUS OF ELASTICITY}

It has been shown that the curvature of the stress-modulus line is found only when the prior plastic extension of annealed nickel is less than about 5 percent. The extension at which the curvature of the stress-modulus line disappears is the extension at which $C_{0}$ reaches a maximum (figs. 2 and 4 ). As the quadratic stress coefficient, $C^{\prime}$, is the index of curvature of the stress-modulus line, consideration should be given to the variation of $C^{\prime}$ with plastic extension to the point where $C^{\prime}$ becomes zero. This variation of $C^{\prime}$ for annealed nickel is shown in figure $10(A)$.

The quadratic stress coefficient was obtained directly from the stress-modulus curve in the following manner. Straight lines were drawn tangent to the curves at the zero values of stress. For some conveniently selected value of stress, which was the same for each curve of the series obtained with a single specimen, the deviation of the tangent from the curve was measured. This deviation, divided by $E_{0} S^{2}$, gave the value of $C^{\prime}$.

The curve of variation of $C^{\prime}$ with extension for annealed nickel (fig. $10 \mathrm{~A}$ ) starts at a low value. Because of the inexactness of the determination of $C^{\prime}$, especially when the curvature of the stressmodulus line is slight, too much significance should not be attached to the course of the $C^{\prime}$ curve near its origin. The general course of this curve indicates that plastic extension tends to cause a rapid increase of $C^{\prime}$ to a maximum, which is reached at a plastic extension of between 1 and 2 percent. With further plastic extension, the curve descends and disappears at a value of about $4 \frac{1}{2}$ percent. At this point, the stress-modulus line becomes straight and $C_{0}$ reaches a maximum.

\section{ELASTIC PROPERTIES OF SEVERELY COLD-DRAWN NICKEL AS AFFECTED BY FURTHER PLASTIC EXTENSION AND BY ANNEAL- ING FOR RELIEF OF INTERNAL STRESS}

One specimen of nickel that had been cold-drawn to 60-percent reduction in cross section was tested as received. Another specimen was tested after annealing at $500^{\circ} \mathrm{F}$ for relief of internal stress. As preliminary experiments had shown that annealing at $500^{\circ} \mathrm{F}$ gave the highest values of the proof stresses, this temperature seemed most suitable for relief of internal stress with a minimum of softening effect.

6 The short horizontal lines at the right-hand border of figure 4 indicate values obtained with cold-drawn unannealed nickel. The horizontal arrows indicate values obtained with cold-drawn nickel that had been annealed for relief of internal stress. 
Stress-set and stress-deviation curves obtained with these specimens are shown in figure $5(A$ and $B)$. A striking feature in these two diagrams is the complexity of some of the curves. The slope of these curves first increases, then decreases. Of this type are curves 2,5 , and 6 of diagram $A$ and curves $3,5,7$, and 11 of diagram $B$. Other stressset curves give evidence of initial negative set; of this type, the most conspicuous are curves 3 of $\operatorname{diagram} A$ and 9 of diagram $B$. When a stress-set curve has an initial increase in slope, the uncorrected stressdeviation curve generally has a similar form. With annealed nickel, a few (less conspicuous) examples of curvature of this type were obtained, for example, curve 9 in figure 1.

Nearly all the specimens that gave curves with reversal or with initial negative set had rested for a relatively long interval before determination of the curves. The curves evidently reveal opposing influences of plastic deformation and rest. As previously shown, rest after plastic deformation tends to lower the proof stresses and to increase both $E_{0}$ and $C_{0}$. If another stress-set curve and the corresponding stress deviation curve are determined with the same specimen and without intervening plastic extension, but with a shorter rest interval [22], the proof stresses generally are raised and $E_{0}$ and $C_{0}$ are lowered. With 18:8 alloy [22], these effects manifest themselves only in the second curve of such a pair; with nickel, they evidently may manifest themselves during the determination of the first curve of a pair, thus causing an increasing slope or an initial negative set. The opposing effects of plastic deformation and rest on the elastic properties will be considered further in section VIII.

Because an uncorrected stress-deviation curve of complex form is associated with a qualitatively similar stress-set curve, the corrected stress-deviation curve has no reversal but inclines continuously forward. Stress-modulus lines, derived from the corrected stressdeviation curves of figure 5, are shown in figure 6 . Only one of these lines (line 1 of diagram $A$ ) is curved from its origin. The other lines may be considered practically straight, at least for a considerable distance from the origin. If some of the lines were drawn strictly in accordance with the experimental points, they would have a sinuous form, or even a slight continuous increase of slope, throughout the extent here shown. As these anomalies may be attributed to variations of the observed values within the limitations of experimental accuracy, such graphs have been represented by straight lines. The evidence in figures 2 and 6 thus indicates that the stress-modulus line for nickel tends to be practically straight when the prior plastic extension, whether by tension or by cold-drawing, is more than about 5 percent.

Proof-stress extension curves, derived from the stress-set curves of figure 5 are shown in figure 7 . In comparing the two diagrams of figure 7 , the great difference in the abscissa scales should be kept in mind. In the unannealed cold-drawn nickel (diagram $A$ ), local contraction began after an extension of only about 1 percent. This slight extension, however, evidently caused considerable improvement in the proof stresses, even in the 0.1-percent proof stress, which is an index of yield strength. Part of the great improvement between points 1 and 2 in each curve probably was due to the great difference in the prior rest intervals. Nevertheless the course of the upper two curves (which may be viewed as a variation of two indices of yield strength) 
indicates that the extension caused considerable work-hardening, though at a rapidly decreasing rate. The improvement in the 0.001 and 0.003 -percent proof stresses, indicated by the rise of the lower two curves, is due chiefly to the resultant of the work-hardening and of a change of internal stress. The initial rise of the $C_{0}$ curve in figure $8(A)$, however, indicates that the plastic extension of this cold-drawn metal caused an increase of internal stress. As an increase of internal stress would tend to depress the 0.001 - and 0.003 -percent proof stresses, the rise of the lower two curves in figure $7(A)$ must be attributed to a dominant influence of work-hardening. In this respect, the cold-drawn nickel behaved differently from severely cold-drawn 18: 8 alloys. Slight plastic extension of the 18: 8 alloys caused a great increase of the lower proof stresses, but a decrease of $C_{0}$ [22].

The effects of annealing at $500^{\circ} \mathrm{F}$ for relief of internal stress are revealed by a comparison of diagrams $A$ and $B$ in figures 7 and 8 . The origins of the proof-stress curves in diagram $B$ of figure 7 are higher than the origins of the corresponding curves in diagram $A$. The difference is slight for the 0.1-percent proof-stress curve and is greatest for the 0.001-percent curve. This improvement in the proof stresses must be attributed to a relief of internal stress. This conclusion is confirmed by a comparison of the origins of the $C_{0}$ curves in diagrams $A$ and $B$ of figure 8 . That the annealing caused a great decrease of internal stress is indicated by the great decrease of $C_{0}$.

The $C_{0}$ curve in figure $8(B)$ rises and evidently approaches a maximum about as high as the maximum in the $C_{0}$ curve in diagram $A$. After an extension of about 1 percent, the $C_{0}$ curve in diagram $B$ is as high as the origin of the $C_{0}$ curve in diagram $A$, thus indicating a restoration of internal stress to the amount initially present in the unannealed specimen. With further plastic extension, the internal stress evidently continues to rise at a decreasing rate.

The basic $E_{0}$ curve in diagram $A$ of figure 8 is qualitatively similar to the $C_{0}$ curve. The $E_{0}$ curve in diagram $B$ however, is very different from the $C_{0}$ curve. The origin of the $E_{0}$ curve in diagram $B$ is slightly higher than the origin in diagram $A$. The annealing for relief of internal stress, although it greatly decreased the curvature $\left(C_{0}\right)$, evidently had little effect on the initial slope $\left(E_{0}\right)$ of the stress-strain line. The factors affecting the course of these curves will be considered in section VIII.

\section{THE SECANT MODULUS AT ANY STRESS}

The secant modulus $(E)$ at any stress may be calculated from corresponding values of $E_{0}$ and $\mathrm{C}_{0}$, provided that the stress-modulus line is straight. When the stress-modulus line is uniformly curved, the modulus at a given stress may be calculated from $E_{0}, C_{0}$, and $C^{\prime}$ by means of eq 6. If the stress-modulus line is available, the value of $E$ for any stress may be obtained directly from this line. The intermediate curves in figures 4 and 8 represent the variation of the moduli corresponding to the indicated stresses. This secant modulus at intermediate stresses is indicated by the latter $E$ with a subscript expressing the value of the stress in thousands. Values of $E 3_{0}$ are given in figure 4 of $E_{100}$ in figure 8. These curves will be discussed in section VIII. 
V. TENSILE MODULUS OF ELASTICITY OF 18:8 CHROMIUMNICKEL STEEL AND OF COPPER AS AFFECTED BY STRESS AND BY PLASTIC EXTENSION

\section{INFLUENCE OF PRIOR PLASTIC EXTENSION OF 18:8 ALLOY ON THE MODULUS OF ELASTICITY AND ON ITS LINEAR STRESS COEFFICIENT, $\mathrm{C}_{0}$}

The influence of plastic extension of "annealed" 18:8 alloy on $E_{0}$ and $C_{0}$ is shown in figure 9 , which is a modified form of a diagram in the previous paper [22]. The alloy, designated 2A-1 (probably originally hot-rolled), had been annealed by the manufacturers, presumably by means of the usual treatment at a temperature of $1,800^{\circ}$ $\mathrm{F}$ or higher, followed by quenching in water.

The $C_{0}$ curve for the 18:8 alloy (fig. 9) is qualitatively similar to the $C_{0}$ curve for annealed nickel (fig. 4 ). The plastic extension at which this curve reaches a maximum is about the extension at which the stress-modulus line becomes straight. In this respect, the 18:8 alloy is similar to nickel (figs. 2 and 4 ). The basic $E_{0}$ curve for the 18:8 alloy (fig. 9), however, is very different from the $E_{0}$ curve for nickel (fig. 4). Whereas the $E_{0}$ curve for nickel first descends then rises at a decreasing rate until it is far above its origin, the $E_{0}$ curve for the 18:8 alloy descends continuously, first at an increasing then at a decreasing rate. ${ }^{8}$ The differences between the $E_{0}$ curves for 18:8 alloy and nickel are due to differences in some factors associated with plastic extension (section VIII).

\section{INFLUENCE OF PRIOR PLASTIC EXTENSION OF COPPER ON THE STRESS-MODULUS LINE}

Three specimens of cold-rolled oxygen-free copper were tested by the previously described methods. One specimen was tested as received, and two specimens were tested after being heated to temperatures high enough to cause complete recrystallization. The annealing temperatures were $600^{\circ}$ and $800^{\circ} \mathrm{F}$; the lower temperature is just above the recrystallization range. Details of the annealing treatment are given in table 2.

The two specimens of annealed copper were extended by small increments of plastic extension to the beginning of local contraction; after each of these increments, a stress-set curve and a stress-deviation curve were determined. Attention will be confined to the stressmodulus lines derived from the corrected stress-deviation curves and to the diagrams derived from the series of stress-modulus lines. All the stress-modulus lines obtained with work-hardened copper $N$, and most of the stress-modulus lines obtained with annealed copper $N-6$ and $N-8$, are shown in figure 11 .

The initial stress-modulus line for copper $N-8$, and lines 4 and 8 for copper $N-6$, are practically straight; all the other stress-modulus lines are curved throughout their extent. Some adjacent lines differ greatly in curvature and in initial slope. Lines 1, 4, and 8 for copper $N-6$ are nearly straight, whereas the adjacent lines are strongly curved. Lines 4 and 8 for copper $N-8$ are vertical at the zero stress axis, whereas the adjacent lines are much less steep. These variations in

7 A specimen quenched from $1,830^{\circ} \mathrm{F}$ by the authors had about the same properties.

${ }_{8}$ With some specimens of annealed cold-drawn 18:8 alloy, there is a slight initial rise of the $E_{0}$ curve accompanying the much greater rise of the $C_{0}$ curve. 
the slope and curvature of the stress-modulus line can be studied by means of the derived diagrams in figures 12,13 , and 14. The curvature of some of the stress-modulus lines, especially some lines near the beginning of each series, is much greater than the curvature of any stress-modulus line ${ }^{9}$ obtained with the other metals considered in this paper. With prior plastic extension, the stress-modulus line for annealed copper eventually tends to become less strongly curved, but does not become straight, as it does for the much stronger metals previously considered. This fact suggests that the straightening of the stress-modulus line may depend not merely on the degree of plastic deformation but on the tensile strength of the metal.

\section{INFLUENCE OF PRIOR PLASTIC EXTENSION OF COPPER ON THE MODULUS OF ELASTICITY AND ON ITS LINEAR STRESS COEFFICIENT, $C_{0}$}

The values of $E_{0}$ and $C_{0}$ derived from the stress-modulus lines in figure 11 are plotted as ordinates in figures 12 and 13 , with abscissas representing the prior plastic extensions.

The basic $E_{0}$ curve (figs. 12 and 13 ) first descends rapidly at a decreasing rate and reaches a minimum at a slight plastic extension. With further plastic extension, the curve rises at first rapidly and then at a decreasing rate throughout the whole range of tensile extension. At the beginning of local contraction, the modulus of elasticity, $E_{0}$, has risen almost to the initial value. With still further plastic extension by cold-rolling, as shown by the $E_{0}$ curve in the diagram for cold-rolled copper $N$ at the right of figure 12, the modulus of elasticity evidently rises to a value slightly above the initial value for fully annealed copper.

The basic $E_{0}$ curve for copper, therefore, is qualitatively similar to the $E_{0}$ curve for nickel (fig. 4 ), and is dissimilar to the $E_{0}$ curve for 18:8 alloy (fig. 9). The rise of the curves for nickel and copper is due to the dominant influence of a change of orientation of the crystallite grains with plastic extension (section VII). This factor and the factor dominant in the initial descent of these curves will be discussed in section VIII.

The basic $C_{0}$ curve for annealed copper (figs. 12 and 13) is similar to the $E_{0}$ curve, at least throughout the initial steep descent. Although there are some indications that the basic $C_{0}$ curve reaches a minimum at a slight plastic extension, it now appears more probable that this curve descends continuously at a decreasing rate. The $C_{0}$ curve for copper is very different from the $C_{0}$ curves for nickel and 18:8 alloy (figs. 4 and 9). Whereas the curves for nickel and 18:8 alloy have an initial rise and then a descent, the curve for copper has a continuous descent. The elevating influence of increasing internal stress, though present, evidently does not become dominant in the $C_{0}$ curve for copper.

For nickel, 18:8 alloy, and copper, the abrupt rises or descents at pairs of experimental points are generally qualitatively the same for both the $E_{0}$ and the $C_{0}$ curves. (Compare figs. 4, 9, 12, and 13.) These rises or descents, however, generally are opposite in direction to the corresponding changes in the proof-stress extension curves. (Compare figs. 3 and 4 and see preceding paper.)

In such comparison, allowance must be made for the differences in the ordinate scales of corresponding diagrams. 
4. INFLUENCE OF PRIOR PLASTIC EXTENSION OF 18:8 ALLOY AND OF COPPER ON THE QUADRATIC STRESS COEFFICIENT, $C^{\prime}$, OF THE MODULUS OF ELASTICITY

With prior plastic extension of either annealed 18:8 alloy or annealed copper, the curvature of the stress-modulus line generally first increases then decreases. The influence of plastic extension on $C^{\prime}$, the index of curvature of the stress-modulus line, is shown for the 18:8 alloy in figure $10(E)$ and for copper in figure 14 .

With plastic extension of the 18:8 alloy, the $C^{\prime}$ curve first rises rapidly to a maximum, then descends less rapidly and disappears at an extension of about 12 percent. At this extension the stressmodulus line becomes straight [22], and $C_{0}$ reaches a maximum (fig. 4). With plastic extension of copper (fig. 14), the $C^{\prime}$ curve rises rapidly from an initially low value to a very high maximum and then descends rapidly. (The fact that this maximum is much higher for $N-8$ than for $N-6$ may possibly be attributed to the somewhat softer condition of $N-8$ because of the higher annealing temperature.) This rise and descent is followed by two similar abrupt rises and descents, and then by a slow downward trend at a gradually decreasing rate. The quadratic stress coefficient for copper, however, does not become zero, at least within the range of tensile extension. Moreover, even after severe cold-rolling, $C^{\prime}$ evidently does not become zero (fig. 14).

\section{TENSILE ELASTIC PROPERTIES OF OPEN-HEARTH IRON AND SOME CARBON STEELS}

The three metals previously considered have face-centered cubic space lattices. The metals now to be considered have body-centered cubic lattices. The first of these is a low-carbon open-hearth iron.

\section{AGE-HARDENING OF OPEN-HEARTH IRON DURING INTER- MITTENT PLASTIC EXTENSION}

For most metals, the general course of a curve of variation of a proof stress with plastic extension is practically the same whether the extension is continuous or is interrupted by repeated removal and replacement of the load. The curve, moreover, generally is no higher when the extension is very slow than when it is at the speed of an ordinary tension test. With a metal subject to age-hardening, however, plastic deformation followed by rest tends to cause precipitation of a hardening microconstituent. Conditions favorable to age-hardening, therefore, exist during the determination of a series of correlated stress-set and stress-deviation curves with a specimen of open-hearth iron.

With open-hearth iron annealed by ordinary furnace-cooling from $1,750^{\circ} \mathrm{F}$, age-hardening manifested itself by an elevation of the proofstress extension curves and by the greatly enhanced tensile strength of the specimen used in determining those curves. The tensile strength of such a specimen was $64,700 \mathrm{lb} / \mathrm{in} .{ }^{2}$, whereas the value obtained by an ordinary tension test is about $42,000 \mathrm{lb} / \mathrm{in}^{2}$.

In order to minimize age-hardening from the precipitation and coalescence of carbides, therefore, additional specimens were given special heat treatments before they were subjected to intermittent 
plastic extension. The iron-carbon equilibrium diagram suggests that a very slow cooling from $1,750^{\circ} \mathrm{F}$, especially between 1,350 and $900^{\circ} \mathrm{F}$, would give the most favored opportunity for precipitation and coalescence of carbides by heat treatment alone. Specimen $P B-F S$, consequently, was given the heat treatment indicated in table 2. This specimen, however, gave evidence of pronounced agehardening during the intermittent extensions made in determining the proof stress-extension curve, although the age-hardening was much less than with specimens annealed by ordinary furnace cooling. As shown in table 3 , the value for the ultimate strength obtained with this intermittently extended specimen was $54,700 \mathrm{lb} / \mathrm{in}^{2}$. Another specimen, therefore, was water-quenched from $1,750^{\circ} \mathrm{F}$ so that all the carbides would be either in solid solution or as widely dispersed fine particles. This specimen was then heated for 140 hours at $900^{\circ} \mathrm{F}$ to facilitate a precipitation of carbides on the widely dispersed nuclei. As shown by the value $\left(54,300 \mathrm{lb} / \mathrm{in}^{2}\right)$ for the ultimate tensile strength after intermittent extension (table 3 ), however, this heat treatment caused no further reduction in agehardening. Age-hardening of annealed open-hearth iron during intermittent extension evidently could not be entirely prevented by a prior heat treatment.

\section{STRESS-SET AND STRESS-DEVIATION CURVES FOR OPEN-} HEARTH IRON

The stress-set and stress-deviation curves obtained with specimens $P A-W-9$ and $P B-F S$, which had been given the previously described special heat treatments for precipitation of carbides, are shown in figures 15 and 19. The curves obtained with cold-drawn iron, unannealed and after annealing for relief of internal stress, are shown in figure 22. Some of the stress-set curves in each of these figures have an initial increase of slope similar to that in some of the curves for nickel (figs. 1 and 5). In figures 15 and 22, nearly every curve of this type is the first curve of a pair (see the derived diagrams, figs. 17 and 24). Curves of this type, however, were obtained after rest intervals of 30 minutes in boiling water (fig. 19); these curves are not distributed in pairs. Curve 1 obtained with specimen $P A-5$ (fig. 22) shows evidence of negative creep. The specimen was actually shorter after being subjected to tensile stresses up to nearly $70,000 \mathrm{lb} / \mathrm{in}^{2}{ }^{2}$ than it was before being stressed. This curve and the curves with initial increase of slope evidently have been affected by creep occurring during the determination of each curve. This creep may be partly due to the influence of microstructural stresses but possibly is a manifestation of variations of lattice expansion. Curve 1 obtained with $P A-5$ (fig. 22) suggests that the tensile stressing of this specimen mobilized the metal enough to permit negative creep. ${ }^{10}$

It is important to know whether the initial increase of steepness of a curve is obtained only when the extension during the determination of a stress-set or stress-deviation curve is by intermittent loading. For this reason, another specimen was extended by the usual small increments, but the stress-set curves (not shown) were determined by continuous loading, at least up to the 0.003 -percent proof stress. The time required for this loading was about the same as that required

10 The prior annealing at $500^{\circ} \mathrm{F}$ removed only part of the internal stresses and lattice expansion. Complete removal would require heating to the temperature of recrystallization. 
for determining a stress-set curve by the intermittent loading, about 1 hour. Some curves obtained by this method were found to have an initial increase of slope.

When a stress-set curve has an initial increase of steepness, the corresponding uncorrected stress-deviation curve is similar in form. The corrected stress-deviation line, consequently, either decreases continuously in slope or is practically straight throughout a considerable portion of its extent. The accuracy of the estimation of $C_{0}$, the index of curvature of the corrected stress-strain line, possibly is somewhat less when the curve from which it is derived is of the complex form than when it is of the simple form.

\section{STRESS-MODULUS LINES FOR OPEN-HEARTH IRON}

Typical stress-modulus lines obtained with open-hearth iron after one of the special heat treatments are shown in figure 16. Typical stress-modulus lines obtained with work-hardened open-hearth iron, unannealed and annealed for relief of internal stress, are shown in figure 23. The initial line obtained with specimen $P A-W-9$ (fig. 16) is straight and vertical. Some of the other lines are vertical at the zero stress axis, but are not straight. Most of the lines are practically straight and inclined slightly from the vertical; they thus represent a low value of $C_{0}$, as indicated by the adjacent numeral. Most of the stress-modulus lines obtained with the unannealed workhardened metal, $P A$ (fig. $23, A$ ), are practically straight and inclined. With the work-hardened metal, $P A-7$, which had been annealed for relief of internal stress, some straight sloping stress-modulus lines were obtained; some of the lines, however, are curved, and are practically vertical at the zero axis of stress. The stress-deviation curve, therefore, evidently is generally a quadratic parabola, but sometimes is a cubic parabola.

\section{INFLUENCE OF PRIOR PLASTIC EXTENSION OF OPEN-HEARTH IRON ON THE MODULUS OF ELASTICITY AND ON ITS LINEAR STRESS COEFFICIENT, $C_{0}$}

The influence of prior plastic extension on the modulus of elasticity of annealed open-hearth iron is illustrated by the curves in figures 18 and 21. With specimen $P A-W-9$ (fig. 18), the extension increments were arranged so that the experimental points are in pairs, and all the rest intervals were at room temperature. The wide oscillations superposed on the basic $C_{0}$ curve make the exact course of this curve uncertain, but the curve is qualitatively similar to the $C_{0}$ curves for annealed nickel (fig. 4) and annealed 18:8 alloy (fig. 9). The basic $E_{0}$ curve has an initial rise to a maximum, which is at about the extension at which the $C_{0}$ curve reaches a maximum, and then descends at a decreasing rate. In its final descent, the $E_{0}$ curve resembles the $E_{0}$ curve for 18:8 alloy, figure 9 .

With open-hearth iron, the effect on $C_{0}$ of the extension spacing and the duration of the rest interval was generally opposite to the effect obtained with the metals previously discussed. With open-hearth iron, the first experimental derived point of each pair generally is lower than the second (fig. 18). A similar effect of the rest interval is found in figure 21. A rest interval of 30 minutes in boiling water evidently tended to decrease $C_{0}$ for open-hearth iron, whereas the same 
treatment applied to any of the metals previously discussed had the same effect as a longer time at room temperature, an increase of both $E_{0}$ and $C_{0}$. With open-hearth iron, therefore, the effect of an increase in the rest interval was similar to the effect of a relief of macroscopic internal stress. The almost complete disappearance of the $C_{0}$ curve due to the treatment with boiling water suggests that macroscopic internal stress is the factor involved in the ascent of the $C_{0}$ curve in figure 18.

With the work-hardened open-hearth iron, the $E_{0}$ curves show no clear evidence of a general trend (diagrams $A$ and $B$ of fig. 24), except possibly a slight initial descent. The basic $C_{0}$ curve obtained with the unannealed metal (diagram $A$ ) rises at a decreasing rate, as indicated by the dotted curve. A similar general trend is apparent in the curve for open-hearth iron $P A-7$, which was annealed for relief of internal stress. (The possible cause of the initial dip in the $E_{0}$ and $C_{0}$ curves for this material will be discussed later.) The general trend of the $C_{0}$ curve for work-hardened open-hearth iron is similar to that of the $C_{0}$ curves for 18:8 alloy (fig. 9) and work-hardened nickel (fig. 8).

\section{INFLUENCE OF PRIOR PLASTIC EXTENSION OF THREE CARBON STEELS ON THE MODULUS OF ELASTICITY AND ON ITS LINEAR STRESS COEFFICIENT, $C_{0}$}

Figures 26, 27, and 28 show the influence of prior plastic extension of three carbon steels on $E_{0}$ and $C_{0}$. In figure 26 , the basic curves probably have the forms indicated by the dotted lines. The evidence indicates that both $E_{0}$ and $C_{0}$ tend to increase at a decreasing rate, and probably reach a maximum at an extension of about 7 percent. A similar initial rise is found in the $E_{0}$ and $C_{0}$ curves in figures 27 and 28. With further extension, the curves descend as indicated qualitatively by the dotted lines in figure 27 . The maximum in each $E_{0}$ curve is at about the same extension as that of the maximum in the corresponding $C_{0}$ curve.

The $E_{0}$ curves obtained with these three carbon steels are similar to the $E_{0}$ curve obtained with open-hearth iron (fig. 18). The $C_{0}$ curves obtained with these three carbon steels are similar to the $C_{0}$ curves obtained with open-hearth iron (fig. 18), annealed nickel (fig. 4), and annealed 18:8 alloy (fig. 9). The descent of the $C_{0}$ curves from the maximum, however, is much slower for the four steels than for the nickel and 18:8 alloy. All these $C_{0}$ curves indicate the successive dominance of an elevating and a depressing factor.

\section{INFLUENCE OF PRIOR PLASTIC EXTENSION OF THREE CARBON STEELS ON THE QUADRATIC STRESS COEFFICIENT, C', OF THE MODULUS OF ELASTICITY}

The stress-modulus lines obtained with these carbon steels are not shown. The variation of the index of curvature $\left(C^{\prime}\right)$, however, is shown for each of the three steels in diagrams $B, C$, and $D$ of figure 10 . The $C^{\prime}$ curves in these three diagrams are qualitatively similar to the $C^{\prime}$ curves for the other metals represented in this figure. Each curve rises rapidly to a maximum, then descends less rapidly to the axis of abscissas. In the diagrams for the 0.42 -percent and 0.73 -percent carbon steels (diagrams $C$ and $D$ ) the $C^{\prime}$ curves disappear at extensions of about 3 and $4 \frac{1}{2}$ percent, respectively. These are about the exten- 
sions at which the corresponding $C_{0}$ curves reach their highest points (figs. 27 and 28). In this respect, therefore, these steels are similar to nickel (figs. 4 and $10, A$ ) and to $18: 8$ alloy (figs. 9 and $10, E$ ). In the diagram for the 0.20 -percent carbon steel (fig. 10, $B$ ), the $C^{\prime}$ curve disappears at an extension of more than 7 percent. This is the extension at which $\mathrm{C}_{0}$ reaches its highest value (fig. 26) and is not far short of the beginning of local contraction.

As a change of crystal orientation with plastic extension is an important factor affecting the modulus of elasticity, crystal orientation and its influence on the modulus will next be considered. Other important factors (associated with plastic extension) affecting the modulus of elasticity will be considered in section VIII.

\section{CRYSTAL ORIENTATION AND ITS INFLUENCE ON ELASTIC PROPERTIES}

\section{DIRECTIONAL VARIATION OF THE MODULUS OF ELASTICITY OF SINGLE CRYSTALS}

In considering the directional variation of the modulus of elasticity of metal crystals, attention will be confined to the two types of space lattice represented by the metals considered in this paper. These are the face-centered and body-centered cubic lattices. The directional variation of the modulus in these lattices is illustrated by the diagrams in figures 29 to 33 , which are adaptations of diagrams found in the book by Schmid and Boas [35]. These diagrams are drawn with spherical coordinates having their origins at the intersection of the three mutually perpendicular cubic axes of symmetry represented by $C$ in the figures. The surface shown in each figure is the locus of all points representing (by distance and direction from the origin) values of the modulus of elasticity.

In the discussion of crystal orientation, use will be made of the Miller indices of crystal planes and directions. A cubic plane is thus represented by (100), an octahedral plane by (111), and a dodecahedral plane by (110). A crystal direction is designated by the plane to which the direction is normal. In order to distinguish a direction from a plane, use is made of brackets instead of parentheses. Thus, a direction making equal angles with all three principal axes is denoted by [111], the direction of a cubic axis of symmetry by [100], and the dodecahedral direction by [110].

A diagram of variation of the tensile modulus of elasticity $(E)$ of a face-centered cubic metal, gold, is shown in figure 29. The modulus for this metal is least in the direction of the cubic axis $(C)$ and greatest in the octahedral direction $(O)$. The ratio between these maximum and minimum values for gold is given as 2.71 [35]. For copper and silver, the ratios given are 2.85 and 2.55 , respectively. Diagrams for copper and silver, therefore, would be similar to the diagram for gold (fig. 29). The diagram for aluminum (fig. 30), however, is very different. The ratio of values of the modulus of elasticity of this facesentered cubic metal in the [111] and [100] directions is given as only 1.2 .

A diagram for a body-centered cubic metal, alpha iron, is shown in figure 31. This diagram is similar in form to the diagram for gold (fig. 29). The ratio of maximum to minimum values of the modulus for this metal is said to be 2.15 [35]. For tungsten, another body- 
centered cubic metal, the ratio is given as about 1.0. A diagram for tungsten, like the diagram for aluminum (fig. 30 ), evidently would be nearly a sphere.

The directional variation of the shearing modulus, $G$, as illustrated by the diagram for alpha iron in figure 32 , evidently is opposite to the variation of the tensile modulus. The maximum value of the shearing modulus is in the direction of the cubic axis, which is the direction of the minimum value of the tensile modulus. The ratios of the maximum to the minimum values of the shearing modulus for alpha iron, gold, copper, and silver are $1.93,2.28,2.48$, and 2.26 , respectively. These ratios are slightly less than the corresponding values of the tensile modulus. For aluminum and tungsten, which give nearly spherical diagrams for the tensile modulus, the ratios of maximum to minimum values of the shearing modulus are small, about 1.16 for aluminum and 1.0 for tungsten [35]. Shearing-modulus diagrams for these metals evidently would be nearly spherical.

When the directional variation of the modulus of elasticity is as great as it is for copper or alpha iron, the orientation of the crystals may have a great effect on the modulus of elasticity of a polycrystalline aggregate. Consideration, therefore, must be given to the influence of plastic deformation of a polycrystalline aggregate on the orientation of the grains.

\section{CYLINDRICAL AND PARALLELOPIPEDAL DEFORMATION}

In the study of the influence of plastic deformation on crystal orientation, it is convenient to consider two types of uniform deformation. One of these is cylindrical deformation, the other is parallelopipedal deformation.

Cylindrical deformation causes equal percentage changes in two dimensions, and a necessarily opposite change in the third dimension. In cylindrical deformation, therefore, the ratio between two of the dimensions remains unchanged, although the external form is not necessarily cylindrical. This type of deformation of a polycrystalline aggregate may be produced by tensile extension, by drawing, by rolling of rod or wire, or by axial compression of a cylinder.

Parallelopipedal deformation is illustrated by the deformation of a cube into a rectangular parallelopiped whose three principal dimensions are unequal. The unidirectional rolling of a plate or sheet is the most common example of this type of deformation. Although the width of the sheet remains practically unchanged by rolling, the ratios of the three dimensions change greatly. Another example of parallelopipedal deformation is the deformation of a single crystal under unidirectional loading without restraints. Slip generally starts on only one set of planes and in one direction on each plane. The slip causes a change of direction of the plane with reference to the direction of loading; an initially circular cross-section thus becomes elliptical. By special procedure [40], however, a single crystal can be subjected to cylindrical deformation, and the orientation thus produced generally differs from the orientation produced by unidirectional loading.

As the investigation here described was made with round rods of polycrystalline metals, attention will be centered on the effect of cylindrical extension on crystal orientation. 


\section{INFLUENCE OF PLASTIC EXTENSION ON THE CRYSTAL ORIENTATION OF FACE-CENTERED CUBIC METALS}

Unidirectional extension of specimens cut from single crystals of aluminum, as shown by Taylor and Elam [38], causes a [112] direction of the crystal to approach and finally to reach the direction of tensile loading. These conclusions have been confirmed by the investigations of others, not only for aluminum, but for other face-centered cubic metals.

Cylindrical extension of single crystals of face-centered cubic metals, however, causes a different type of crystal orientation, as has been shown for copper by Vacher [40]. Cylindrical specimens of copper, some consisting of single crystals and some of two crystals, were swaged cold to various degrees of reduction, ranging from 30 to 95 percent. If the angle between the octahedral direction and the axis of the specimen was initially less than the angle between the cubic axis and the axis of the specimen, the crystal approached the [111] orientation; otherwise, it approached the [100] orientation. The cause of this difference between cylindrical and unidirectional extensions is the lateral restraint necessary for the cylindrical extension. If either an octahedral direction or a cubic axis is in the direction of extension, either three or four planes of slip and either six or eight directions of slip, respectively, are symmetrically placed with reference to the direction of extension, and the resolved shearing stresses in these symmetrically placed directions are equal. If this alinement could be maintained during tensile extension, the extension would be by cylindrical deformation. This alinement, however, is metastable for tensile extension; a small deviation from alinement would cause still further deviation. A small lateral restraint, however, would preserve the alinement and thus would keep either the cubic axis or the octahedral direction in the direction of the axis of the specimens. When neither the octahedral nor the cubic axis is initially in the direction of the specimen axis, extension with lateral restraint (as by swaging) evidently causes approach to either the octahedral or the cubic orientation [40].

In a polycrystalline aggregate under cylindrical deformation, each crystal is under lateral restraint by adjacent crystals, and thus undergoes cylindrical rather than parallelopipedal deformation. Cylindrical extension of a polycrystalline aggregate of a face-centered cubic metal, therefore, might be expected to cause some of the crystals to assume the cubic orientation and others to assume the octahedral orientation. Such a duplex orientation of polycrystalline aggregates was found long before the investigation by Vacher [40] of the cylindrical extension of single crystals. It was shown by Ettisch, Polanyi, and Weissenberg $[6,7]$ that hard-drawn wires of face-centered cubic metals have both cubic and octahedral orientations (double fiber texture). Sachs and Schiebold [33], however, found that aluminum has almost entirely the octahedral orientation. This conclusion was confirmed by Schmid and Wassermann [36], who showed also that the orientation textures of face-centered cubic metals differ only in the proportions of the [111] and [100] orientations. They found the following proportions of [100] and [111] orientations in cylindrically extended metals. 


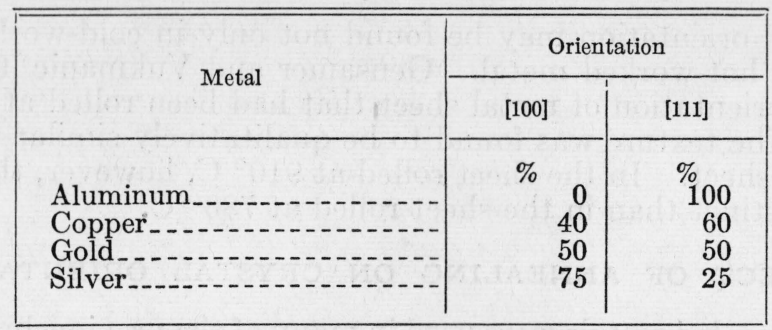

Schmid and Wassermann [36] found also that the amount of preferred orientation in wire is small in the outer layer, but increases toward the center. In the outer layers, moreover, the preferred crystal axes are not exactly in the direction of the wire axis but make a small angle, so that the orientation is conical rather than longitudinal. This angle, however, decreases toward the center and, at a certain depth, the orientation becomes longitudinal. Vargha and Wassermann [41] found that the orientation texture is the same in the interior of both drawn and rolled wires, and that the same duplex orientation is produced by tensile extension.

Cold-drawn wires of nickel were found by Greenwood [15] to have a double-fiber texture, consisting of [100] and [111] orientations, with the [111] orientation predominating. As binary alloys of nickel and copper form a continuous series of solid solutions, all these alloys in the form of rod or wire would be expected to have qualitatively similar texture. Cold-drawn rods of a nickel-copper alloy, Monel metal, are said ${ }^{11}$ to have a double-fiber texture with the [111] orientation greatly predominating.

\section{INFLUENCE OF PLASTIC EXTENSION ON THE CRYSTAL ORI- ENTATION OF BODY-CENTERED CUBIC METALS}

The most common body-centered cubic metals are alpha iron, chromium, molybdenum, and tungsten. Carbon steels are bodycentered cubic unless the composition and heat treatment are such as to produce austenite (gamma iron), a face-centered cubic metal. A body-centered cubic metal alloyed with iron tends to produce a body-centered cubic alloy; a face-centered cubic metal (such as nickel or manganese), if alloyed with iron, may cause the alloy to be face-centered cubic. The space lattice of steels containing iron, carbon, chromium, and nickel, therefore, depends on the proportions of these elements. If the percentage of nickel is high enough, as in the 18:8 chromium-nickel steel, the alloy is face-centered cubic.

As shown by Ettisch, Polanyi, and Weissenberg [6] and confirmed by a number of other investigators [9], cold-drawn iron rod or wire gives preferred dodecahedral [110] orientation in the axial direction. A more recent investigation by Barrett and Levenson [1] leads to the same conclusion. Dodecahedral [110] orientation, with no trace of other textures, was found after severe cold-drawing, or after swaging followed by drawing. This orientation was found with iron, ironsilicon alloys, and iron-vanadium alloy; it was found both with single crystals and with polycrystalline aggregates. The single crystals generally became fragmented whether or not lateral constraint was imposed (by adjacent crystals or by the walls of a die).

\footnotetext{
${ }^{11}$ Private communication from O. B. J. Fraser, Director of Technical Service of Mill Products, International Nickel Co. (August 2, 1939).
} 
Preferred orientation may be found not only in cold-worked metal but also in hot-worked metal. Gensamer and Vukmanic [9] investigated the orientation of metal sheet that had been rolled at $780^{\circ}$ and $910^{\circ} \mathrm{C}$. The texture was found to be qualitatively similar to that of cold-rolled sheet. In the sheet rolled at $910^{\circ} \mathrm{C}$, however, the texture was less distinct than in the sheet rolled at $780^{\circ} \mathrm{C}$.

\section{EFFECT OF ANNEALING ON CRYSTAL ORIENTATION}

Fully annealed metals were used in many of the previously described experiments made to determine the influence of tensile extension on the elastic properties of metals. As these metals had been given a preferred orientation during the forming of the cylindrical rods, it is important to know the effect of the annealing on the crystal orientation. Consideration must also be given to the possibility of changes of crystal orientation due to annealing for relief of internal stress.

In considering the effect of annealing on preferred orientation, attention will be given first to face-centered cubic metals. It has been shown that these metals, after cylindrical extension, generally have a duplex structure with both [100] and [111] directions in the direction of extension. Annealing some of these metals tends to cause a decrease in the ratio of crystals with [111] orientation to those with [100] orientation. Farnham and O'Neill [8] obtained such a result by annealing hard-drawn copper wires. Even after annealing at $130^{\circ} \mathrm{C}$ $\left(266^{\circ} \mathrm{F}\right)$, a temperature too low to cause recrystallization, they found an appreciable increase in the ratio of the crystals with [100] to those with [111] orientations. After annealing at $280^{\circ} \mathrm{C}\left(536^{\circ} \mathrm{F}\right)$, a temperature that caused complete recrystallization, there was a further increase in this relative amount of [100] orientation.

Annealing aluminum after plastic extension [38] caused no new preferred orientation. Annealing at temperatures above $500^{\circ} \mathrm{C}$, however, was said to give a random orientation. Burgers and Louwerse [4] found that when single crystals of aluminum were deformed by compression and then recrystallized (at $600^{\circ} \mathrm{C}$ ) new grains appeared with orientations different from those of the parent crystal. Polycrystalline aluminum, after axial compression, was reported to have a [110] orientation and to retain this orientation after recrystallization. A different conclusion, however, was recently expressed by Barrett [2]. He found that the deformation and recrystallization textures of axially compressed high-purity aluminum were similar. Practically the same results were obtained whether the compressed cylinders were single crystals or polycrystalline aggregates. The texture obtained consisted of a range of orientations with the mean orientation approximately [110].

Collins and Mathewson [5] state that no simple relation was found that would rationalize the relation of the orientation of a recrystallized aluminum grain to that of the original crystal.

Göler and Sachs [12] state that the effect of annealing on crystal orientation is sensitive to impurities and to slight variations in treatment. Two specimens of copper with practically the same rolling texture had very different textures after apparently the same annealing treatment. One specimen had a random orientation, the other had a new preferred orientation. The great effect of impurities on the recrystallization texture is also mentioned by Farnham and O'Neill [8]. They state that impurities in copper may greatly affect 
the tendency to change from a deformation texture to a recrystallization texture.

Sheet material has been used almost exclusively in investigations of the recrystallization texture of body-centered cubic metals. The texture of body-centered cubic metals after rolling to sheet form consists of a [110] direction in the direction of rolling, another [110] direction in the direction of the width of the sheet, and a [100] direction normal to the surface. The recrystallization texture of iron has been studied by Barrett, Ansel and Mehl [3], by Gensamer and Lustman [10], and by others. They found that recrystallization causes rotation of the rolling texture $15^{\circ}$ to $17^{\circ}$ each way about the normal to the surface of the sheet. Such a rotation may be visualized with the help of the diagram in figure 30 .

Cold-rolled or drawn rod or wire of body-centered cubic metals has a [110] direction in the direction of the axis of the rod or wire, and generally a random radial orientation. It seems probable that the recrystallization of cold-worked rod or wire would cause a rotation of the deformation texture, just as it causes a rotation of the texture of a plate or sheet.

\section{DIRECTIONAL VARIATION OF THE ELASTIC STRENGTH OF A SINGLE CRYSTAL}

It is important to know the influence of crystal orientation not only on the modulus of elasticity but also on the elastic strength. The directional variation of the tensile elastic limit in a face-centered cubic crystal has been calculated by E. Schmid [34] on the basis of his observation that the critical shearing stress (stress necessary to cause slip, resolved in the direction of slip) is constant and independent of the normal stress on the plane of slip. The results of his calculations are represented by the diagram in figure 33 . The tensile elastic limit evidently is greatest in the octahedral direction, the direction in which the tensile modulus of elasticity is greatest. The ratios of values in the cubic, the dodecahedral, and the octahedral directions are $1: 1: 1 \frac{1}{2}$. The directional variation of the tensile elastic limit, therefore, is less than the directional variation of the tensile modulus of elasticity of a metal such as gold or alpha iron (figs. 29 and 31).

With 100-percent preferred orientation, a bar or sheet would become practically a single crystal, and its elastic limit in any direction would be very low. For practical purposes, grains with preferred orientation should be intermingled with grains having random orientation.

\section{SOME IMPORTANT FACTORS ASSOCIATED WITH} PLASTIC EXTENSION; THEIR EFFECTS ON THE MODULUS OF ELASTICITY AND ON ITS STRESS COEFFICIENTS

\section{RESULTS OBTAINED BY OTHER INVESTIGATORS OF THE INFLU- ENCE OF PLASTIC EXTENSION ON THE TENSILE MODULUS OF ELASTICITY}

Curves of variation of the modulus of elasticity with extension have been reported by various investigators. Kuntze [21], in an investigation of the elastic properties of copper, obtained a curve of variation of the "modulus of elasticity" qualitatively similar to the 
$E_{0}$ curves in figures 12 and 13 . He attributed the initial descent in the curve for annealed copper to increasing internal stress, and the subsequent rise of the curve to the influence of "pure plastic deformation" (deformation free from the influence of varying internal stress). As shown in the preceding section of this paper, however, the ascent of the $E_{0}$ curve is due to a change of crystal orientation. The initial descent of the curve, moreover, probably is not due to either macroscopic internal stress or microstructural stress.

With copper, nickel, and aluminum (body-centered cubic metals), Kawai [20] obtained modulus-extension curves similar to the $E_{0}$ curves in figures 4,12 , and 13 . With open-hearth iron and mild steel, however, he obtained curves that descend continuously at a decreasing rate. A similar effect of plastic extension on the modulus of elasticity of steels was reported by Honda and Yamada [19]. The modulus values studied in both investigations, however, are not values of $E_{0}$, but are based on a range between maximum and minimum values of stress and strain. No study was made of the form of the stress-strain curve.

The rise of the curves for copper, nickel, and aluminum was correctly attributed by Kawai to a change of crystal orientation. ${ }^{12}$ The initial descent of the curves for copper, nickel, and aluminum, and the continuous descent of his curves for steels, were attributed to increasing internal stress. He thus expressed agreement with the views of Heyn [17], Sachs [32], and Honda and Yamada [19], that increase of internal stress decreases the modulus of elasticity. His views evidently also are in agreement, in this respect, with the previously mentioned views of Kuntze [21]. As shown in figures 9, 18,21, 26,27 , and 28 , however, the curves of variation of $E_{0}$ with plastic extension are more complex than those presented by Kawai. The evidence indicates that the course of a modulus-extension curve cannot be explained in terms of only two factors.

Erroneous views have been reached as to the factors affecting the modulus-extension curves because attention has been confined to the modulus at some indefinite point on the stress-strain curve. A study of the variation of the modulus of elasticity with plastic extension should envisage the entire stress-strain curve; it therefore should include in its scope $E_{0}, C_{0}, C^{\prime}$, and the secant modulus at some defined yield stress $E_{y}$.

\section{FACTORS AFFECTING THE VARIATIONS OF $\mathrm{C}_{0}$ AND $\mathrm{C}^{\prime}$ WITH PRIOR PLASTIC EXTENSION}

The basic $C_{0}$ curves for annealed nickel (fig. 4), annealed 18:8 alloy (fig. 9), open hearth iron (fig. 18), and three carbon steels (figs. 26, 27 , and 28) are all similar. Each of these curves apparently is influenced by at least two important factors, one of which is dominant in the initial rise, and the other in the descent. The basic $C_{0}$ curves for annealed copper (figs. 12 and 13), however, show the dominant influence of only one of these factors, the depressing factor; the factor tending to cause an initial rise probably is present, but does not become dominant.

There is conclusive evidence that the factor tending to cause an initial rise of these curves is the increasing internal stress. Relief

12 The effect of reorientation on the tensile modulus of elasticity of aluminum, however, would be expected to be small (section VII-1). 
of macroscopic internal stress in cold-drawn nickel causes a great decrease in $C_{0}$ (fig. 8). ${ }^{13} \quad \mathrm{~A}$ slight extension after annealing for relief of internal stress, moreover, raises $C_{0}$ to about the value found for the unannealed metal (fig. 8, $B$ ). This increase of $C_{0}$ doubtless is due to an increase of either macroscopic or microstructural internal stress. A logical conclusion is that an increase of internal stress is the chief cause of the initial rise of the $C_{0}$ curves for annealed nickel, annealed 18:8 alloy, open-hearth iron, and the three carbon steels.

The descent of these $C_{0}$ curves, however, cannot be attributed to a decrease of internal stress. The factor that is dominant in the descent of these curves probably is the same factor that is dominant throughout the entire $C_{0}$ curve for copper (figs. 12 and 13). The highest point on the basic $C_{0}$ curve for annealed copper is at zero extension; at this point the metal is practically free from internal stress. The curve descends as the internal stress increases. Masing and Haase [29] have shown, that the macroscopic internal stress tends to increase with increasing amounts of cold work. ${ }^{14}$ The slowness of the rise of the basic 0.001-percent proof stress curve with plastic extension (figs. 3,17 , and 20), moreover, apparently indicates that the depressing influence of internal stress on this proof stress tends to increase with the prior plastic extension.

The descent of the $C_{0}$ curves cannot be attributed to a decrease of the microstructural stresses. The Bauschinger effect, which is due to stresses of this kind, tends to increase continuously with the prior plastic extension [27]. Templin and Sturm [39], moreover, showed that prior plastic extension causes a continuous increase in the difference between the yield stresses (0.2-percent offset) in tension and compression. The microstructural stresses, therefore, evidently tend to increase continuously with plastic extension. The evidence, consequently, indicates that the $C_{0}$ curves cannot be explained in terms of the variations of a single factor.

The same two factors that determine the course of the $C_{0}$ curves are successively dominant in the curves of variation of $C^{\prime}$ with prior plastic extension. As shown in figures 10 and 14, these curves rise to a maximum and then descend. The maximum in a $C^{\prime}$ curve, however, is reached before the maximum in the corresponding $C_{0}$ curve. The elevating influence of increasing internal stress doubtless is the cause of the initial rise. Although this influence does not become dominant in the $C_{0}$ curve for copper (figs. 12 and 13), it is initially dominant in the $C^{\prime}$ curve (fig. 14). The factor dominant in the descent of the $C^{\prime}$ curves doubtless is the same factor that is dominant in the descent of the $C_{0}$ curves and will be identified later as the "lattice-expansion factor."

\section{FACTORS AFFECTING THE VARIATIONS OF $E_{0}$ WITH PRIOR PLASTIC EXTENSION}

In addition to the factors that affect the $C_{0}$ curves, the $E_{0}$ curves are affected by another factor, the change of crystal orientation. The preferred orientation of nickel and copper is predominantly octahedral [111] (section VII). A change from a random orientation or from a recrystallization texture toward a predominantly octahedral orienta-

13 The evidence in figure 8 is supported by ample evidence obtained with other metals, although the evidence obtained with open hearth iron (fig. 25) is inconclusive.

14 This relationship exists in spite of the fact that the tendency of brass to season cracking first increases then decreases with increasing amounts of cold work. 
tion causes a great increase in the mean value of $E_{0}$ for a polycrystalline aggregate (fig. 29). The influence of changing crystal orientation, therefore, becomes dominant in the ascent of the $E_{0}$ curves for nickel (fig. 4) and copper (figs. 12 and 13). Plastic extension of body-centered cubic metals, however, tends to produce a predominantly dodecahedral [110] orientation. A study of the diagram in figure 31 leads to the conclusion that a change from a random to a preferred orientation would cause only a slight increase in the mean value of the modulus of elasticity of the iron or carbon steels. The influence of the reorientation factor, therefore, does not become finally dominant in the $E_{0}$ curves for these steels, except possibly in one of the curves for open-hearth iron (fig. 21).

The factor dominant in the initial rise of the $E_{0}$ curve for openhearth iron (fig. 18), of the curves for the three carbon steels, and sometimes of the $E_{0}$ curve for 18:8 alloy (manifest in fig. 9 merely as a bulge in the curve) probably is the same factor that is dominant in the initial rise of the $C_{0}$ curves. It appears significant that the maximum in the $E_{0}$ curve often is at the same extension as that of the maximum in the $C_{0}$ curve. Although the initial rise of the $E_{0}$ curves for the carbon steels is helped by the reorientation factor, this factor apparently is slower in its initial effect than the influence of increasing internal stress. The chief cause of the initial rise of these $E_{0}$ curves, therefore, probably is increasing internal stress.

The factor dominant in the initial descent of the $E_{0}$ curves for nickel (fig. 4) and copper (figs. 12 and 13) probably is the factor that is dominant in the final descent of the $C_{0}$ curve for nickel, in the descent of the entire $C_{0}$ curve for copper, and in the final descent of the $E_{0}$ curves for open-hearth iron (fig. 18) and the three carbon steels (figs. 26, 27, and 28). The same factor contributes to the final descent of the $E_{0}$ curve for annealed 18:8 alloy (fig. 9), and may be the sole cause of this descent. ${ }^{15}$

The factor that is dominant in the descent of the $C_{0}$ curves and in the $E_{0}$ curves (with the possible exception of the $E_{0}$ curve for annealed 18:8 alloy) probably is connected with one or more of the structural changes (other than change of crystal orientation) involved in workhardening, such changes as slip on crystal planes, grain fragmentation, lattice distortion, etc. The factor is possibly associated with the lattice expansion. An increase in the lattice expansion possibly tends to cause a decrease in the modulus of elasticity and in its stress coefficients. In the absence of sufficient evidence to determine the indentity of the factor that tends to depress the $C_{0}$ and $E_{0}$ curves, it might be termed the "work-hardening factor," with the understanding that the term does not imply any direct relation between the modulus of elasticity and hardness. In future reference, however, this factor will be termed tentatively the "lattice-expansion factor." 16

No published information has been found regarding the directional variation of the index of curvature of the stress-strain line, $C_{0}$. There is no clear evidence, moreover, that the reorientation factor becomes dominant in any of the $C_{0}$ curves, although the basic $C_{0}$ curve for

\footnotetext{
18 No definite information is available as to the preferred orientation of this face-centered cubic alloy. The great descent of the $E_{0}$ curve for this alloy, however, indicates that the reorientation factor has little tendency to elevate this curve, and suggests that this factor may even tend to depress the curve. A depressing tendency of the reorientation factor would exist if this alloy approached a predominantly cubic [100] orientation, as do some of the face-centered cubic metals investigated by Schmitt and Wasserman [36] (section VII)

10 Results obtained by Smith and Wood [37] suggest that the lattice expansion, unlike the internal stresses, increases almost linearly with the plastic extension.
} 
annealed copper (figs. 12 and 13) may possibly reach a minimum at an extension of 5 percent or less, and may then rise slightly in accompaniment with the rise of the $E_{0}$ curve. If so, the directional variation of $C_{0}$ in a metal crystal evidently is qualitatively similar to the variation of $E_{0}$.

\section{THE SECANT MODULUS AT THE YIELD STRESS}

If the corrected stress-strain curve up to the yield stress be viewed as the ascending portion of a hysteresis loop, the inclination of the loop is the inclination of a straight line drawn from the origin to the vertex. An index of the inclination of this line, and of the loop, is the secant modulus of elasticity $\left(E_{y}\right)$ at the yield stress. If a series of hysteresis loops is made with the same specimen and with the same stress range, the successive loops may vary greatly in width [22] yet change little in inclination. Such a change in width involves a qualitatively similar change in the curvature $\left(C_{0}\right)$ of the ascending curve and in the initial slope $\left(E_{0}\right)$. An increase of internal stress tends to increase $C_{0}$, and thus tends to increase the width of the hysteresis loop; the lattice-expansion factor tends to decrease $C_{0}$, and thus tends to decrease the width of the loop. The effect of the reorientation factor on the width of the loop has not been determined, but probably is small. Consideration will now be given to the influence of each of these factors on the inclination of the corrected stress-strain curve as indicated by the modulus of elasticity at the yield stress.

The variation of $E_{y}$ with prior plastic extension may be studied qualitatively by means of the curves of variation of $E_{25}, E_{30}, E_{50}$, or $E_{100}$. The trend of each of these curves is qualitatively similar to that of the corresponding $E_{v}$ curve (not shown).

The forms of the $E_{y}$ curves for annealed nickel and copper may be deduced by a comparison of the $E_{0}$ and $E_{30}$ curves in figure 4 and of the $E_{0}$ and $E_{25}$ curves in figures 12 and 13 . The $E_{y}$ curves for nickel and copper would have an initial descent followed by a rise at a gradually decreasing rate. The significant feature common to these three curves is the final rise. A final rise of the $E_{\nu}$ curve was obtained only with these face-centered cubic metals; it was not obtained with the 18:8 alloy (fig. 9) or with the annealed body-centered cubic metals (figs. 18, 26,27 , and 28). A final rise of the $E_{\nu}$ curve, therefore, evidently is obtained only when the elevating influence of the reorientation factor is prominent; it evidently is due to a dominant influence of this factor. When the reorientation factor tends to increase the initial slope $\left(E_{0}\right)$, it also tends to increase $E_{y}$, and thus tends to decrease the forward tilt of the stress-strain curve to the yield stress. When the reorientation factor tends to decrease the initial slope $\left(E_{0}\right)$, as it does with silver [36] and possibly with the 18:8 alloy, it also tends to increase the forward tilt of the stress-strain curve.

With the open-hearth iron, with the carbon steels, and possibly with the 18:8 alloy, the reorientation factor does not become dominant in any part of the $E_{y}$ curve. ${ }^{17}$ The course of this curve then is determined qualitatively by the internal-stress factor and the latticeexpansion factor. The influence of the latter factor on $E_{y}$ may be deduced by comparing the intermediate curves for open-hearth iron (fig. 18) and the carbon steels (figs. 26, 27, and 28) with the correspond-

\footnotetext{
${ }^{17}$ Except possibly when open-hearth iron has been annealed in boiling water (fig. 21).
} 


\section{Journal of Research of the National Bureau of Standards}

ing $E_{0}$ and $C_{0}$ curves. The $E_{y}$ curves (not shown) for these metals are similar to the intermediate curves; they either descend continuously from the origin (figs. 27 and 28) or descend after an initial rise (figs. 18 and 26). The $E_{\nu}$ curve invariably descends with extension beyond the point at which the $C_{0}$ curve reaches a maximum (figs. 18 , 27, and 28). Throughout this range of extension, the lattice-expansion factor is dominant in the $C_{0}$ and $E_{0}$ curves. The corresponding descent of the $E_{v}$ curve, therefore, may be attributed to the dominant influence of this factor. The lattice-expansion factor evidently tends not only to decrease the curvature, $C_{0}$, of the stress-strain curve, but also to tilt the curve forward.

This influence of the lattice-expansion factor, like the influences of the internal-stress factor and the reorientation factor, is greatest at the origin of a curve of variation of either $C_{0}, E_{0}$, or $E_{y}$ with prior plastic extension. The depressing influence of the lattice-expansion factor on $E_{y}$, therefore, must be prominent not only after the $C_{0}$ curve reaches a maximum, but also while the $C_{0}$ curve is under the dominant influence of increasing internal stress. The course of the $E_{y}$ curve while the $C_{0}$ curve is rising (figs. 18,26, 27, and 28) is the resultant of the depressing influence of the lattice-expansion factor and the elevating influence of the rising internal stress.

If a specimen from a bar of severely cold-drawn metal is tested in tension, and if another specimen from the same bar is tested after a long time at room temperature, it is found that this rest interval has decreased both $E_{0}$ and $C_{0}$, but has caused practically no change in $E_{y}$. Relief of macroscopic internal stress has decreased the initial slope and the curvature, but has not changed the inclination of the stress-strain curve as represented by the secant modulus at the yield stress. Relief of internal stress by slight plastic extension of four severely cold-drawn 18:8 alloys (fig. 19 of the preceding paper) had a similar effect. The evidence thus implies that variation of internal stress by slight plastic extension or by rest at room temperature has practically no effect on $E_{y}$.

The initial extension of the three carbon steels caused a great increase of $C_{0}$ (figs. 26, 27, and 28). The accompanying decrease of $E_{50}$ was slight for the 0.20 -percent carbon steel (fig. 26), was greater for the 0.73-percent carbon steel (fig. 28), and was greatest for the 0.42-percent carbon steel (fig. 27). As these steels had not been coldworked prior to the tension test, however, the lattice-expansion factor probably had considerable influence and may have been the dominant influence on the initial course of the $E_{v}$ curve, whereas the internalstress factor was the dominant influence on the corresponding part of the $C_{0}$ curve. The lattice-expansion factor, moreover, may have been the dominant influence in the steep descent of the $E_{y}$ curve for 18:8 alloy (fig. 9), although the reorientation factor possibly contributed to this descent.

The annealing of nickel for relief of internal stress (fig. 8) caused a great decrease of $C_{0}$, a slight increase of $E_{0}$, and a great increase of $E_{50}$. A similar, though less prominent effect was caused by relief of internal stress in severely cold-worked open-hearth iron (fig. 25). The restoration of internal stress by plastic extension (figs. $8, B$, and $25, B$ ) caused a rise of the $C_{0}$ curve and a descent of the $E_{50}$ curve. These effects suggest that an increase of internal stress not only increases the curvature of the stress-strain line but also tends to tilt it 
forward. Annealing at elevated temperatures, however, generally causes permanent changes other than the relief of internal stress. The elevation of the proof stresses and the changes in $E_{0}$ and $C_{0}$ due to such annealing are the resultants of changes of internal stress, of lattice expansion, and probably of other properties. In judging the effect of the internal-stress factor on $E_{y}$, therefore, chief consideration should be given to the evidence based on changes of internal stress at room temperature.

The weight of evidence appears to indicate that the principal effect of the internal-stress factor is on the curvature of the stressstrain line. Although an increase of internal stress may sometimes tend to tilt the stress-strain curve forward, the chief cause of the descent of a curve such as the intermediate curves in figures 18,26 , 27 , and 28 evidently is an increase of the lattice-expansion factor.

\section{CONCLUSIONS}

1. An incomplete view of the tensile elastic properties of a metal is obtained by considering either the stress-set or the stress-strain relationship alone. Consideration should be given to both relationships.

2. From a stress-set curve, proof stresses may be derived to represent the stresses causing various amounts of permanent set. From corresponding stress-strain and stress-set curves may be derived corrected stress-strain curves to represent the variation of elastic strain with stress.

3 . Curves of variation of proof stresses with prior plastic extension often have many wide abrupt oscillations superposed on a gradual wavelike mean curve. These oscillations generally are associated with variations in the duration of the rest interval and in the extension spacing of the experimental points.

4. With prior plastic extension, the proof stresses representing permanent set values of 0.03 and 0.1 percent generally increase continuously. The 0.001-percent proof stress and sometimes the 0.003percent proof stress do not increase or decrease continuously, but either increase to a maximum or decrease to a minimum; beyond this maximum or minimum, these proof stresses oscillate with little or no general upward trend. The 0.01-percent proof stress may follow a course somewhat similar to either the two upper or the two lower proof stresses.

5. The variation of the proof stresses with prior plastic extension is affected by the rate of work-hardening, by the change of internal stress (both macroscopic and microstructural), and by the duration of the rest interval prior to the determination of a stress-set curve. Workhardening tends to increase the proof stresses. Increase of macroscopic internal stress, and probably of microstructural internal stress, tends to decrease the proof stresses, especially the proof stresses that may be regarded as indices of elastic strength (0.001-and 0.003-percent proof stress). The slowness of the rise of these lower proof stresses with prior plastic extension probably is due to a general upward trend of the internal stress. The greater the Bauschinger effect, the higher are the tensile proof stresses (obtained in the determination of a proof-stress extension curve).

6. From the corrected stress-strain curves may be derived curves of variation of the secant modulus with stress. The initial stress- 
modulus line for fully annealed metals generally is nearly vertical at the origin and is only slightly curved. The initial stress-modulus line for annealed copper, however, is strongly curved. With prior plastic extension, the curvature of the stress-modulus line first increases, then decreases. With sufficient plastic extension, the stress-modulus line for nickel, 18:8 alloy, and carbon steels, becomes practically straight, but the stress-modulus line for copper does not become quite straight.

7. The straightness of the stress-modulus line indicates that the corresponding stress-strain line is a quadratic parabola. The curvature of the parabola may be measured by the linear stress coefficient, $C_{0}$, of the modulus. The modulus at zero stress, $E_{0}$, may be obtained by extrapolating the stress-modulus line to zero stress.

8. When the stress-modulus line is curved from the origin, a second constant, $C^{\prime}$, is needed to represent the curvature of the stress-modulus line. For some fully annealed metals and for some other metals that are free from the effects of cold work, $C_{0}$ is zero, and the stress-strain line, consequently, is a cubic parabola. When the stress-modulus line is curved and is not vertical at the origin, the stress-strain line may be viewed either as the superposition of a cubic parabola on a quadratic parabola or as a single parabola whose exponent is between 2 and 3.

9. When $E_{0}, C_{0}, C^{\prime}$ and the five proof stresses are known, a fairly good picture is available of the elastic properties in tension.

10. Because of the great directional variation of the modulus of elasticity of some metal crystals, a change of orientation of the grains of a polycrystalline aggregate may greatly affect the course of the modulus-extension curve. With most face-centered cubic metals, cylindrical extension causes such a change of crystal orientation that $E_{0}$ tends to increase. Some face-centered cubic metals, however, exhibit the opposite tendency. With body-centered cubic metals, a change from random to preferred orientation tends to cause some increase of $E_{0}$. Annealing may greatly affect the crystal orientation and thus may affect the modulus of elasticity.

11. The directional variation of the stress coefficient $\left(C_{0}\right)$ of the modulus of elasticity of a metal crystal has not been determined. If such a variation exists, it probably is small, and possibly is similar to the directional variation of $E_{0}$.

12. The curves of variation of $E_{0}$ with prior plastic extension are continuously influenced by three important variables: crystal orientation, internal stress, and the lattice-expansion factor. The curves of variation of $C_{0}$ and $C^{\prime}$ are continuously influenced by at least the latter two of these factors. A change in dominance from one factor to another is accompanied by a reversal of the curve of variation of either $E_{0}, C_{0}$, or $C^{\prime}$ with plastic extension.

13. The reorientation factor tends to elevate the curve of variation of $E_{0}$ with plastic extension for all the metals considered in this paper, except possibly for 18:8 chromium-nickel steel, but becomes dominant only in the curves for annealed nickel and copper. No conclusive evidence has been found of an effect of the reorientation factor on $C_{0}$.

14. An increase of macroscopic internal stress, and probably of microstructural internal stress, tends to cause an increase of $C_{0}$. It is possible, however, that both $C_{0}$ and $E_{0}$ tend to decrease with an increase of the Bauschinger effect induced by the microstructural stresses.

15. A decrease of internal stress, either by plastic extension or by annealing, tends to cause a decrease of $C_{0}$. 
16. An increase of internal stress tends to cause an increase of $E_{0}$, but generally tends to cause little change in $E_{y}$.

17. Annealing at elevated temperatures for relief of internal stress may cause no change or even a slight increase in $E_{0}$. Because of the decrease of $C_{0}$, the annealing thus may cause an increase of $E_{y}$. As the annealing causes changes of macroscopic and microstructural internal stresses, and of the lattice expansion, however, the effect of the annealing on $E_{0}$ and $E_{y}$ is a resultant of the effects on all these factors.

18. Rest after plastic extension tends to cause a decrease of the proof stresses, especially those representing $0.001-$ and $0.003-$ percent permanent set, but tends to cause an increase of both $C_{0}$ and $E_{0}$. The effect of the rest, therefore, is opposite to the effect of macroscopic internal stress. The predominant effect of the rest probably is chiefly due to a decrease in the lattice expansion, but could be partly due to a decrease in the unsymmetry of the stress-strain curve between the tensile and compressive yield stresses. Such unsymmetry, however, may be largely due to a directional variation of the lattice expansion, and only partly due to the microstructural stresses.

19. Rest after plastic extension causes practically no change in $E_{v}$.

20. A long rest of a cold-drawn bar at room temperature tends to cause a decrease of both $C_{0}$ and $E_{0}$, with practically no change of $E_{y}$. The predominant effect of the long rest, therefore, evidently is a relief of macroscopic internal stresses.

21. Change of macroscopic or microstructural internal stress generally tends to cause little change of $E_{y}$.

22. The lattice-expansion factor tends to cause a decrease of the index of curvature, $C_{0}$, and of the initial slope, $E_{0}$, of the corrected stress-strain curve. It also tends to cause a decrease of $E_{y}$.

23 . When the reorientation factor tends to increase $E_{0}$, it also tends to increase $E_{y}$. This influence is finally dominant in $\mathrm{E}_{0}$ and $E_{v}$ curves for some face-centered cubic metals.

\section{REFEREITCES}

[1] C. S. Barrett and L. H. Levenson, Structure of iron after drawing, swaging and elongating in tension, Metals Tech. 6, No. 2, Tech. Pub. No. 1038 (1939).

[2] C. S. Barrett, Recrystallization texture of aluminum after compression, Metals Tech. 7 , No. 1, Tech. Pub. No. 1141 (1940).

[3] C. S. Barrett, G. Ansel, and R. F. Mehl, Preferred orientation in iron-silicon alloys, Trans. Am. Inst. Mining Met. Engrs. 125, 516-528 (1937).

[4] W. G. Burgers and P. C. Louwerse, Über den Zusammenhang zwischen Deformationsvorgang und Rekristallisationstextur bei Aluminum, Z. Physik 67, 605-678 (1931).

[5] J. A. Collins and C. H. Mathewson, Plastic deformation and recrystallization of aluminum single crystals, Metals Tech. $\boldsymbol{7}$, Tech. Pub. No. 1145, No. 1 (1930).

[6] M. Ettisch, M. Polanyi, and K. Weissenberg, Über Faserstruktur bei Metallen, Z. Physik \%, 181-184 (1921).

[7] M. Ettisch, M. Polanyi, and H. Weissenberg, Faserstruktur hartgezogener Metalldrahte, Z. physik. Chem. 99, 332-337 (1921).

[8] G. Farnham and H. O'Neill, Crystal reorientation on heating drawn copper wires, J. Inst. Metals 55, No. 2, 201-208 (1934).

[9] M. Gensamer and P. A. Vukmanic, Preferred orientations in hot-rolled lowcarbon steel, Trans. Am. Inst. Mining Met. Engrs. 125, 507-511 (1937).)

[10] M. Gensamer and B. Lustman, Preferred orientations produced by recrystallizing cold-rolled low-carbon sheet steel, Trans. Am. Inst. Mining Met. Engrs. 125, 501-506 (1937). 
[11] V. Goler and G. Sachs, Walz-und Rekristallisationstextur regulär flächenzentrierter Metalle, I., Z. Physik 41, 873-888 (1927).

[12] V. Goler and G. Sachs, Walz-und Rekristallisationstextur regulär flächenzentrierter Metalle, II, Z. Phys. 41, 889-906 (1927).

[13] V. Goler and G. Sachs, Walz-und Rekristallisationstextur regulär flächenzentrierter Metalle, III., Z. Phys. 56, 477-484 (1929).

[14] V. Goler and G. Sachs, Walz-und Rekristallisationstextur regulär flächenzentrierter Metalle, IV., Z. Phys. 56, 485-494 (1929).

[15] G. Greenwood, Fibre texture in nickel wires, Z. Krist., 72, 309-317 (1929).)

[16] E. Heyn and O. Bauer, Über Spannungen in kaltgereckten Metallen, Int. Z. Metallog. 1, 16-50 (1911).

[17] E. Heyn, Internal strains in cold-wrought metals, and some troubles caused thereby, J. Inst. Metals 12, pt. 2, 3-37 (1914).

[18] E. Heyn, Einige Fragen aus dem Gebiet der Metallforschung, Metall u. Erz 15, 411-422, 436-441 (1918).

[19] $\mathrm{K}$. Honda and R. Yamada, On the change of elastic constant in metals caused by cold-working, Science Repts., Tôhoku Imperial Univ. 17, No. 3, 723-742 (1928).

[20] T. Kawai, The effect of cold-working on Young's modulus of elasticity, Science Repts., Tôhoku Imperial Univ. 19, No. 9, 209-234 (1930).

[21] W. Kuntze, Abhängigkeit der elastischen Dehnungszahl " $\alpha$ " des Kupfers von der Vorbehandlung, Z. Metallkunde 20, 145-150 (1928).

[22] D. J. McAdam, Jr., and R. W. Mebs, Tensile elastic properties of 18:8 chromium-nickel steel as affected by plastic deformation, NACA Tech. Rep. 670 (1939).

[23] D. J. McAdam, Jr., and R. W. Mebs, Tensile elastic properties of typical stainless steels and nonferrous metals as affected by plastic deformation and by heat treatment, NACA Tech. Rep. 696, (1940). (Restricted; not available for distribution.)

[24] G. Masing, Ueber elastische Nachwirkung und elastische Hysteresis bei Metallen, Z. Metallkunde 12, 33-43 (1920).

[25] G. Masing, Zur Heynschen Theorie der Verfestigung der Metalle durch verborgen elastische Spannungen, Wiss. Veröffent. Siemens-Konzern 3, Nr. 1, 231-239 (1924).

[26] G. Masing, Ueber die Entwicklung von Eigenspannungen beim Kaltwalzen von Messing, Z. Metallkunde 17, 183-186 (1925).

[27] G. Masing, Rekristallisation und Erholung (Kristalvergutung) bei Metallen, Wiss. Veröfrent. Siemens-Konzern 4, Nr. 2, 230-243 (1925).

[28] G. Masing, Eigenspannungen in kaltgerechten Metallen, Z. technische Physik 6, 569-573 (1925).

[29] G. Masing and C. Haase, Ueber die Grösse und Verteilung von Eigenspannungen in kaltgereckten Rundmessing, Wiss. Veröffent. Siemens-Konzern 4, Heft 1, 69-73 (1925).

[30] G. Masing and W. Mauksch, Einfluss der plastischen Dehnung und Stauchung auf die Festigkeitseigenschaften und inneren Spannungen des Messings, Wiss. Veröffent. Siemens-Konzern 4, Nr. 1, 74-90 (1925).

[31] G. Masing and W. Mauksch, Eigenspannungen und Verfestigung des plastisch gedehnten und gestauchten Messings, Wiss. Veröffent. Siemens-Konzern 4, Nr. 2, 244-256 (1925).

[32] G. Sachs, Innere Spannungen in Metallen, Z. Ver. deut. Ing. 71, 1511-1516 (1927).

[33] G. Sachs and E. Schiebold, Rekristallisation und Entfestigung im Röntgenbild, Z. Metallkunde $\%, 400-402$ (1925).

[34] E. Schmid, Zur Fliessgefahr von Metallkristallen, Z. Metallkunde 10, 154-157 (1927).

[35] E. Schmid and W. Boas, Kristallplastizität (Julius Springer, Berlin, 1935).

[36] E. Schmid and G. Wassermann, Ueber die Textur hartgezogener Drähte, Z. Physik 42, 779-794 (1927).

[37] S. L. Smith and W. A. Wood, A stress-strain curve for the atomic lattice of iron, Proc. Roy Soc. (London) [A] 178, 93-106 (1941).

[38] G. I. Taylor and C. F. Elam, The distortion of an aluminum crystal during a tensile test, Proc. Roy. Soc. (London) [A] 102, 643-667 (1923).

[39] R. L. Templin and R. G. Sturm, Some stress-strain studies of metals, J. Aeron. Sci. 7, 189-198 (1940).

[40] H. C. Vacher, Development of a fibrous texture in cold-worked rods of copper, J. Research NBS 22, 6, 651-668 (1939) RP1210.

[41] G. Vargha and G. Wassermann, Ueber den Einfluss des Formgebungsverfahrens auf die Kristallgleichrichtung in Drähten, Z. Metallkunde 25;310-313 (1933). 
TABLE 1.-Description of metals

\begin{tabular}{|c|c|c|c|c|c|c|c|c|c|c|c|c|c|}
\hline \multirow[b]{2}{*}{ Metal } & \multirow[b]{2}{*}{$\begin{array}{c}\text { NBS } \\
\text { desig- } \\
\text { nation }\end{array}$} & \multicolumn{2}{|c|}{$\begin{array}{l}\text { Mechanical } \\
\text { treatment }\end{array}$} & \multirow{2}{*}{ 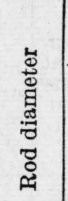 } & \multicolumn{9}{|c|}{ Chemical composition } \\
\hline & & Method & 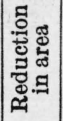 & & C & $\mathrm{Fe}$ & $\mathrm{Ni}$ & $\mathrm{Cu}$ & $\mathrm{Cr}$ & Mn & $\mathbf{P}$ & $\mathbf{S}$ & Si \\
\hline $\begin{array}{l}\text { Nickel- } \\
\text { 18:8 Cr-Ni steel }\end{array}$ & & Cold-drawn. & $\begin{array}{c}\% \\
60.0\end{array}$ & in. & $\begin{array}{l}\% \\
0.07\end{array}$ & $\begin{array}{l}\% \\
0.08\end{array}$ & $\begin{array}{c}\% \\
99.49\end{array}$ & $\%$ & $\%$ & $\begin{array}{l}\% \\
0.24\end{array}$ & $\%$ & $\%$ & $\begin{array}{l}\% \\
0.08\end{array}$ \\
\hline $\begin{array}{l}\text { 18:8 Cr-Ni steel.-.-.- } \\
\text { Oxygen-free copper. }\end{array}$ & $2 A \ldots$ & $\begin{array}{l}\text { Annealed.... } \\
\text { Cold-drawn. }\end{array}$ & $-\overline{75} . \overline{0} \mid$ & $\begin{array}{l}.875 \\
.875\end{array}$ & .06 & (n- & 9.5 & 99.97 & 18.7 & $-\cdots$ & $\cdots$ & $-\cdots$ & $-\cdots$ \\
\hline Open-hearth iron. & $P A$ & Cold-drawn. & 249.3 & .718 & .045 & (n) & $\mid-\cdots+$ & 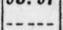 & (n) & .04 & .003 & .03 & $<.01$ \\
\hline Open-hearth iron. & $P B$ & Cold-drawn. & 48.0 & .721 & .045 & & $-\cdots$ & $\ldots$ & $\ldots$ & .04 & .003 & .03 & \\
\hline $\begin{array}{l}0.20 \text {-percent carbon } \\
\text { steel. }\end{array}$ & & & & 1.125 & .20 & & $-\cdots$ & $-\cdots$ & & & .039 & .049 & \\
\hline $\begin{array}{l}\text { 0.42-percent carbon } \\
\text { steel. }\end{array}$ & $U_{--.}$ & Hot-rolled.-- & $-\ldots$ & 1.125 & .42 & & & & & .60 & .033 & .050 & .20 \\
\hline $\begin{array}{l}\text { 0.73-percent carbon } \\
\text { steel. }\end{array}$ & $V_{-\ldots}$ & Hot-rolled..- & $-\cdots$ & 1.125 & .73 & $-\ldots$ & $-\cdots$ & $-\cdots$ & $-\ldots$ & .31 & .019 & .017 & .24 \\
\hline
\end{tabular}

- Cold-drawn 12 percent by manufacturer. Remaining cold-drawing received in laboratory.

TABLE 2.-Details of the heat treatment

\begin{tabular}{|c|c|c|c|c|c|c|c|}
\hline Material & $\begin{array}{l}\text { Specimen } \\
\text { designa- } \\
\text { tion }\end{array}$ & $\begin{array}{l}\text { Tem- } \\
\text { pera- } \\
\text { ture }\end{array}$ & Time held & Cooled in- & $\begin{array}{l}\text { Tem- } \\
\text { pera- } \\
\text { ture }\end{array}$ & $\begin{array}{c}\text { Time } \\
\text { held }\end{array}$ & Cooled in- \\
\hline Nickel...- & $\left\{\begin{array}{l}R \\
R-\overline{5} \\
R-14\end{array}\right.$ & $\begin{array}{c}{ }^{\circ} \mathrm{F} \\
500 \\
1,400\end{array}$ & $\begin{array}{c}\text { Hours } \\
\text { As received. } \\
2\end{array}$ & & ${ }^{\circ} \mathrm{F}$ & Hours & \\
\hline 18:8 Cr-Ni steel & $2 A-1^{b} \ldots$ & $-\ldots$ & As received - - & & & & \\
\hline Oxygen-free copper.-. & $\left\{\begin{array}{l}N \\
N-6 \\
N-8\end{array}\right.$ & $\begin{array}{l}600 \\
800\end{array}$ & $\begin{array}{l}\text { As received. - } \\
22 \\
5\end{array}$ & & & & \\
\hline Open-hearth iron... & $\left\{\begin{array}{l}P A \\
P A-7 \\
P A-W-9 . \\
P B-F S \ldots\end{array}\right.$ & $\begin{array}{r}700 \\
1,750 \\
1,750\end{array}$ & $\begin{array}{l}\text { As received } \\
7 \\
1 / 2\end{array}$ & $\begin{array}{l}\text { Furnace.--- } \\
\text { Water-.--- } \\
\text { Furnace.-. }\end{array}$ & $\begin{array}{r}900 \\
1,350\end{array}$ & $\begin{array}{r}140 \\
1\end{array}$ & $\begin{array}{l}\text { Furnace. } \\
\text { Slow cool.• }\end{array}$ \\
\hline $\begin{array}{l}\text { 0.20-percent carbon steel-.--- } \\
0.42 \text {-percent carbon steel---- } \\
0.73 \text {-percent carbon steel-.-- }\end{array}$ & $\begin{array}{l}T-W-9 \\
U-O-10- \\
V-0-10\end{array}$ & $\begin{array}{l}1,625 \\
1,525 \\
1,450\end{array}$ & $11-2-1$ & $\begin{array}{l}\text { Water...... } \\
\text { Oil. } \\
\text { Oil. }\end{array}$ & $\begin{array}{r}900 \\
1,000 \\
1,000\end{array}$ & $\begin{array}{l}3 \\
2 \\
2\end{array}$ & $\begin{array}{l}\text { Air. } \\
\text { Air. } \\
\text { Air. }\end{array}$ \\
\hline
\end{tabular}

- In the designation of the condition of the material, one or more letters following a dash indicate method of cooling: $W$, water quench; $O$, oil quench; $F$, furnace cool; $S$, unusually slow cooling rate. The numbers following the final dash indicate the final annealing or tempering temperature (degrees Fahrenheit, in hundreds).

6 As originally designated in NACA Technical Report, No. 670.

- Cooled in furnace at rate of about 17 degrees Fahrenheit per hour. 
TABLE 3.-Tensile properties

\begin{tabular}{|c|c|c|c|c|c|c|c|c|c|}
\hline \multirow[b]{2}{*}{ Material } & \multirow[b]{2}{*}{$\begin{array}{l}\text { Specimen } \\
\text { designa- } \\
\text { tion }\end{array}$} & \multirow[b]{2}{*}{$\begin{array}{l}\text { Diam- } \\
\text { eter } \\
\text { over } \\
\text { gage } \\
\text { length }\end{array}$} & \multirow[b]{2}{*}{$\begin{array}{l}\text { Exten- } \\
\text { sion at } \\
\text { maxi- } \\
\text { mum } \\
\text { load }\end{array}$} & \multirow[b]{2}{*}{$\begin{array}{l}\text { Tensile } \\
\text { strength }\end{array}$} & \multicolumn{5}{|c|}{ Initial proof stress } \\
\hline & & & & & $\begin{array}{l}\text { 0.1- } \\
\text { percent } \\
\text { proof } \\
\text { set }\end{array}$ & $\begin{array}{c}0.03- \\
\text { percent } \\
\text { proof } \\
\text { set }\end{array}$ & $\begin{array}{c}0.01- \\
\text { percent } \\
\text { proof } \\
\text { set }\end{array}$ & $\begin{array}{c}0.003- \\
\text { percent } \\
\text { proof } \\
\text { set }\end{array}$ & $\begin{array}{c}0.001- \\
\text { percent } \\
\text { proof } \\
\text { set }\end{array}$ \\
\hline Nickel & $\left\{\begin{array}{l}R \\
R-\overline{5} \\
R-14\end{array}\right.$ & $\begin{array}{l}\text { in. } \\
0.417 \\
.417 \\
.417\end{array}$ & $\begin{array}{c}\text { Percent } \\
0.68 \\
5.13 \\
35.1\end{array}$ & $\begin{array}{c}l b / \text { in. }^{2} \\
117,300 \\
124,600 \\
73,400\end{array}$ & $\begin{array}{r}\text { lb/in.2 } \\
103,600 \\
105,800 \\
18,400\end{array}$ & $\begin{array}{l}l b / \text { in. } 2 \\
82,600 \\
91,200 \\
18,300\end{array}$ & $\begin{array}{l}l b / \text { in. }{ }^{2} \\
60,600 \\
75,500 \\
16,700\end{array}$ & & $\begin{array}{r}l b / \text { in. } \\
5,800 \\
58,000 \\
10,200\end{array}$ \\
\hline 18:8 Cr-Ni steel. & $2 A-1$ & .505 & 66.1 & 83,630 & 28,200 & 24,000 & 19,500 & 13,300 & 8,200 \\
\hline Oxygen-free $c$ & $\left\{\begin{array}{l}N-6 \\
N-6 \\
N-8\end{array}\right.$ & $\begin{array}{l}.505 \\
.505 \\
.505\end{array}$ & $\begin{array}{l}40.0 \\
40.0\end{array}$ & $\begin{array}{l}33,000 \\
33,400\end{array}$ & $\begin{array}{r}49,700 \\
7,760 \\
7,100\end{array}$ & $\begin{array}{r}41,200 \\
6,470 \\
5,900\end{array}$ & $\begin{array}{r}30,800 \\
5,330 \\
4,700\end{array}$ & & $\begin{array}{r}10,000 \\
3,500 \\
2,500\end{array}$ \\
\hline Open-hearth iron & $\left\{\begin{array}{l}P A \\
P A-\overline{7} \\
P A-W-9 \\
P B-F S\end{array}\right.$ & $\begin{array}{l}.417 \\
.417 \\
.417 \\
.417\end{array}$ & $\begin{array}{c}1.72 \\
4.0 \\
14.00 \\
12.53\end{array}$ & $\begin{array}{l}87,700 \\
76,600 \\
54,300 \\
54,700\end{array}$ & $\begin{array}{l}83,700 \\
68,800 \\
22,600 \\
13,380\end{array}$ & $\begin{array}{l}76,600 \\
67,700 \\
22,100 \\
12,660\end{array}$ & $\begin{array}{l}67,600 \\
64,400 \\
21,800 \\
12,330\end{array}$ & $\begin{array}{l}58,700 \\
60,000 \\
20,500 \\
11,880\end{array}$ & $\begin{array}{l}19,000 \\
56,300 \\
18,800 \\
10,330\end{array}$ \\
\hline $\begin{array}{l}0.20 \text {-percent carbon steel } \\
0.42 \text {-percent carbon steel. } \\
0.73 \text {-percent carbon steel_ }\end{array}$ & $\begin{array}{l}T-W-9 \\
U-O-10 \\
V-O-10\end{array}$ & $\begin{array}{l}.505 \\
.505 \\
.505\end{array}$ & $\begin{aligned} 7.25 \\
11.0 \\
9.0\end{aligned}$ & $\begin{array}{l}102,000 \\
114,800 \\
151,200\end{array}$ & $\begin{array}{r}76,500 \\
79,700 \\
101,970\end{array}$ & $\begin{array}{r}76,500 \\
79,700 \\
101,970\end{array}$ & $\begin{array}{r}76,500 \\
79,700 \\
100,500\end{array}$ & $\begin{array}{l}76,500 \\
77,700 \\
85,000\end{array}$ & $\begin{array}{r}72,000 \\
47,000 \\
4,000\end{array}$ \\
\hline
\end{tabular}




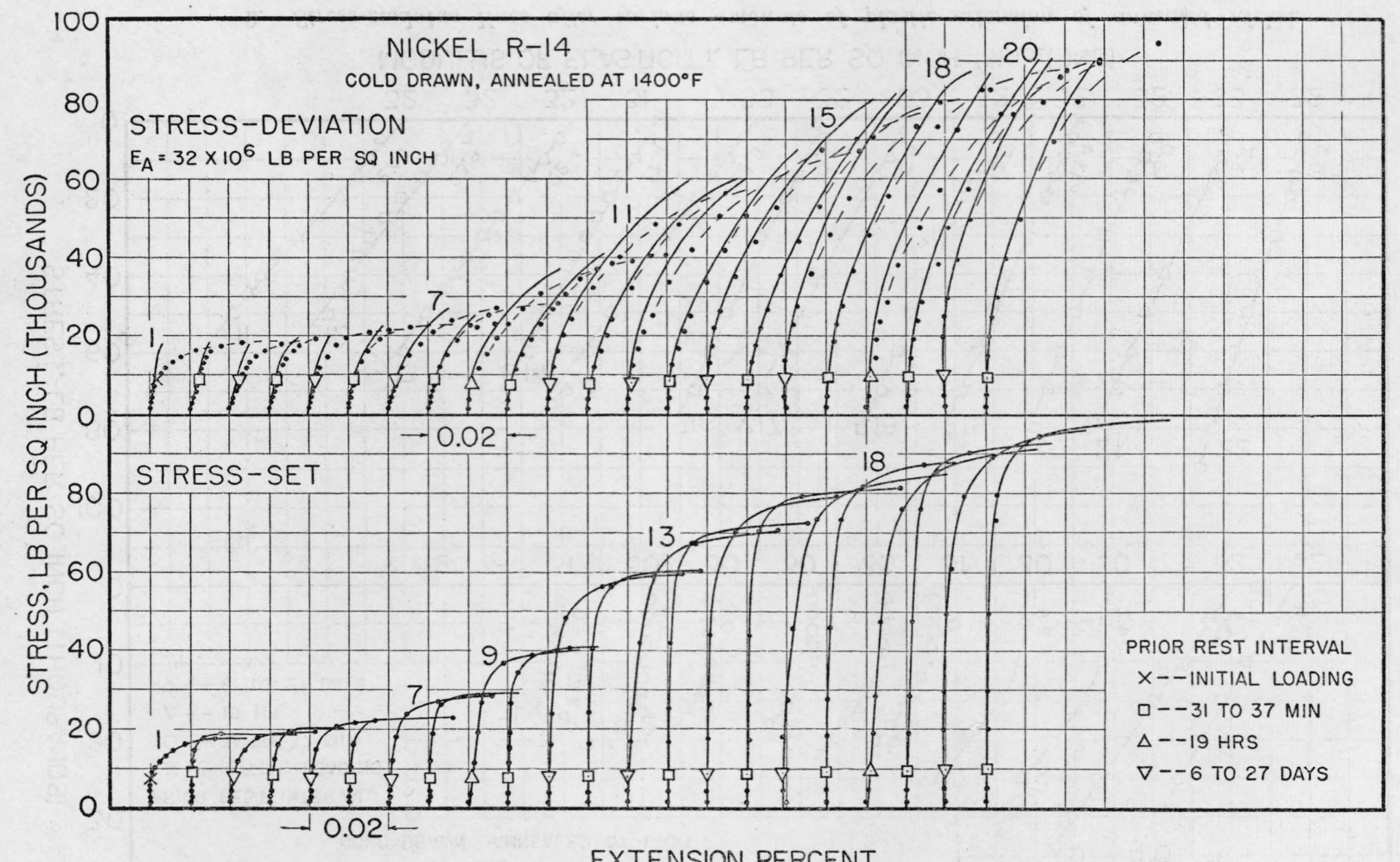

\section{EXTENSION, PERCENT}

FIGURE 1.-Stress-deviation and stress-set curves after various amounts of plastic extension of annealed nickel. 


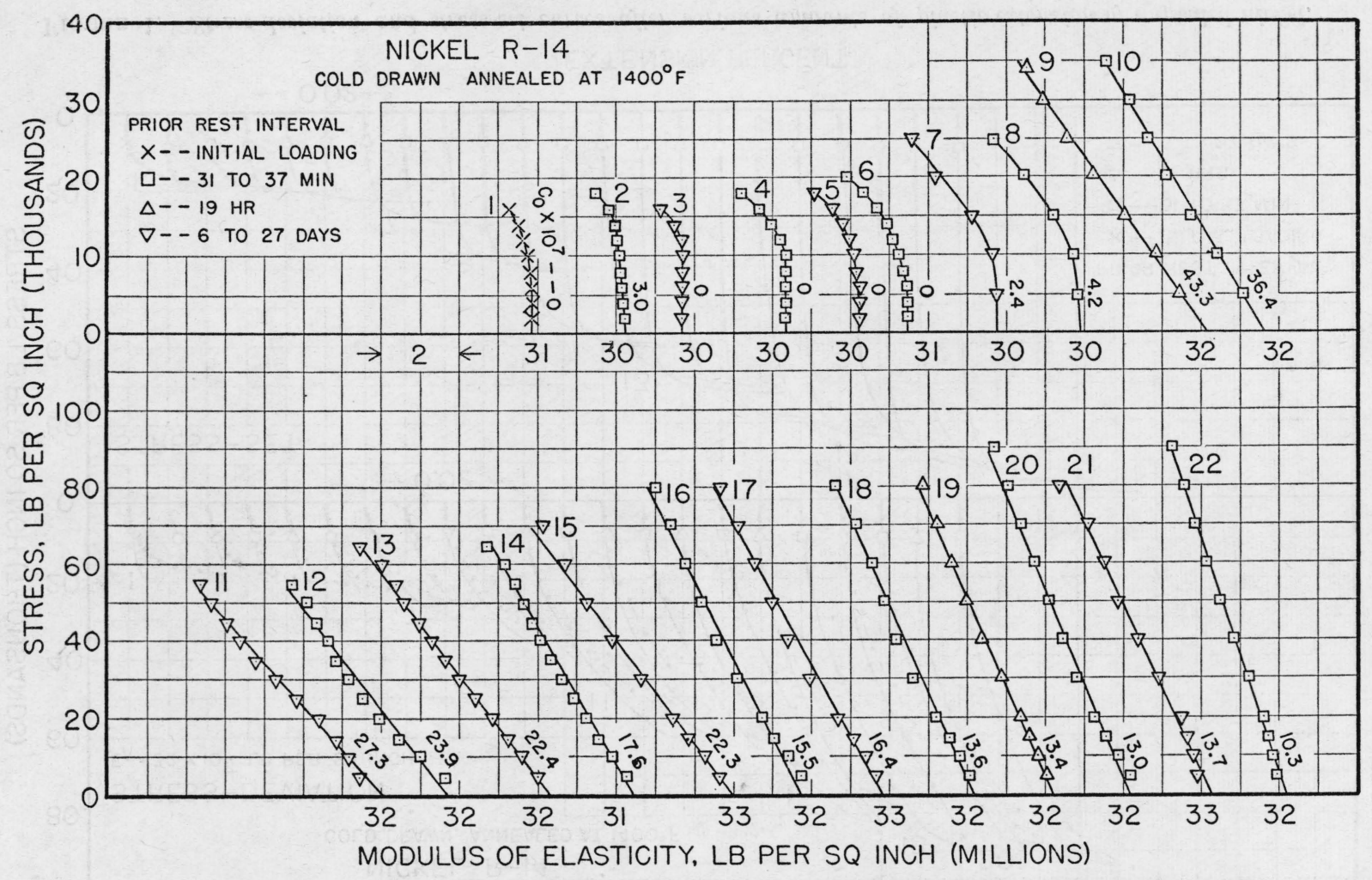

यू

2.-Stress-modulus lines after various amounts of plastic extension of annealed nickel. 


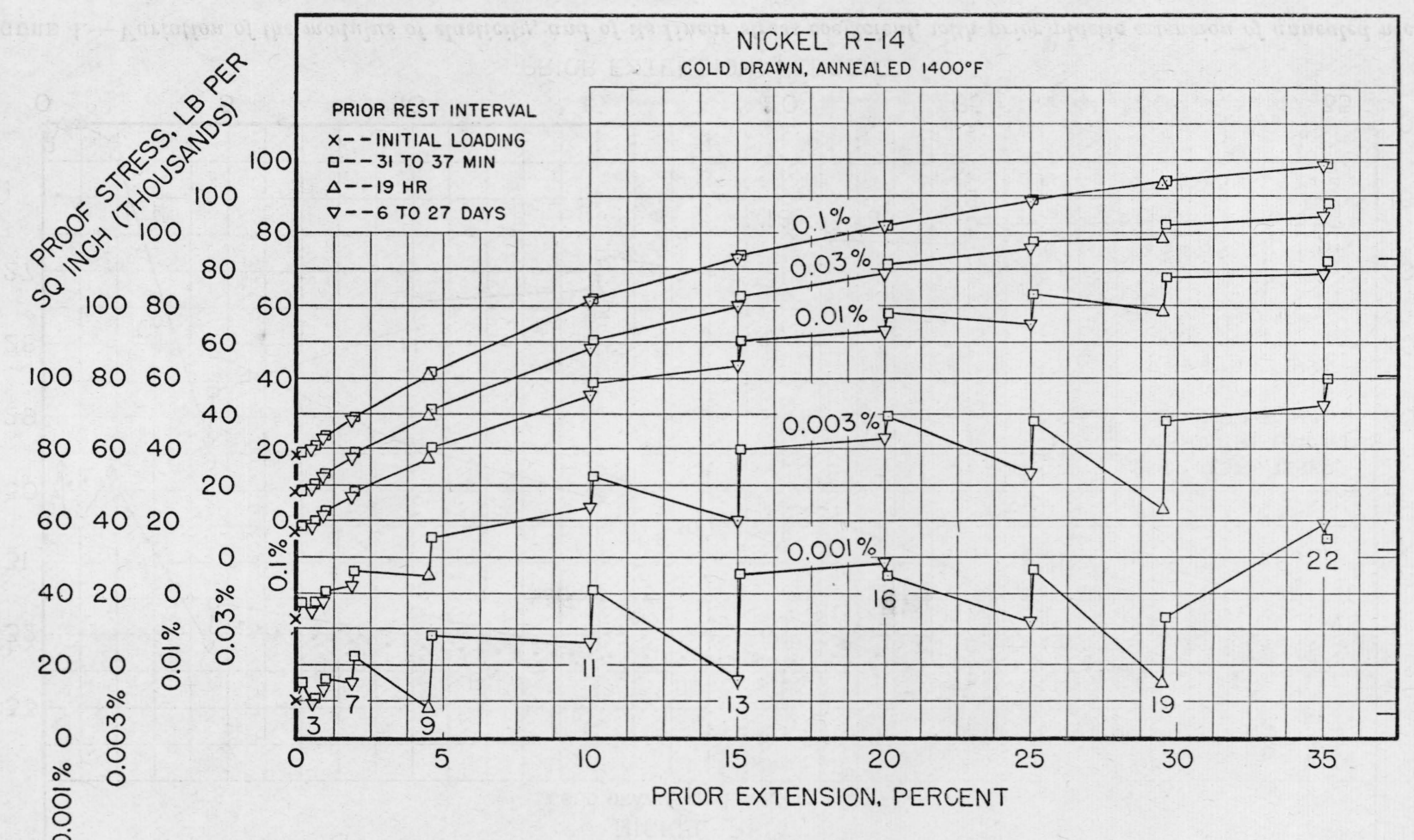

FIGURE 3.-Variation of proof stresses with prior plastic extension of annealed nickel. 


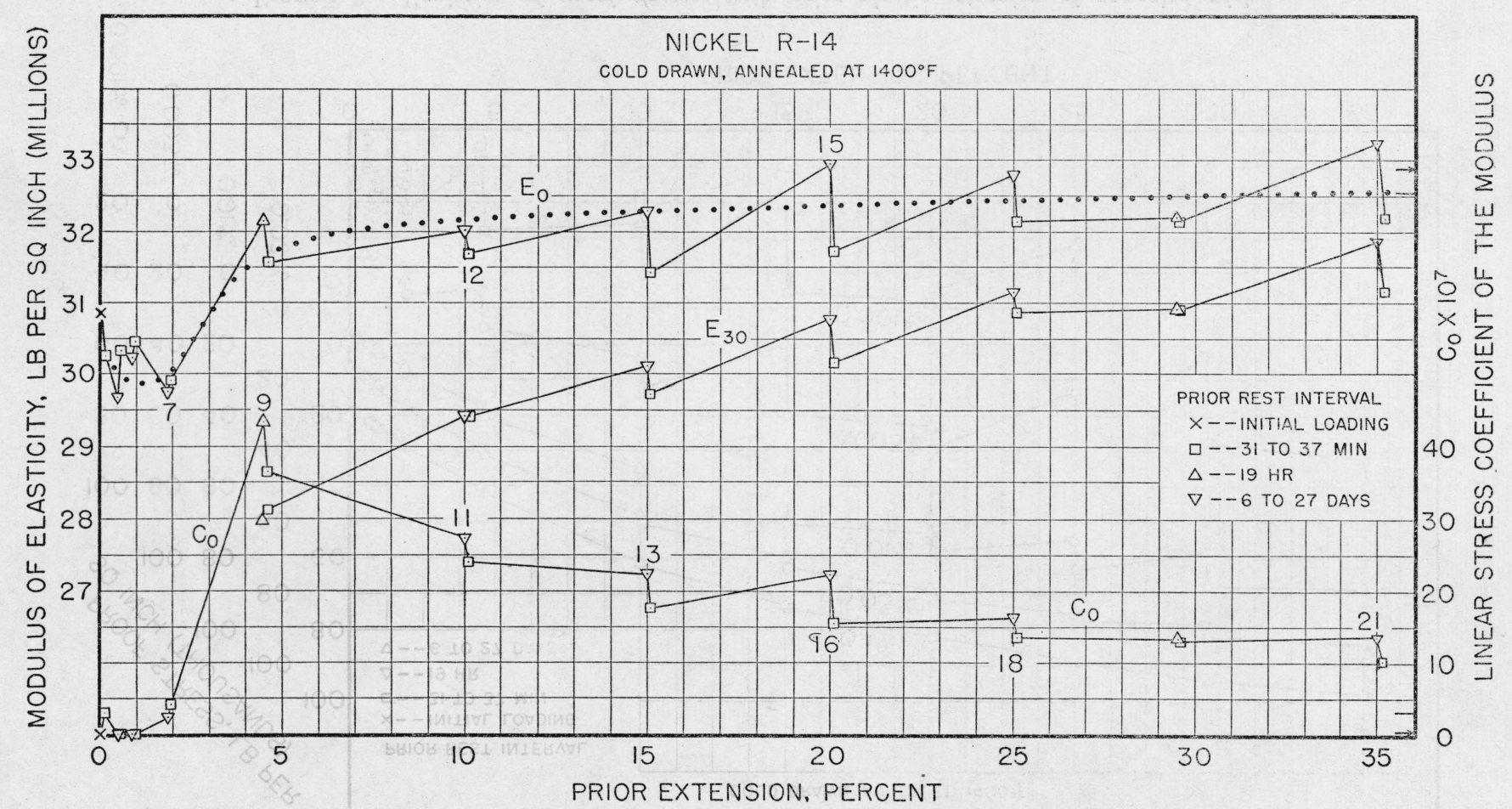

FIGURE 4.-Variation of the modulus of elasticity, and of its linear stress coefficient, with prior $\$$ plastic extension of annealed nickel. 


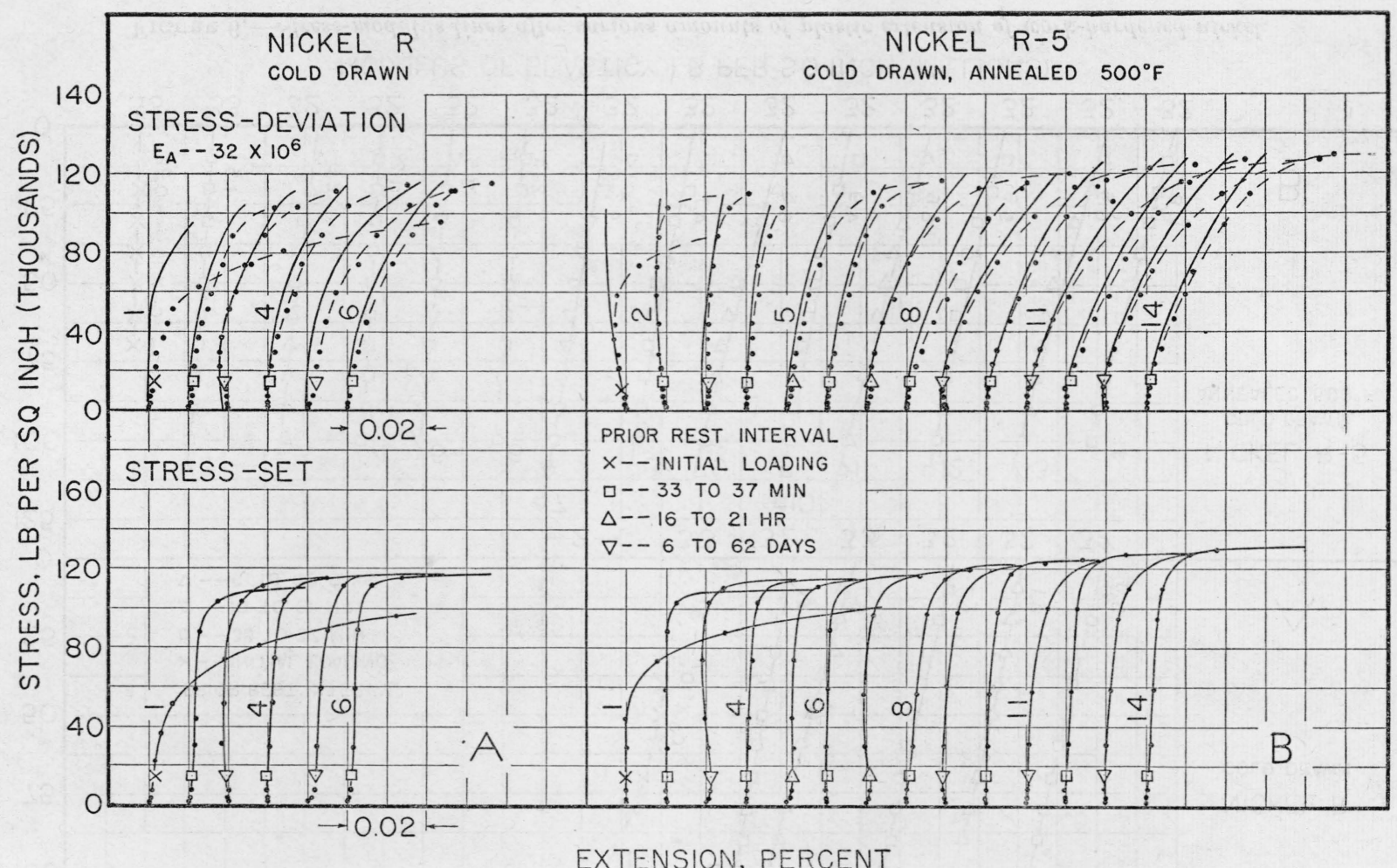

FIGURE 5.-Stress-deviation and stress-set curves after various amounts of plastic extension of work-hardened nickel. 


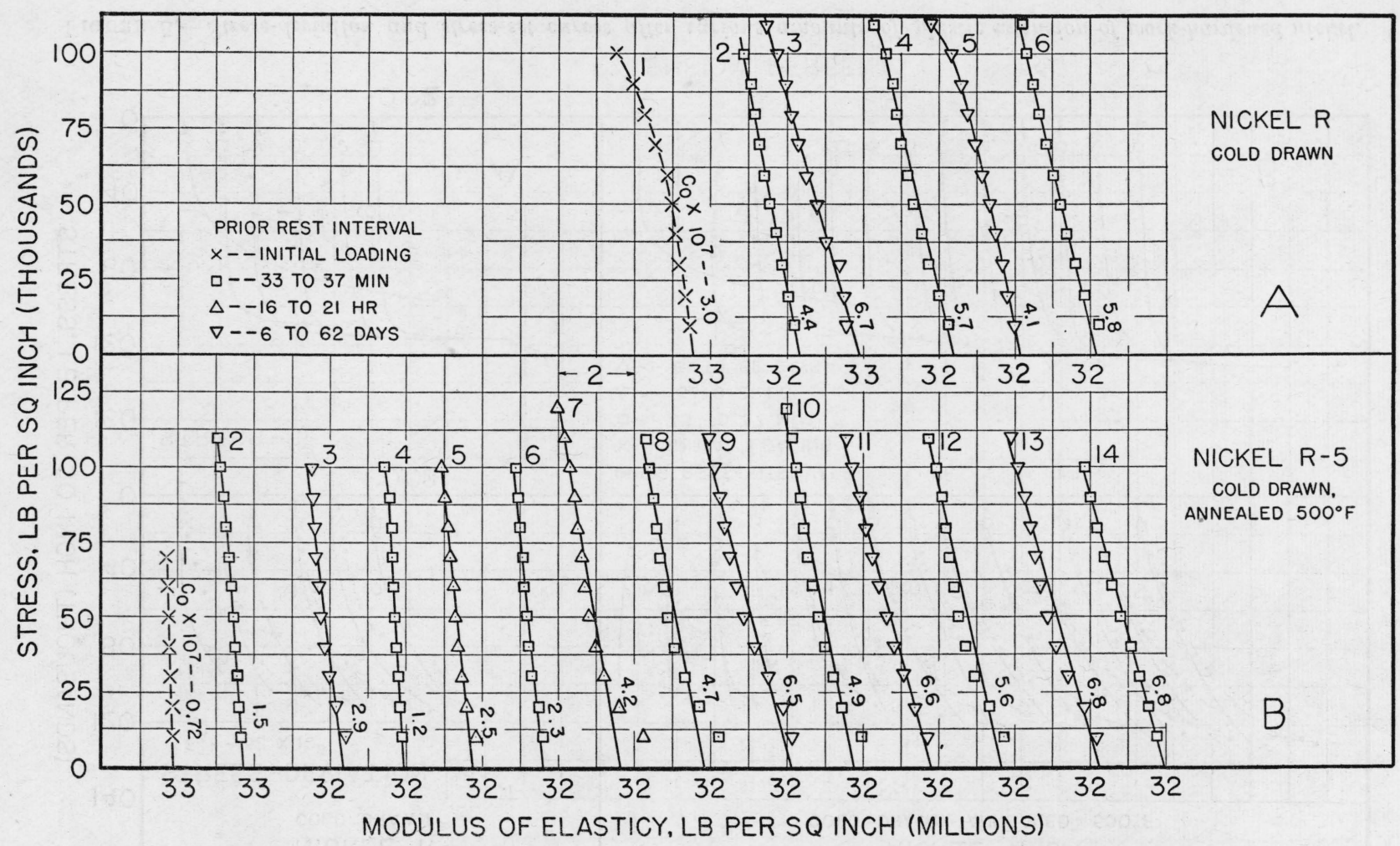

品

FIGURE 6.-Stress-modulus lines after various amounts of plastic extension of work-hardened nickel. 


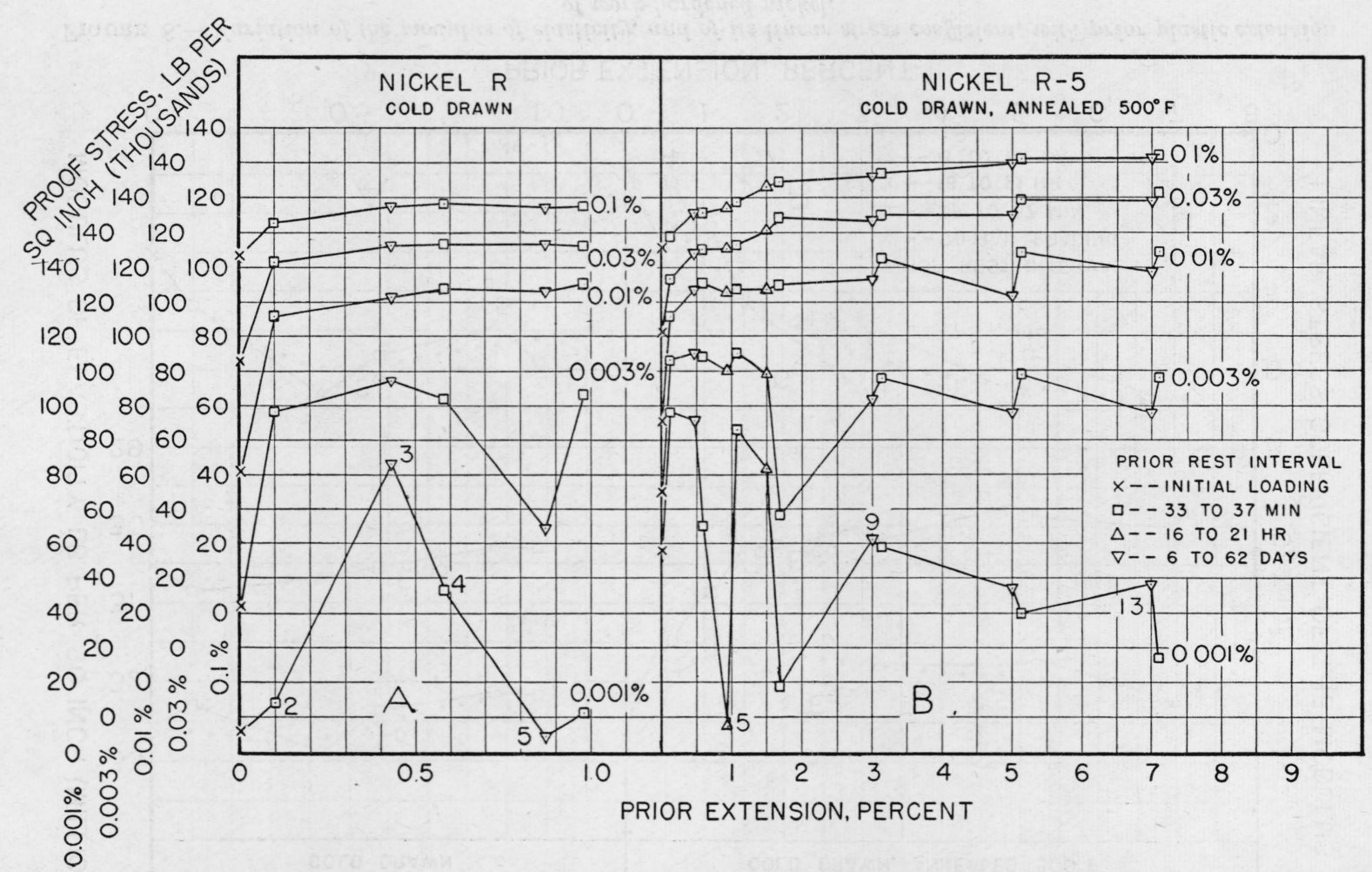

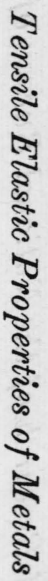

FigURE 7.-Variation of proof stresses with prior plastic extension of work-hardened nickel. 


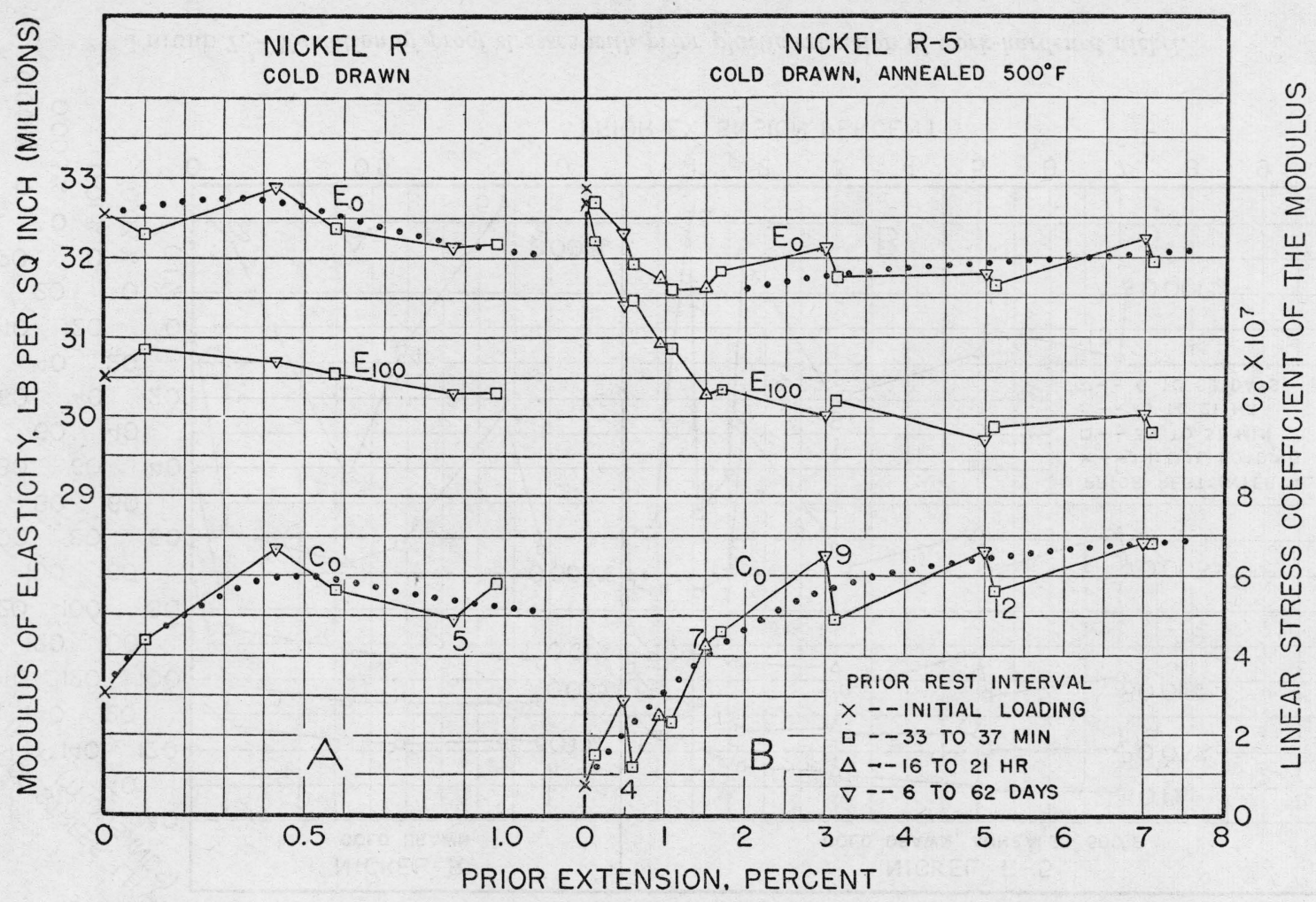

FIGURe 8.-Variation of the modulus of elasticity, and of its linear stress coefficient, with prior plastic extension of work-hardened nickel. 


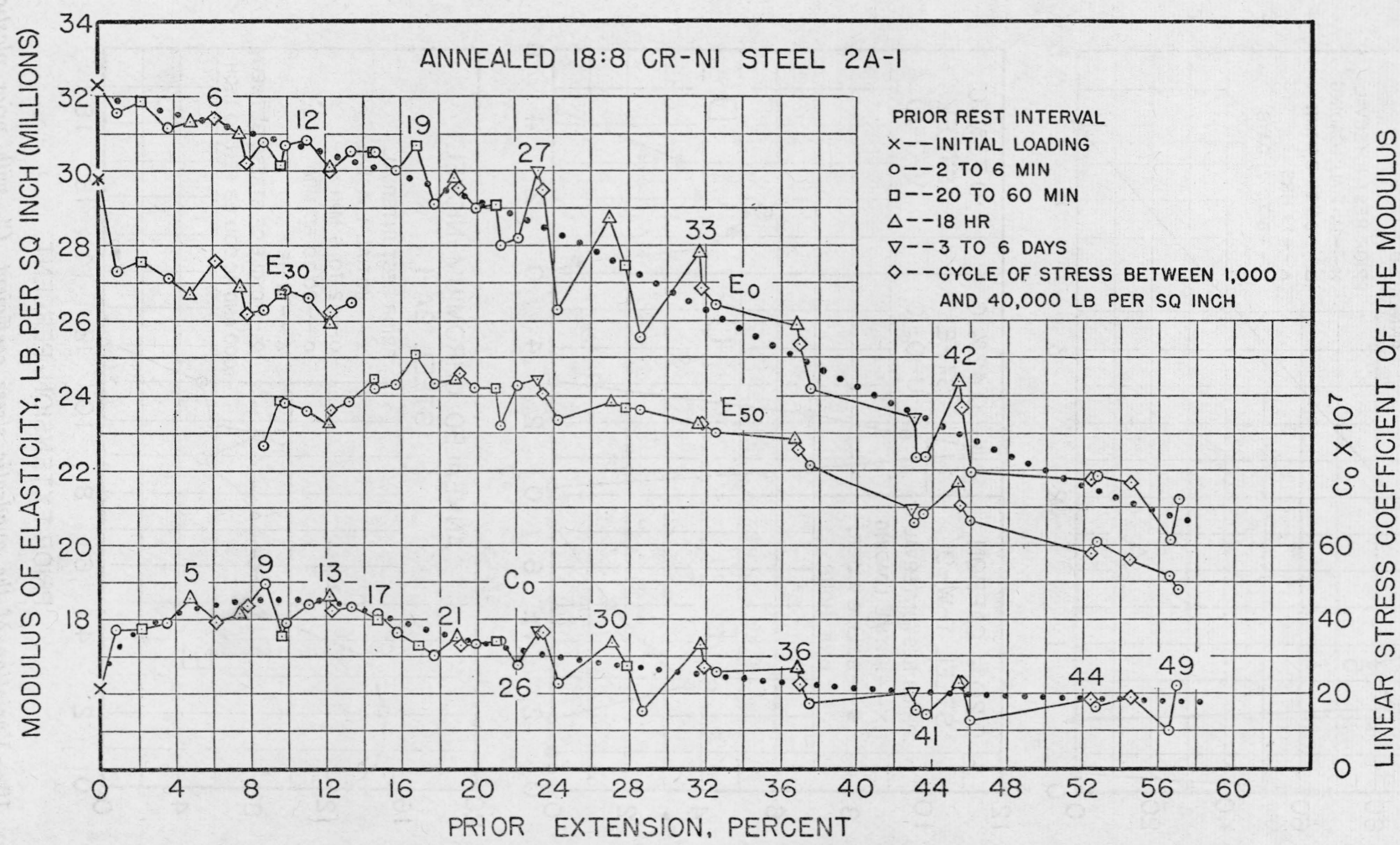

FIGURE 9.-Variation of the modulus of elasticity, and of its linear stress coefficient, with prior plastic extension of annealed 18:8 chromium-nickel steel. 

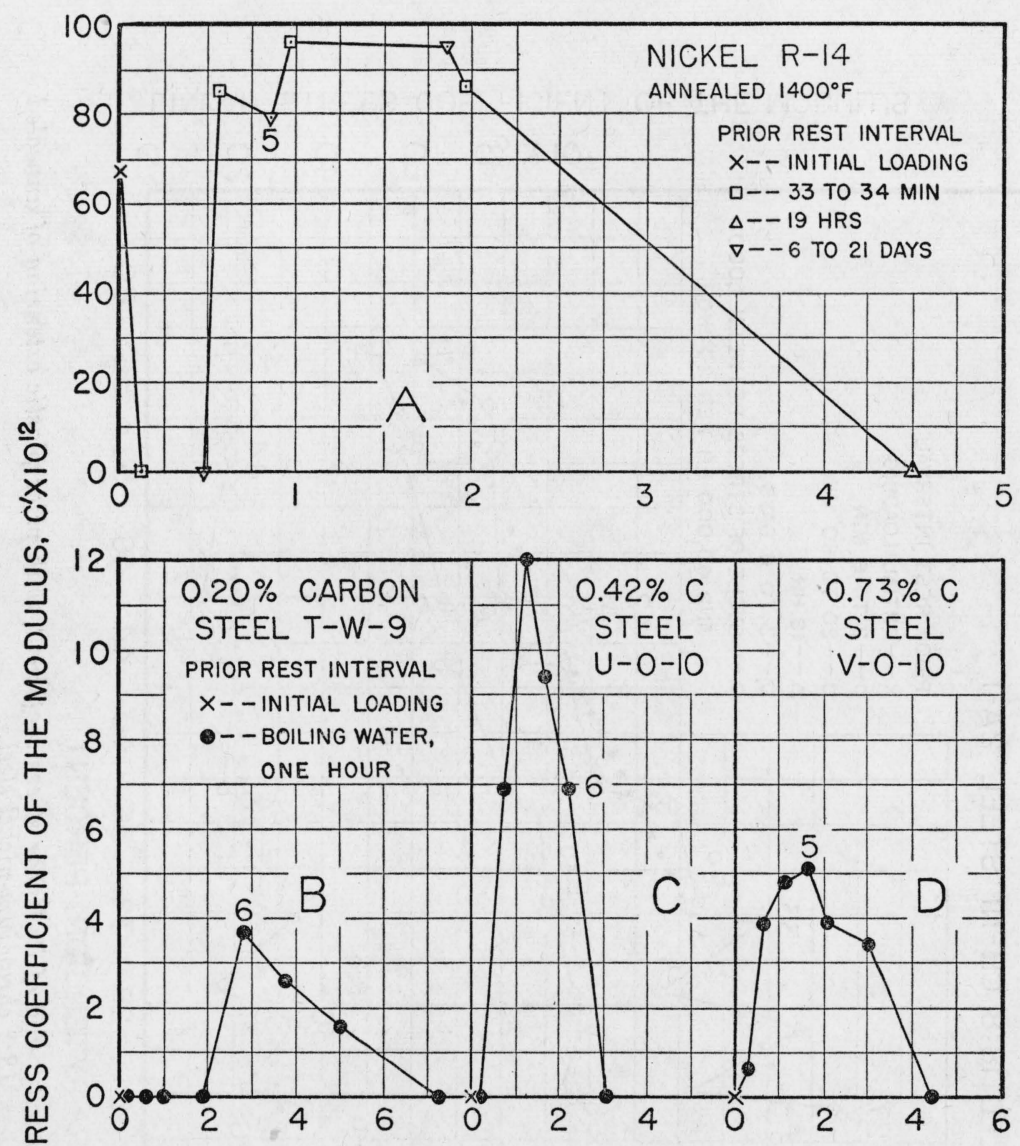

点

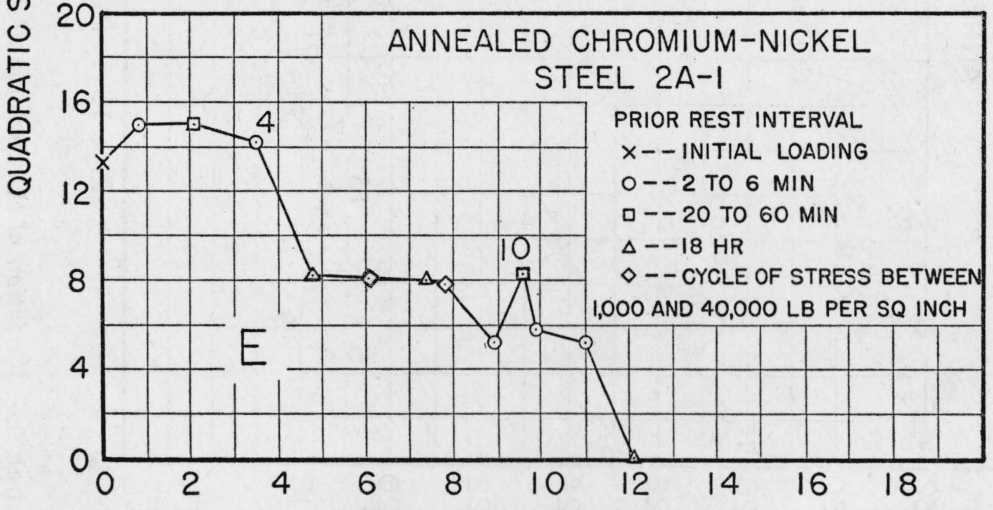

PRIOR EXTENSION, PERCENT

Figdre 10.-Variation of the quadratic stress coefficient, $C^{\prime}$, with prior plastic extension; nickel and various steels. 


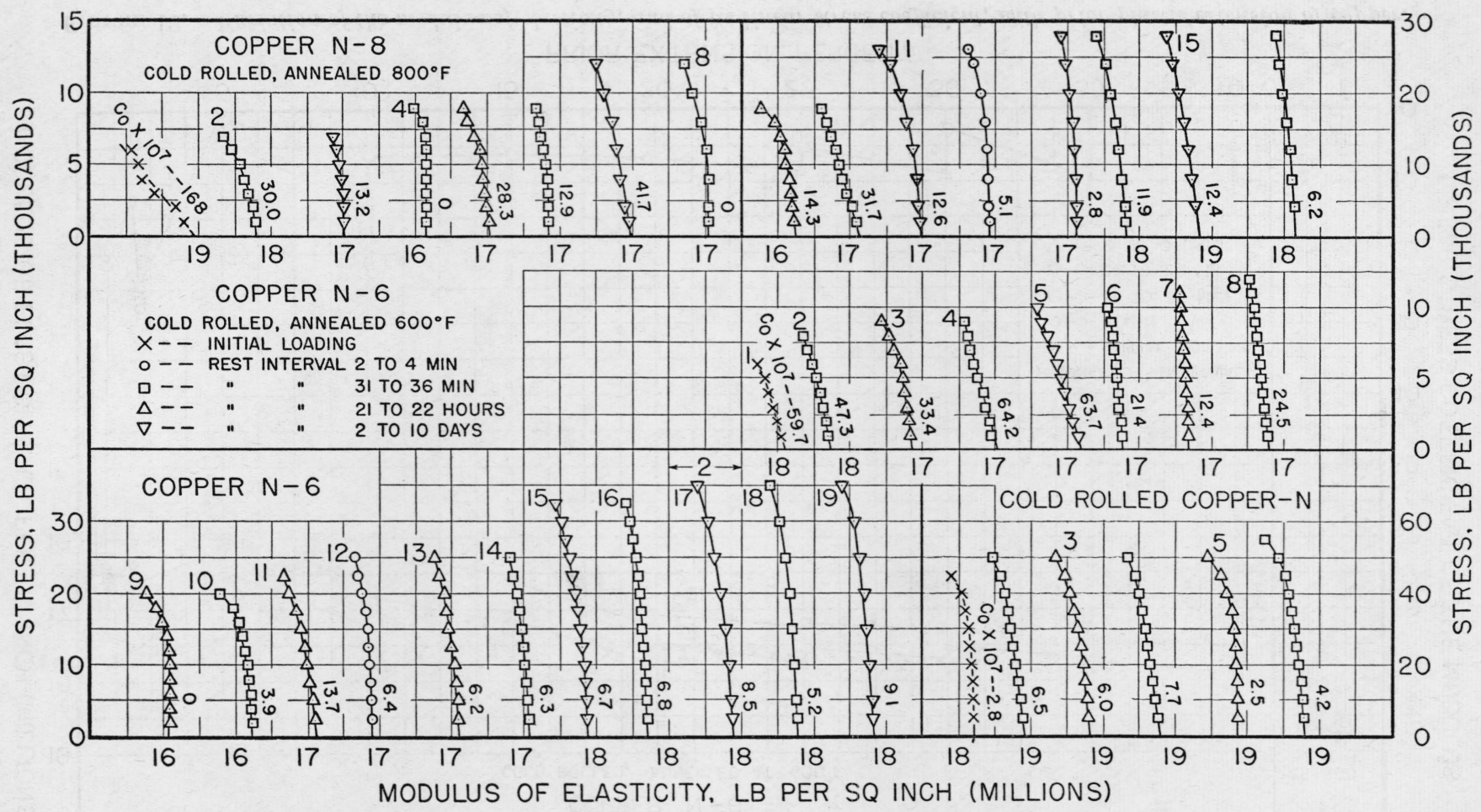

है

FIGURE 11.-Stress-modulus lines after various amounts of plastic extension of copper. 


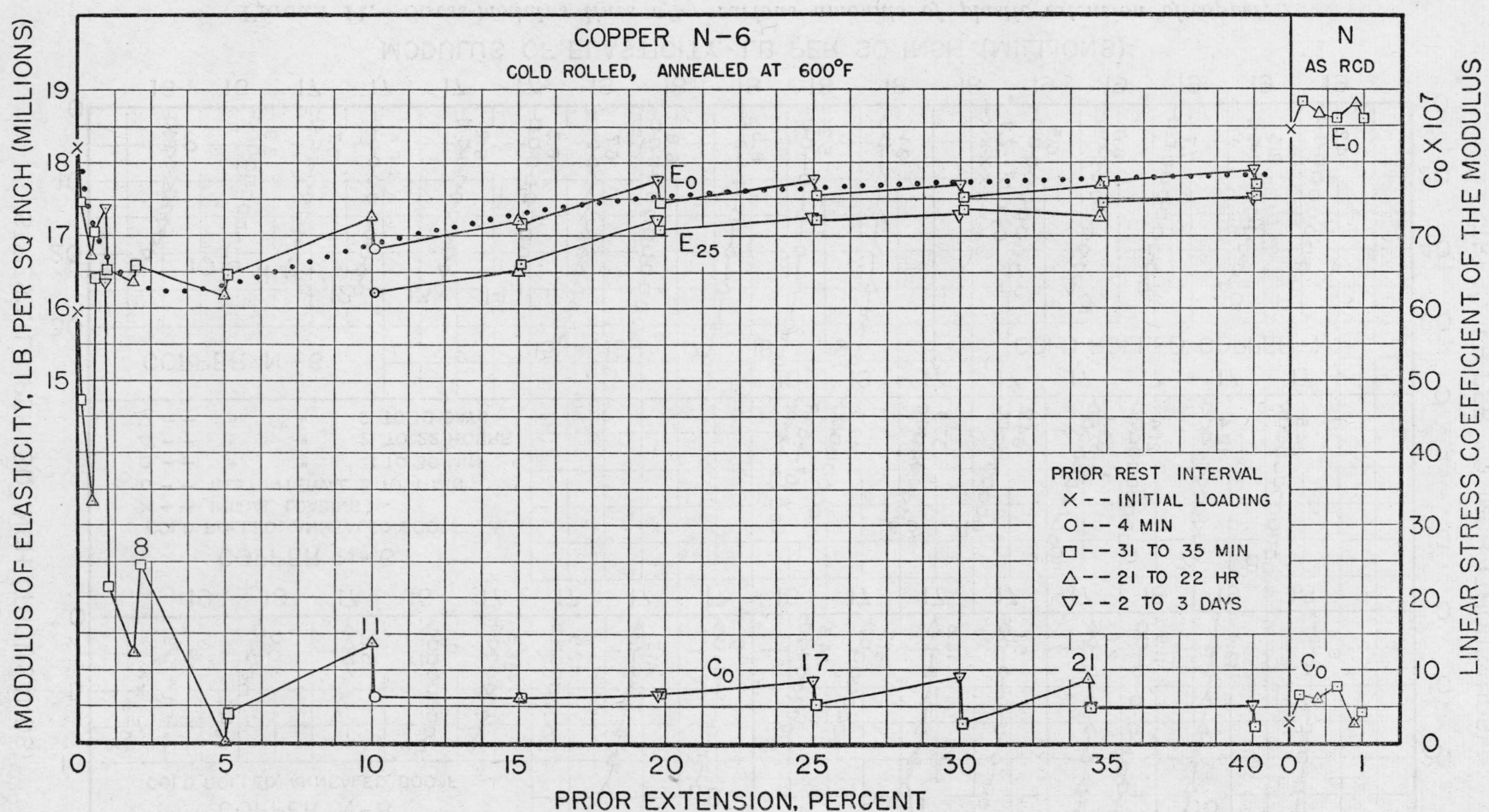

FIGURE 12.-Variation of the modulus of elasticity, and of its linear stress coefficient, with prior plastic extension of copper. 


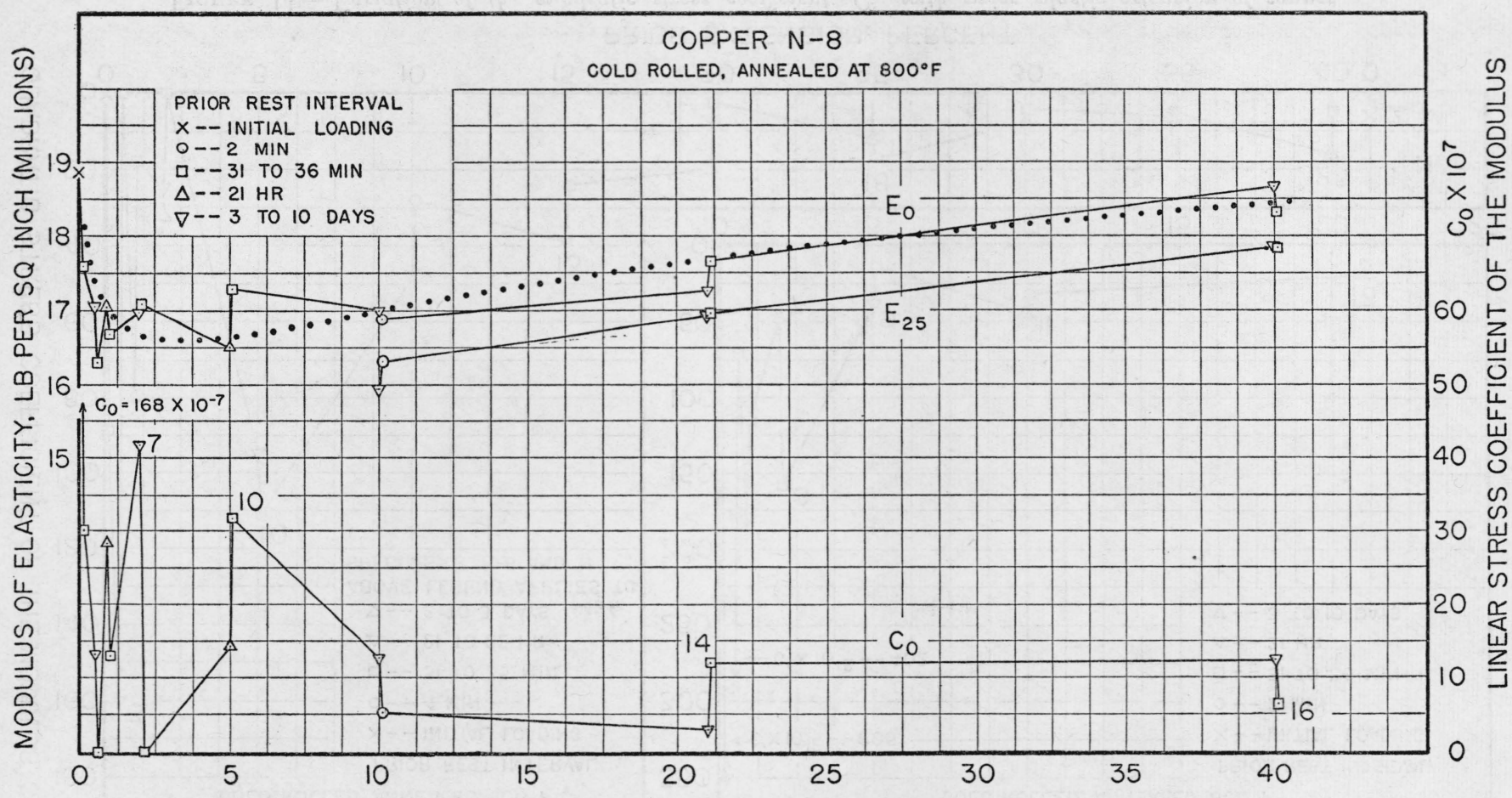

PRIOR EXTENSION, PERCENT

FIGURE 13.-Variation of the modulus of elasticity, and of its linear stress coefficient, with prior plastic extension of annealed copper. 


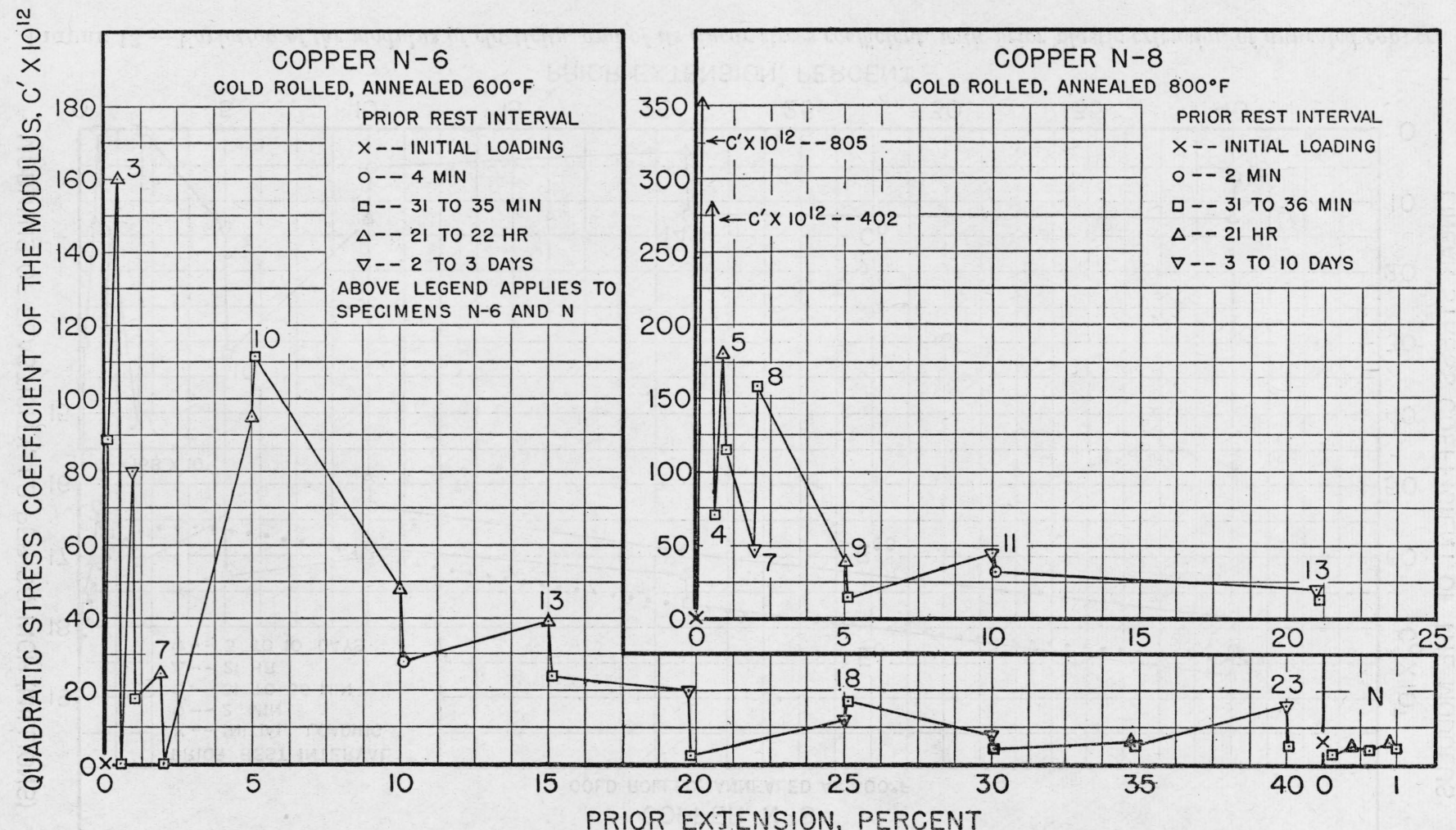

FIGURE 14.-Variation of the quadratic stress coefficient, $C^{\prime}$, with prior plastic extension of copper. 


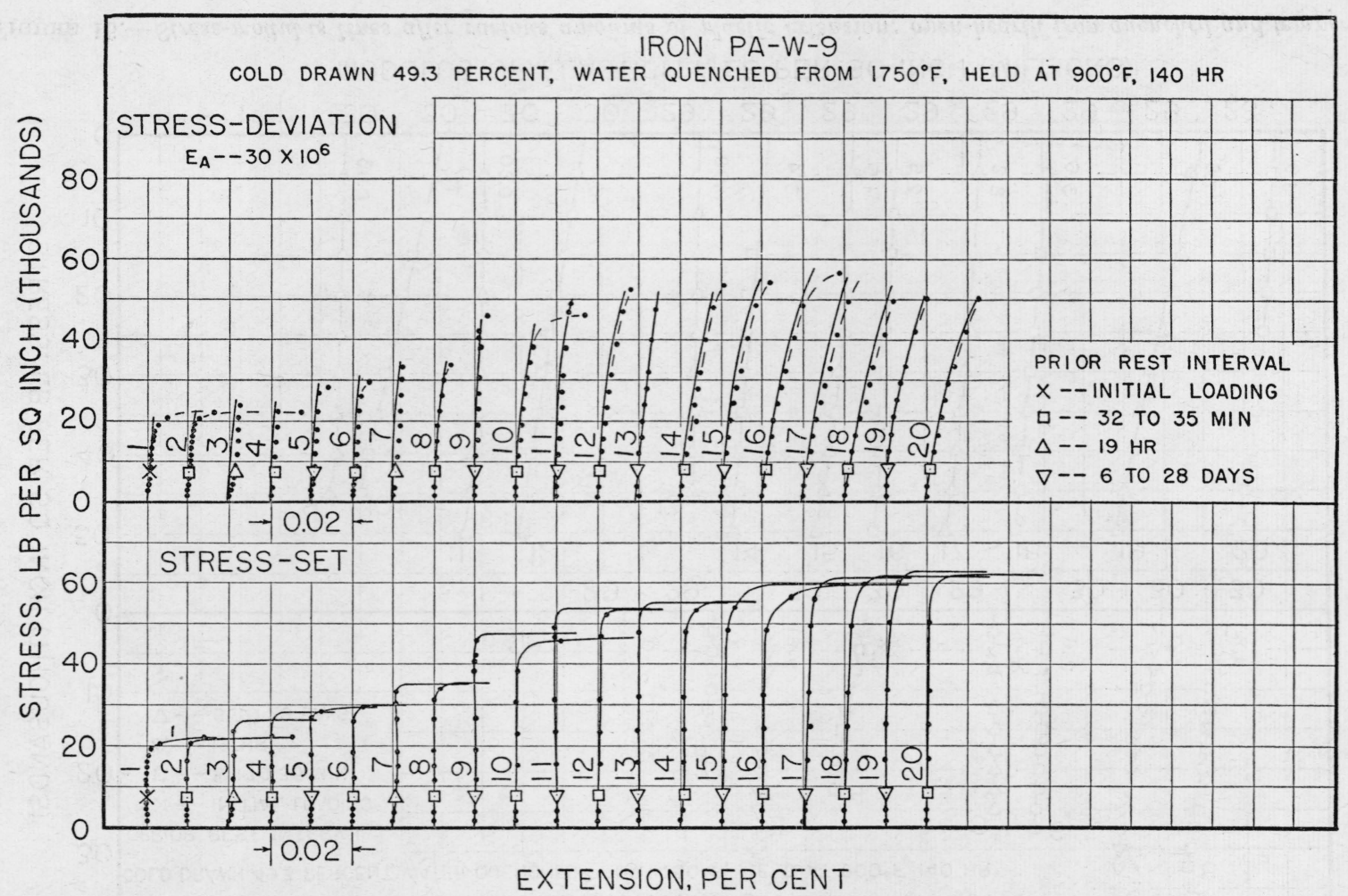

FIGURE 15.-Stress-deviation and stress-set curves after various amounts of plastic extension; open-hearth iron quenched and tempered. 


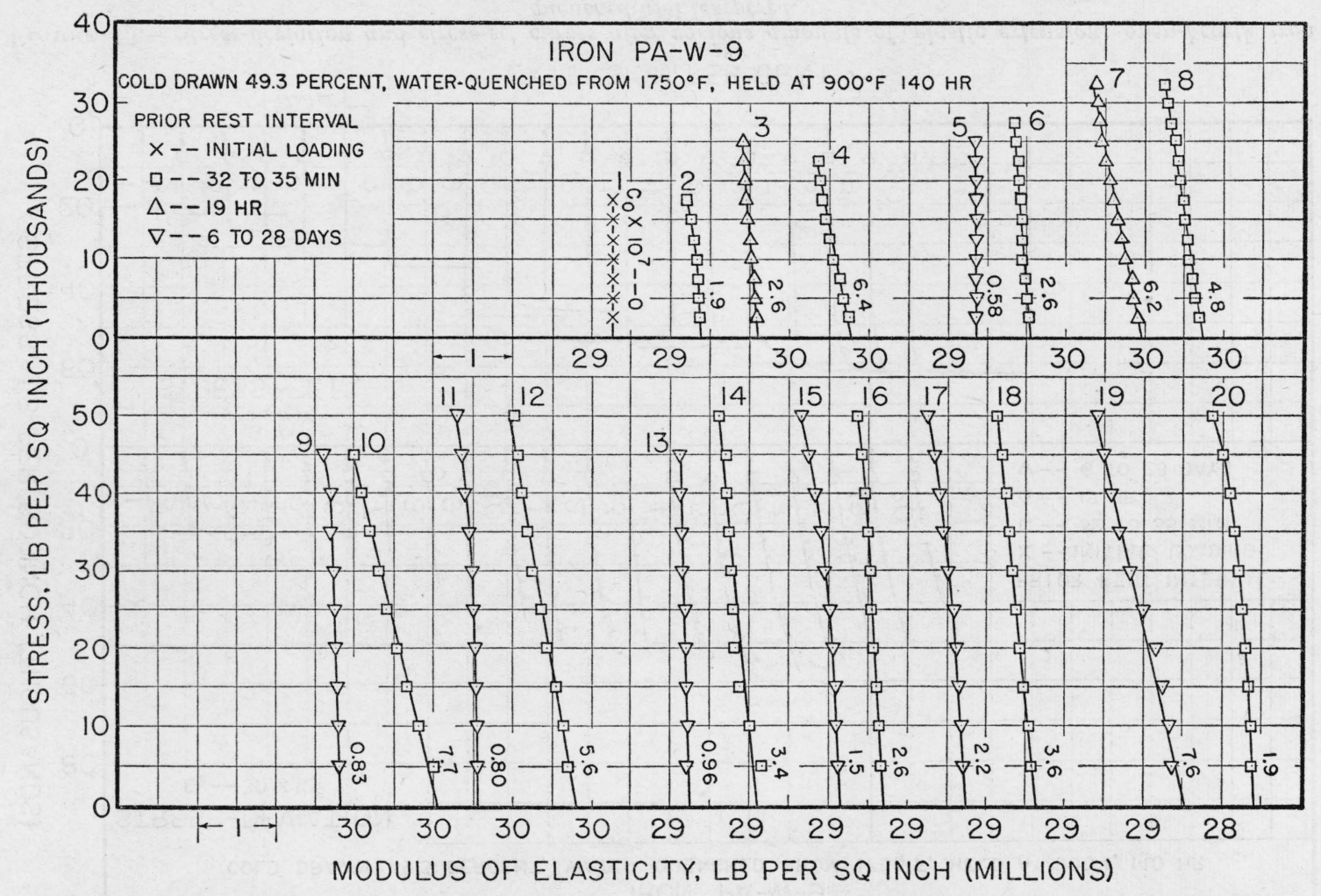

FIGURE 16.-Stress-modulus lines after various amounts of plastic extension; open-hearth iron quenched and tempered. 


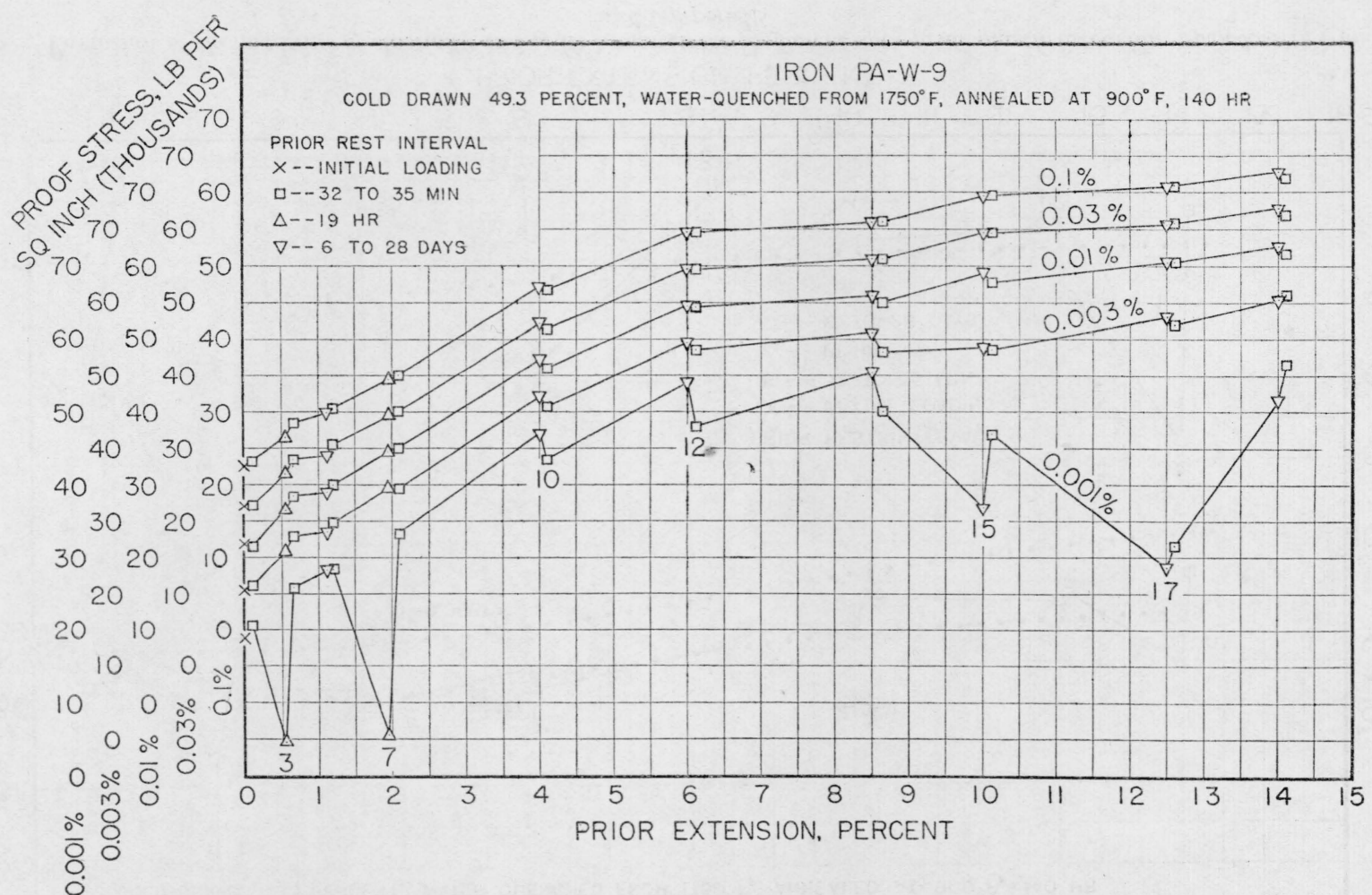

वें.

FIGURE 17.-Variation of proof stresses with prior plastic extension; open-hearth iron quenched and tempered. 


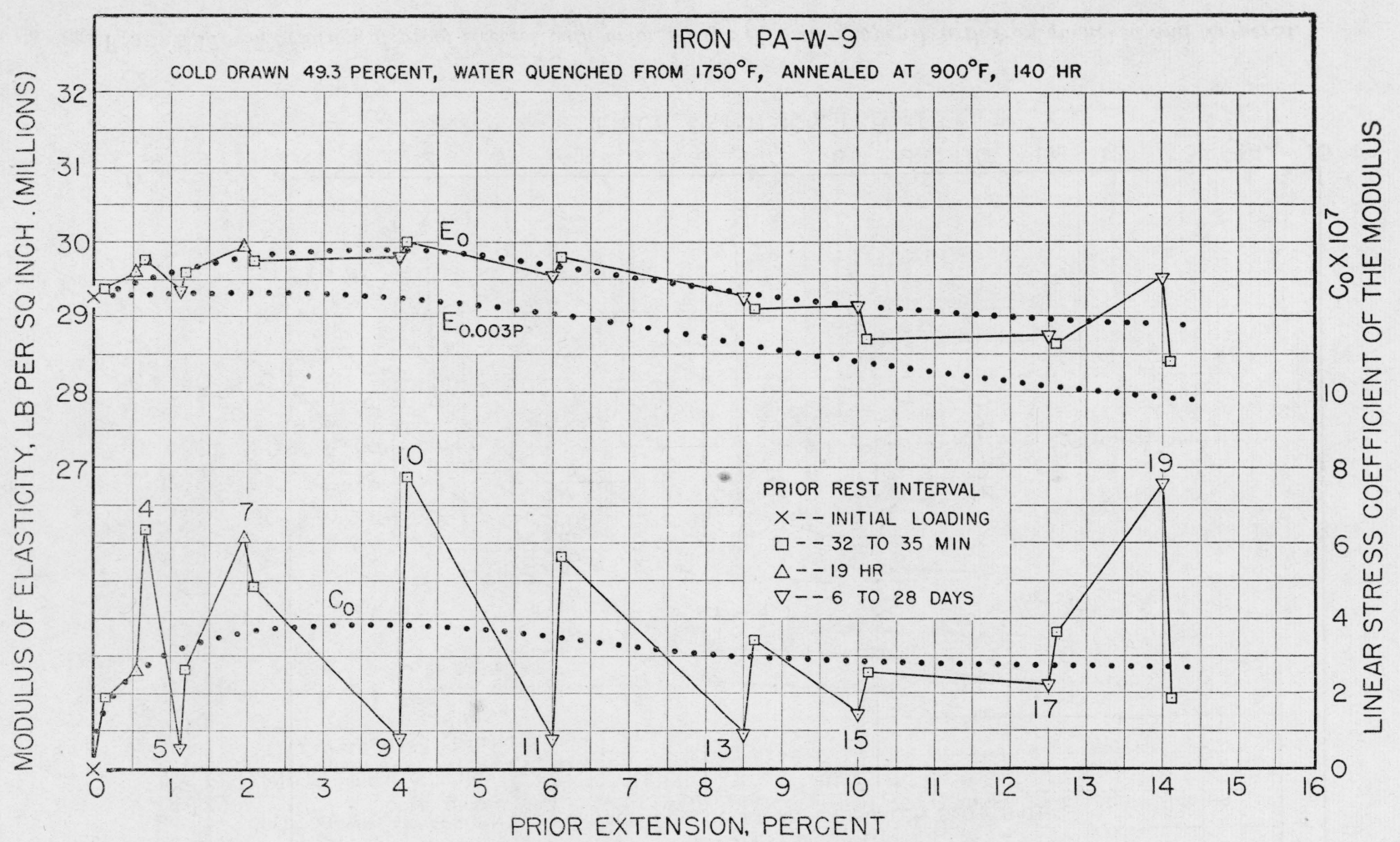




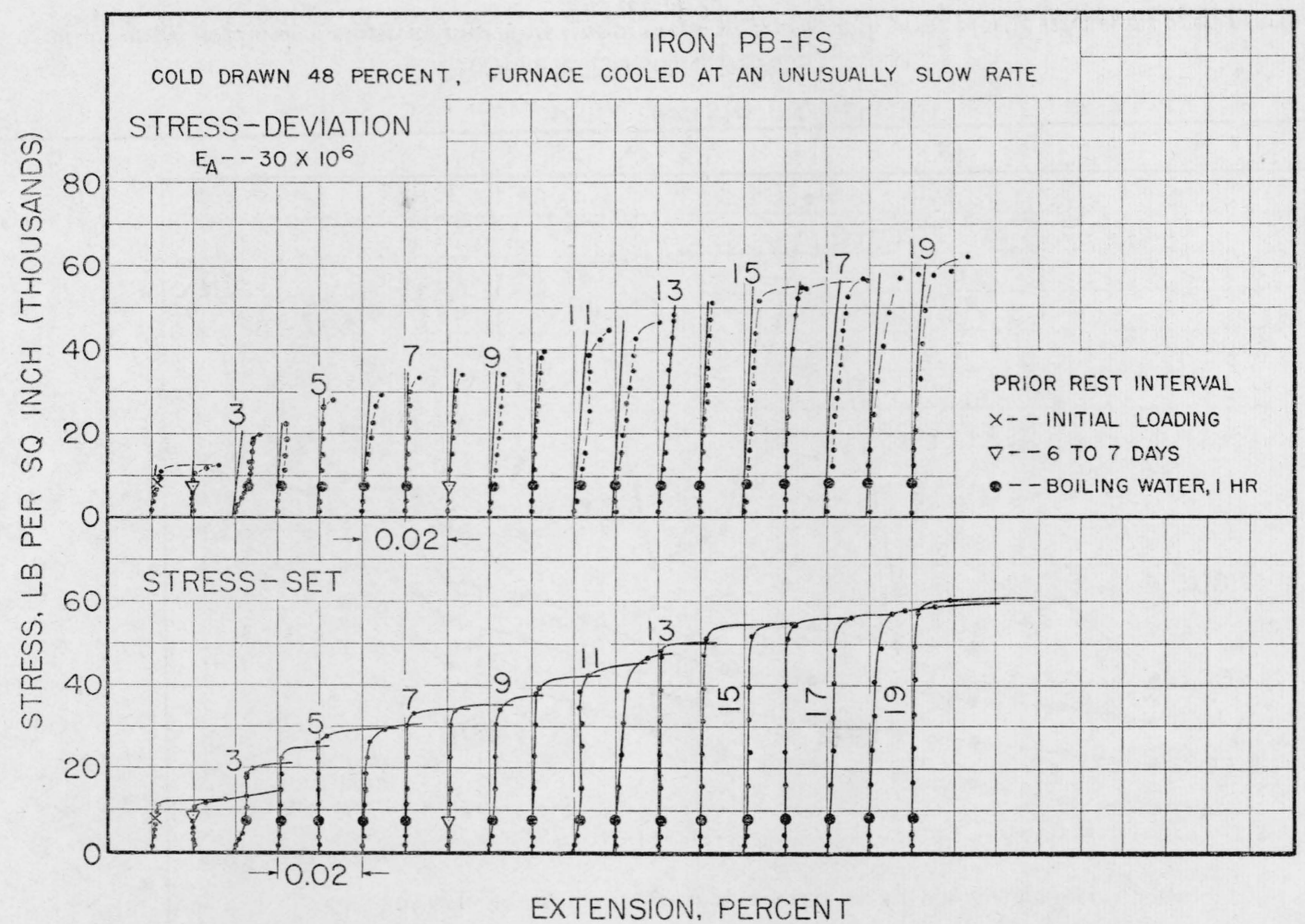

FIGURE 19.-Stress-deviation and stress-set curves after various amounts of plastic extension; open-hearth iron annealed. 


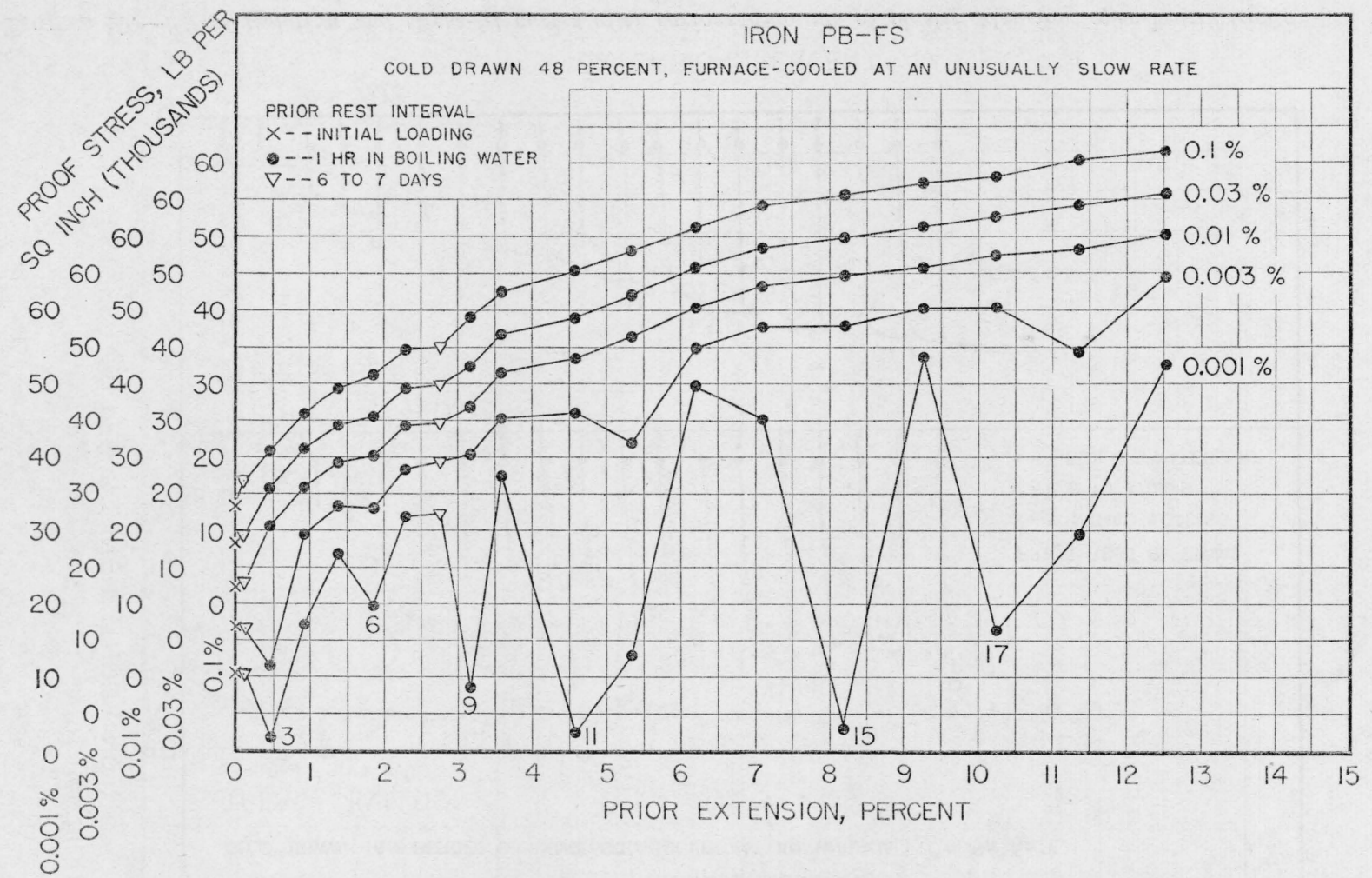

FIGURE 20.-Variation of proof stresses with prior plastic extension; open-hearth iron annealed. 


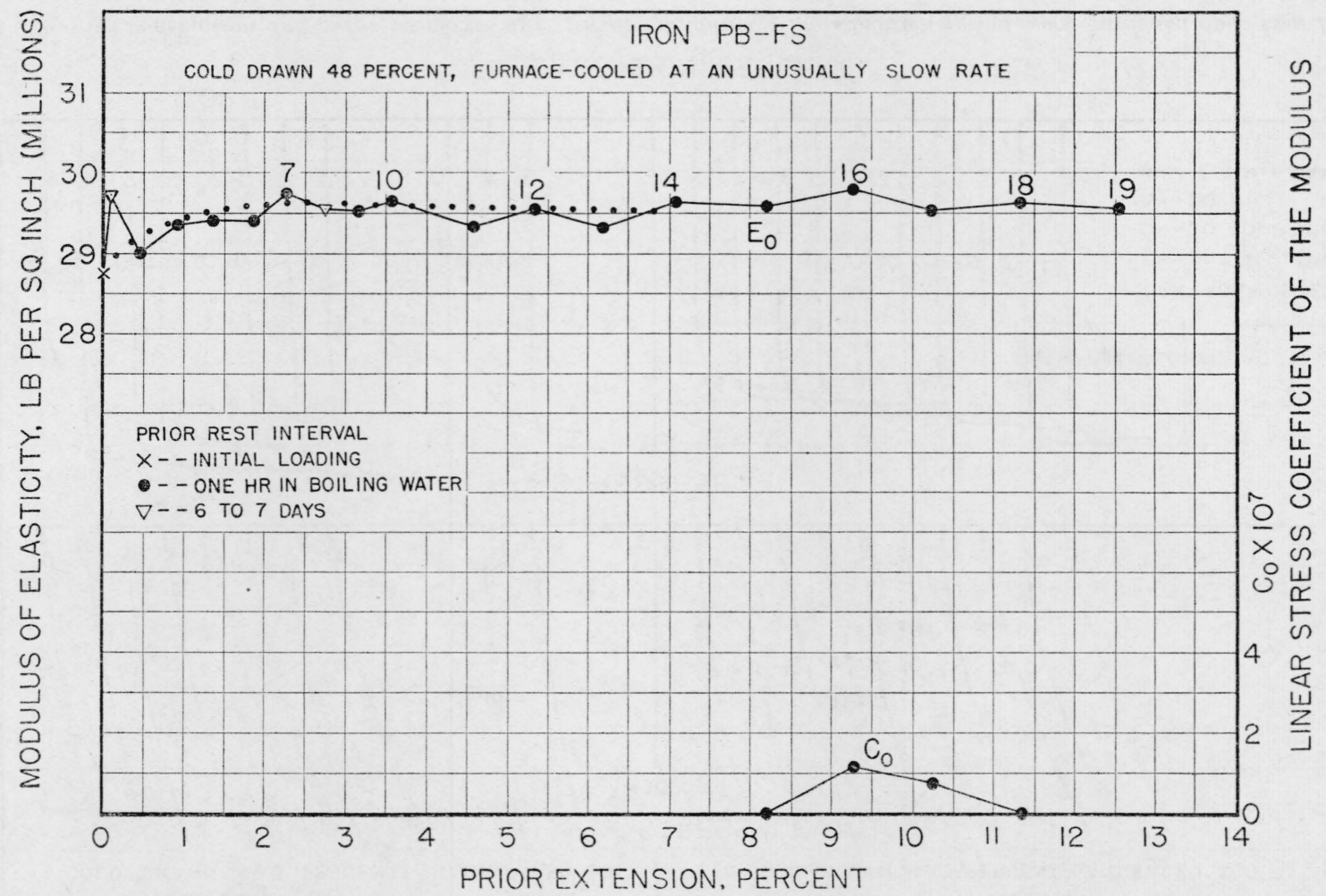
annealed. 


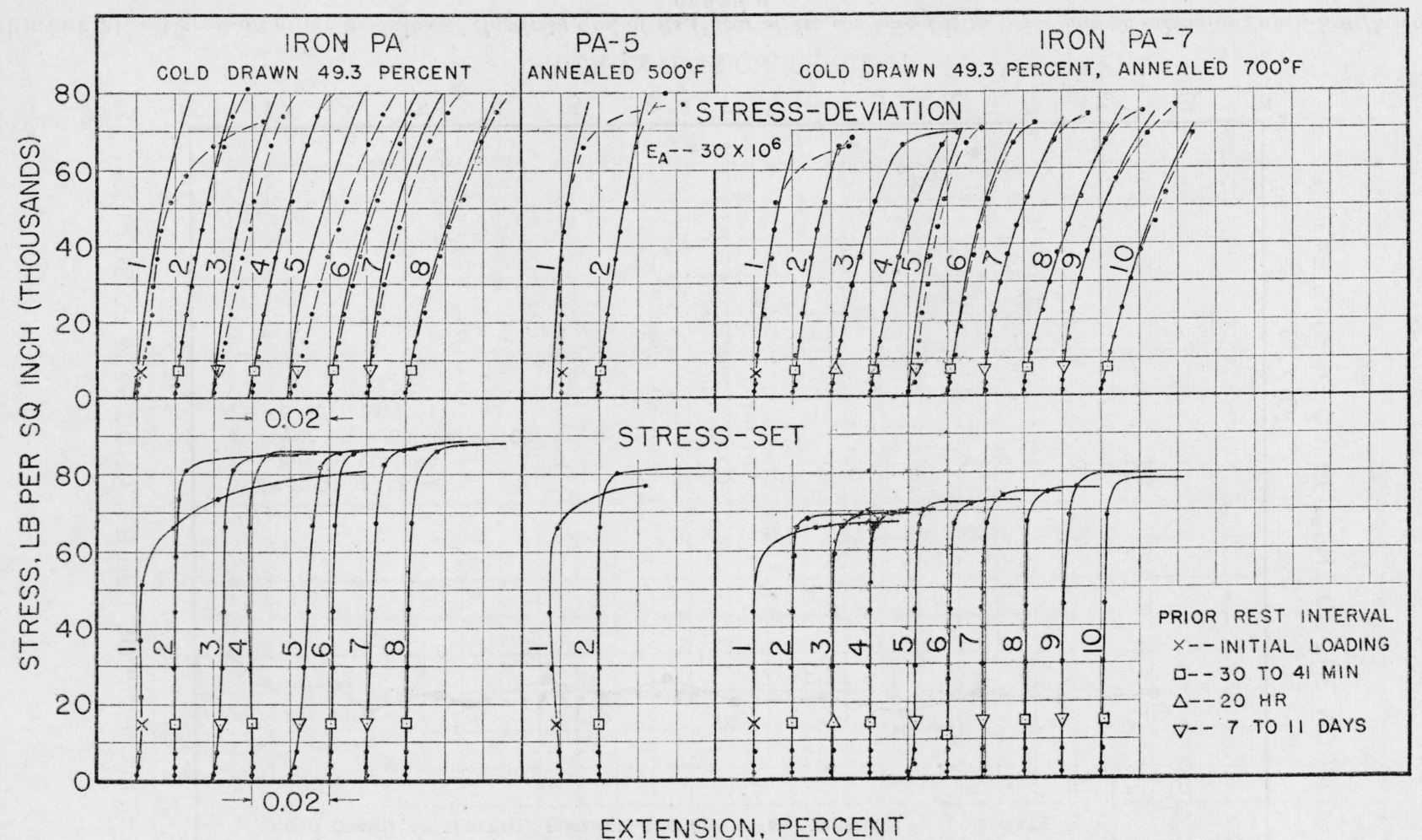

FIGURE 22.-Stress-deviation and stress-set curves after various amounts of plastic extension of work-hardened open-hearth iron. 


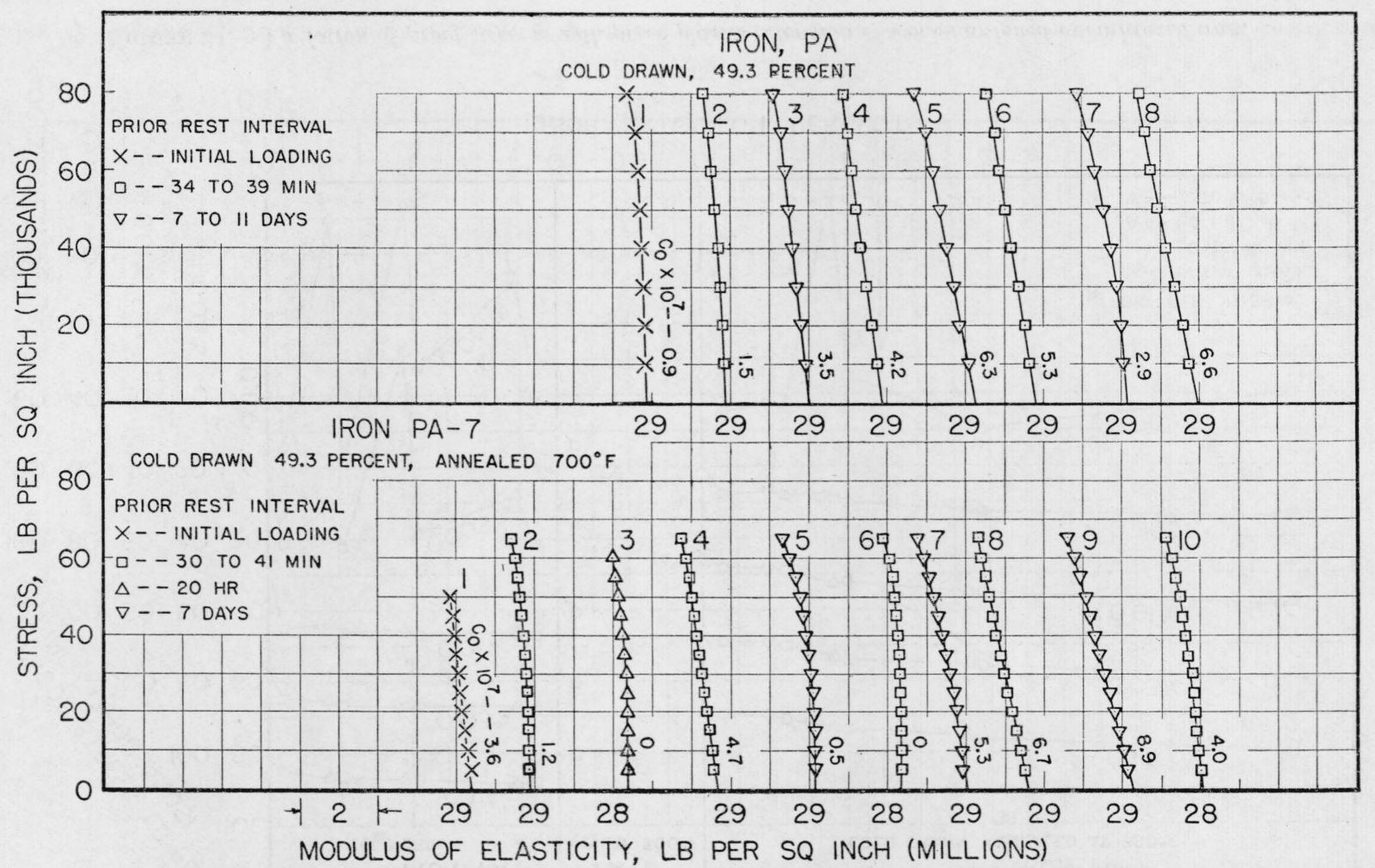

FIGURE 23.-Stress-modulus lines after various amounts of prior plastic extension of work-hardened open-hearth iron. 


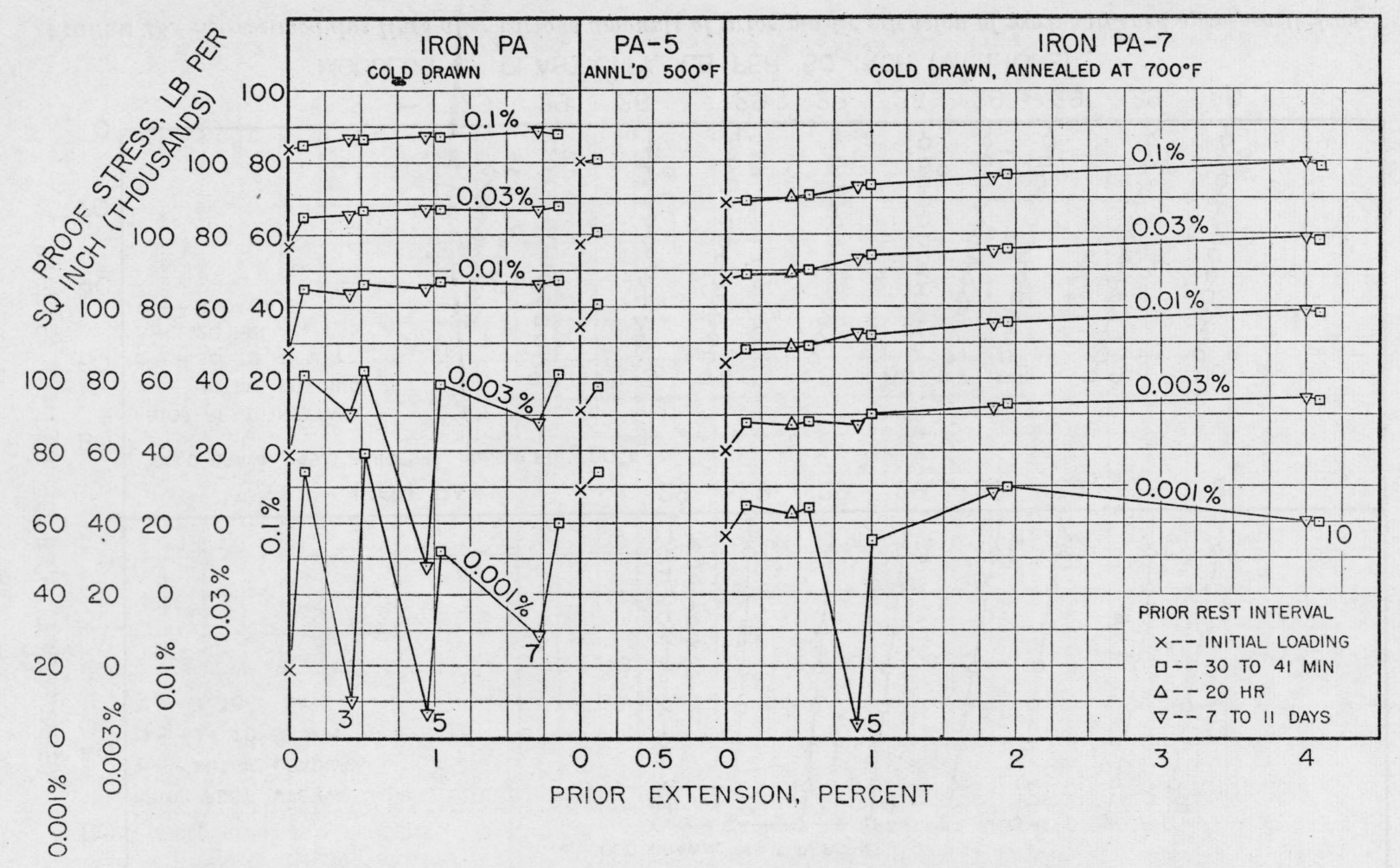

1)

FIGURE 24.-Variation of proof stresses with prior plastic extension of work-hardened open-hearth iron. 


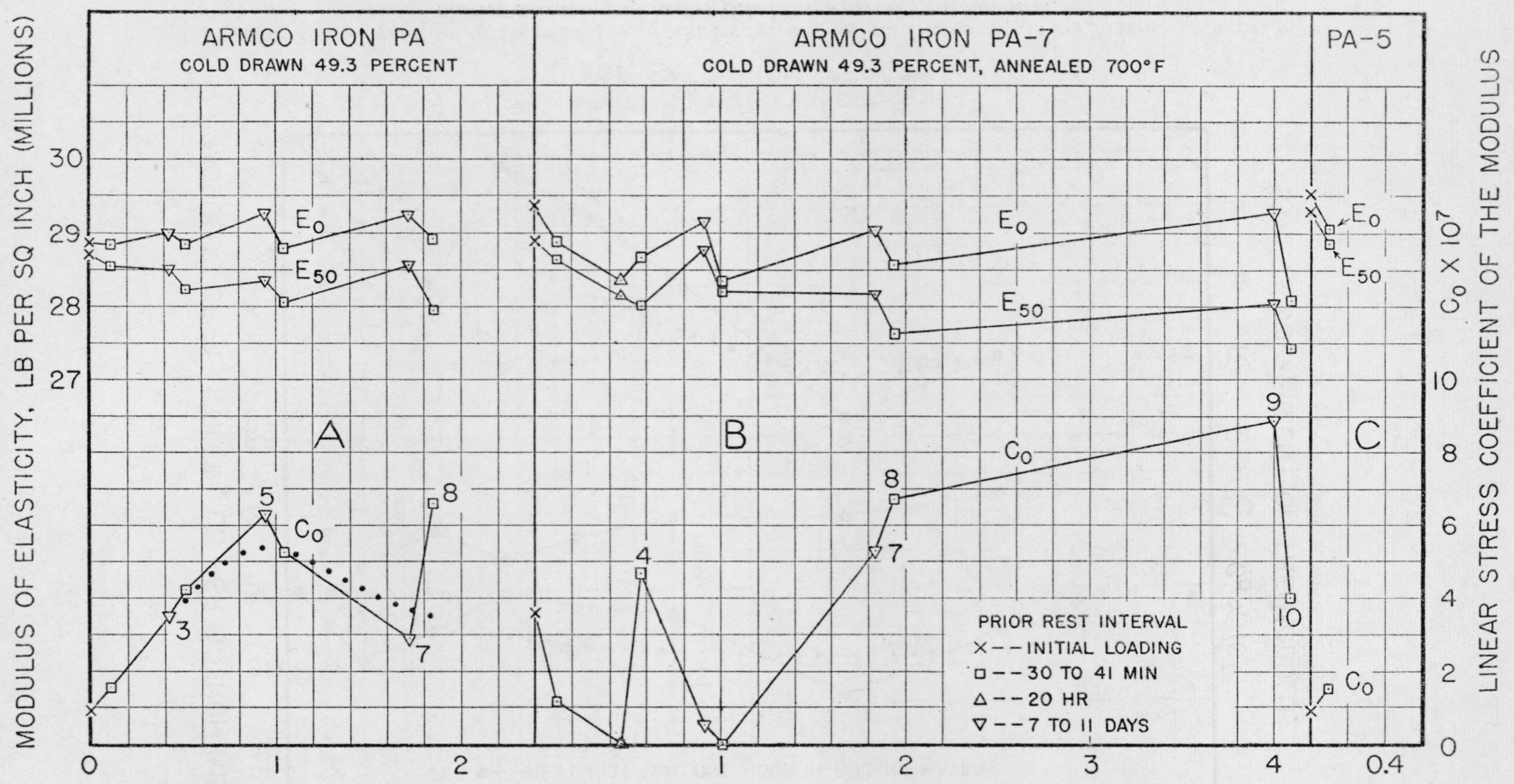

PRIOR EXTENSION, PERCENT

FIGURE 25.-Variation of the modulus of elasticity, and of its linear stress coefficient, with prior plastic extension of work-hardened open-hearth iron. 


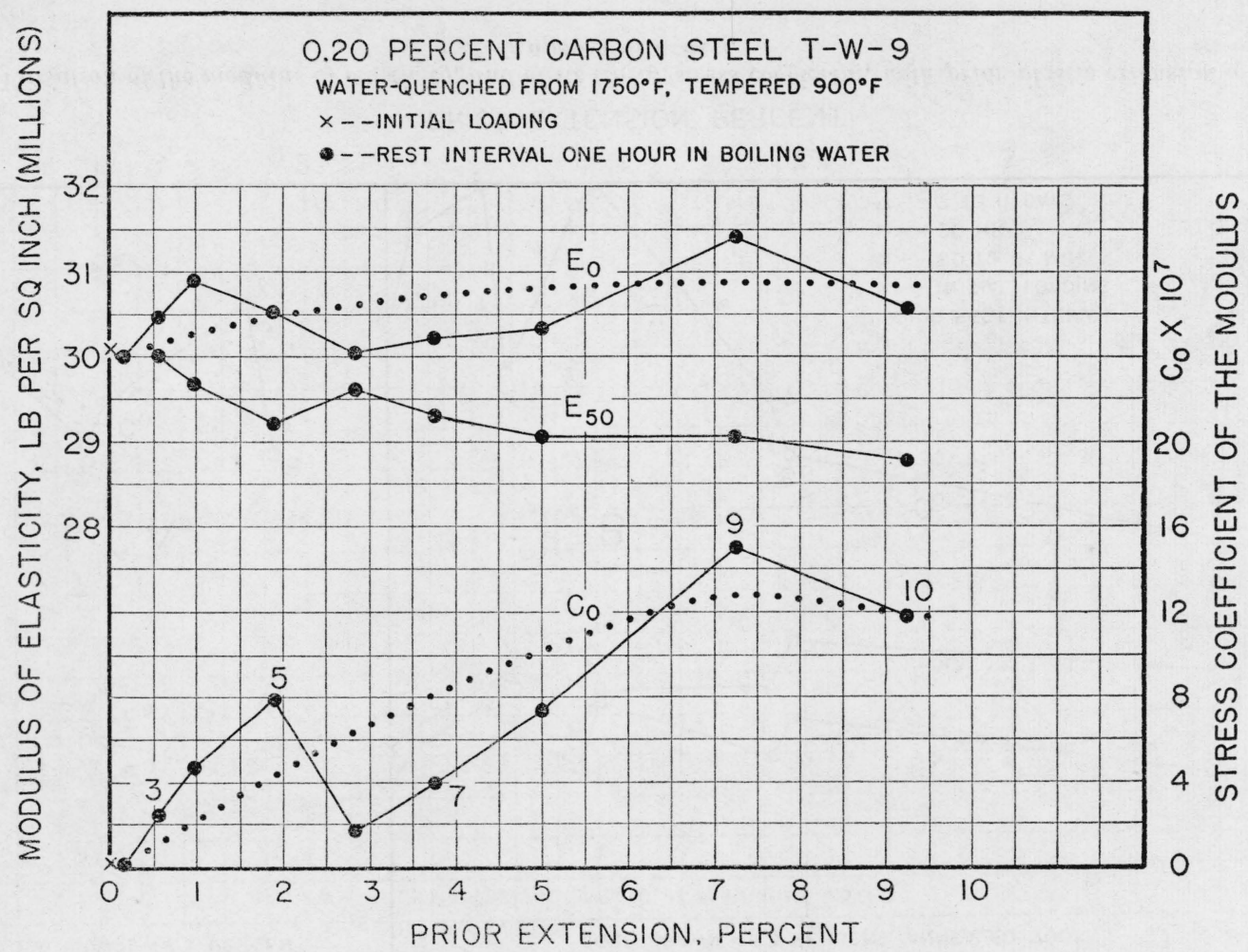

FIGURE 26.-Variation of the modulus of elasticity, and of its linear stress coefficient, with prior plastic extension of heat-treated 0.20 -percent carbon steel. 


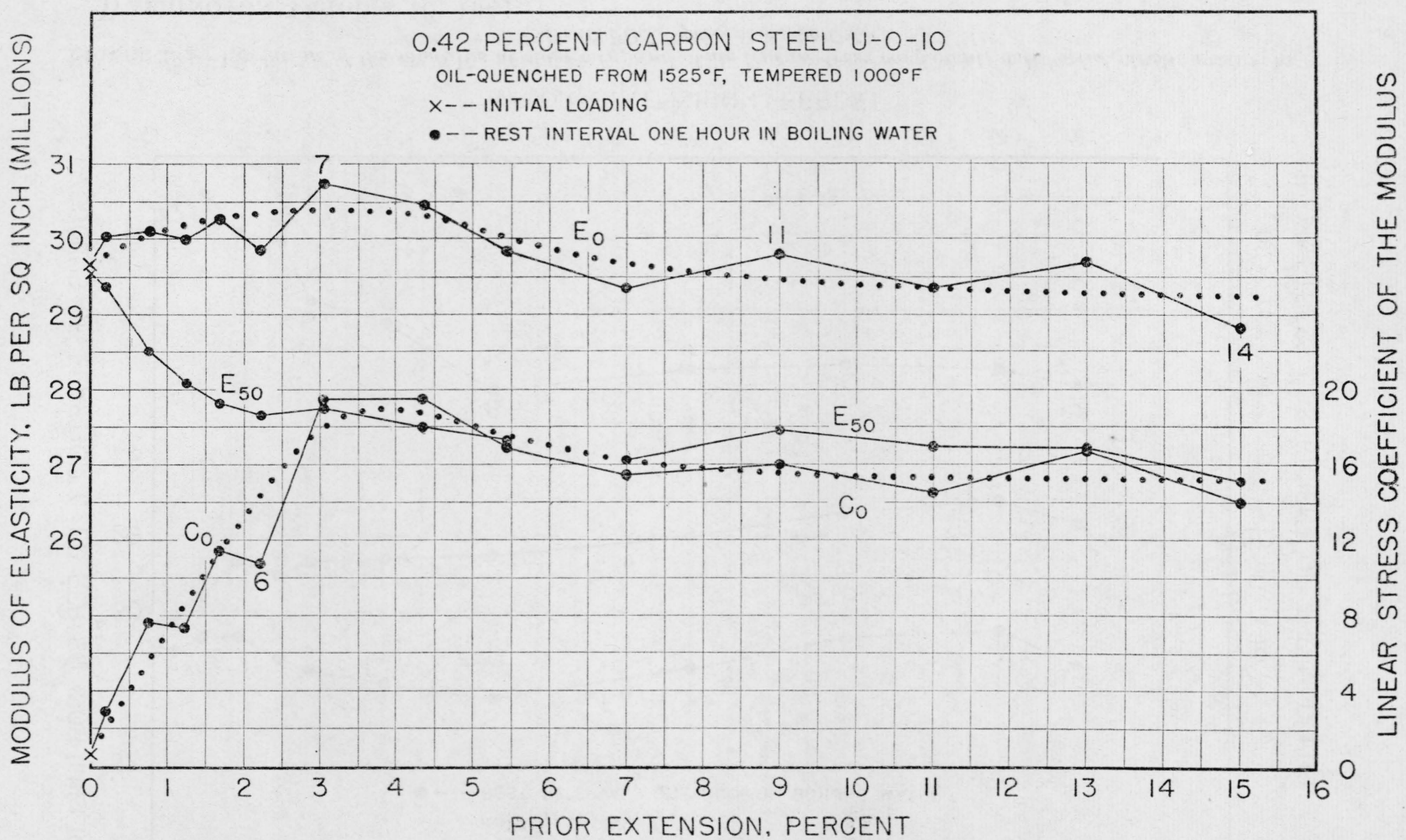

FIGURE 27.-Variation of the modulus of elasticity, and of its linear stress coefficient, with prior plastic extension of heat-treated $0.42-$ percent carbon steel. 


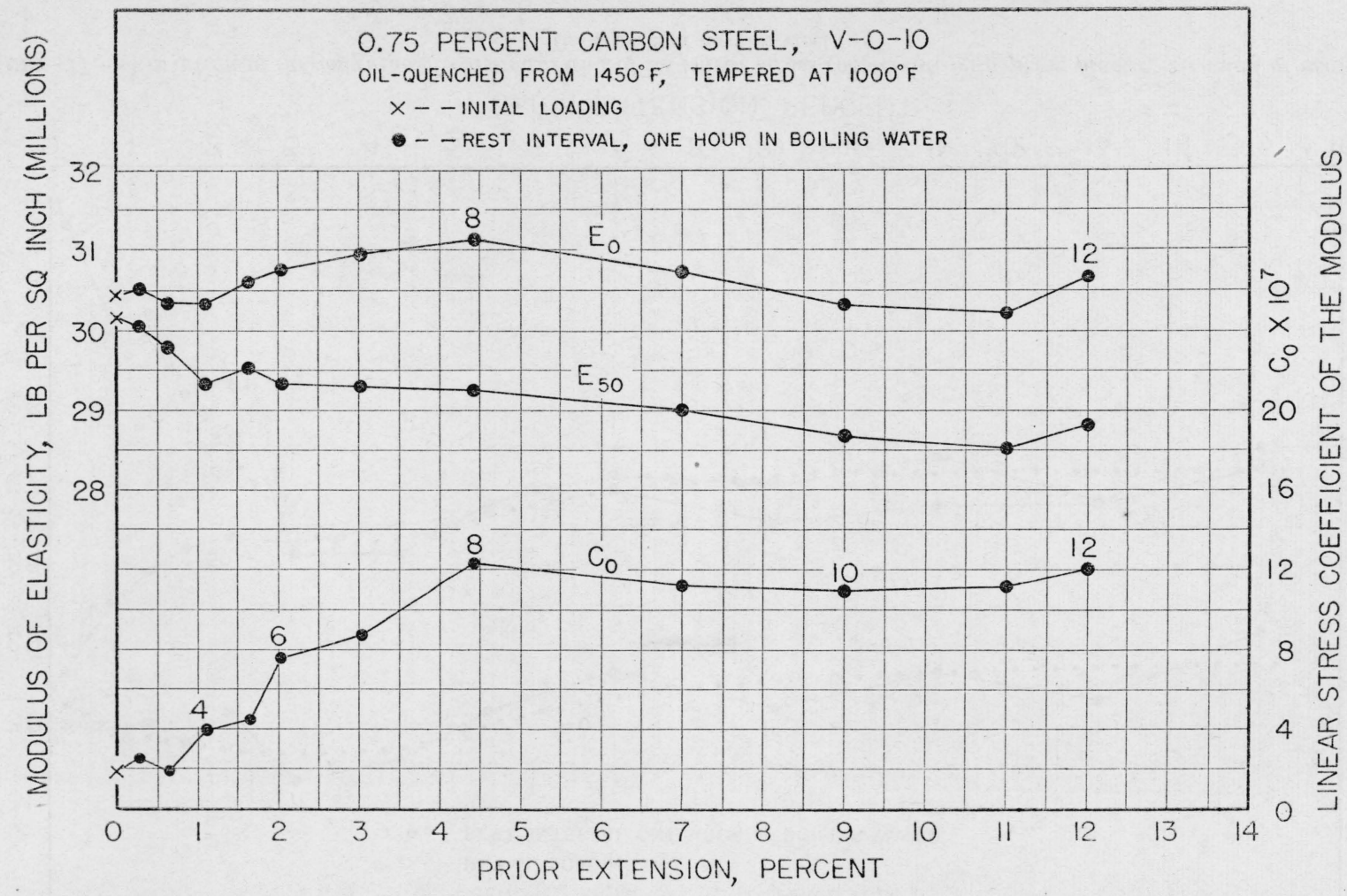
LIENCHED FROM $1450^{\circ} \mathrm{F}$, TEMPERED AT $1000^{\circ} \mathrm{F}$

है

FIGURE 28.-Variation of the modulus of elasticity, and of its linear stress coefficient, with prior plastic extension of Washington, October 10, 1941 . 


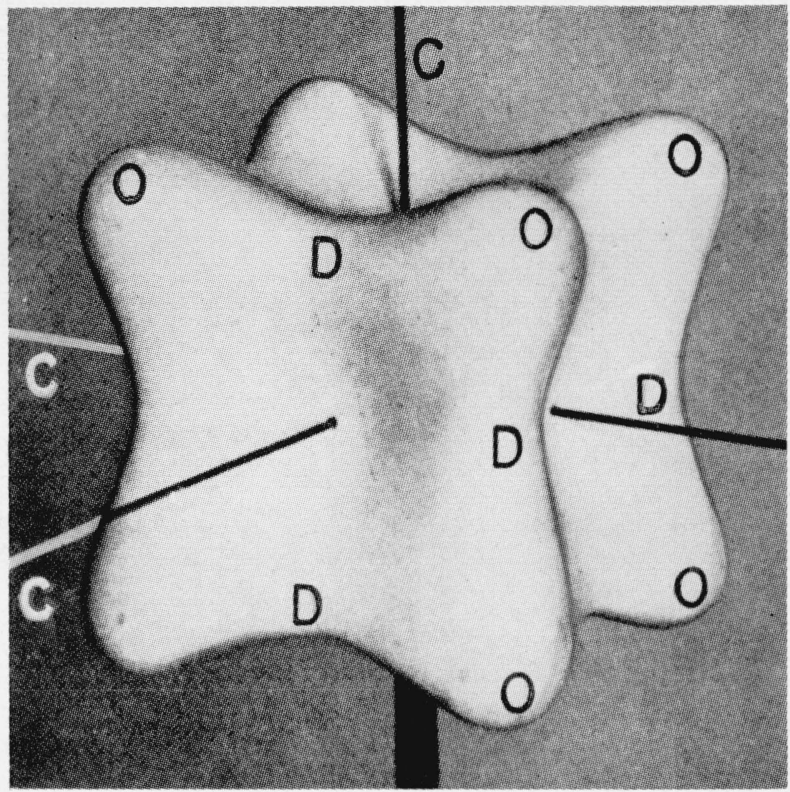

Figure 29.-Directional variation of the tensile modulus of elasticity of a crystal of gold.

$C$, cubic; $O$, octahedral; $D$, dodecahedral.

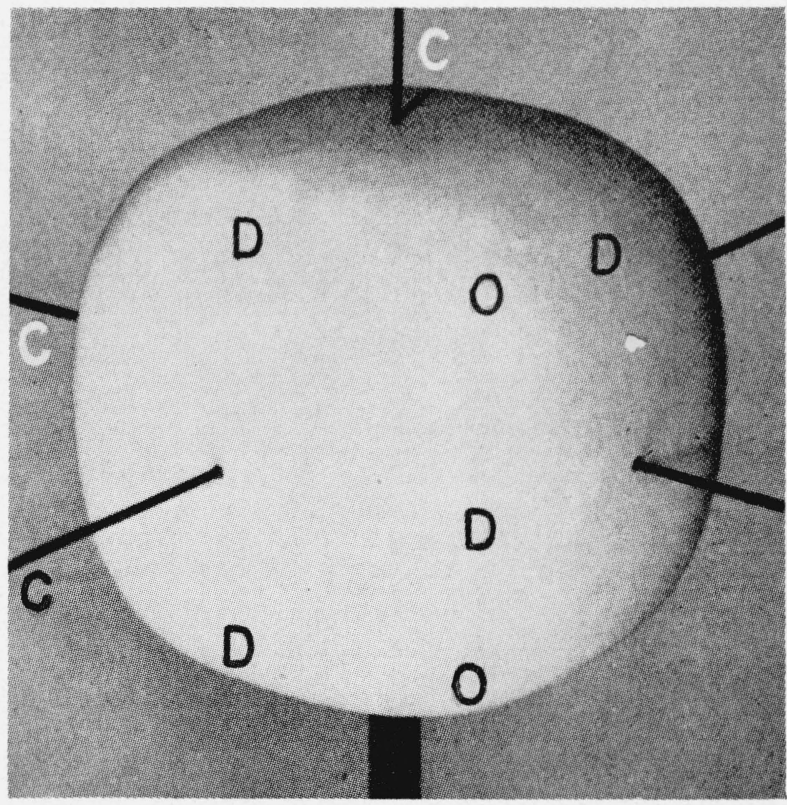

Figure 30.-Directional variation of the tensile modulus of elasticity of a crystal of aluminum.

$C$, cubic; $O$, octahedral; $D$, dodecahedral. 


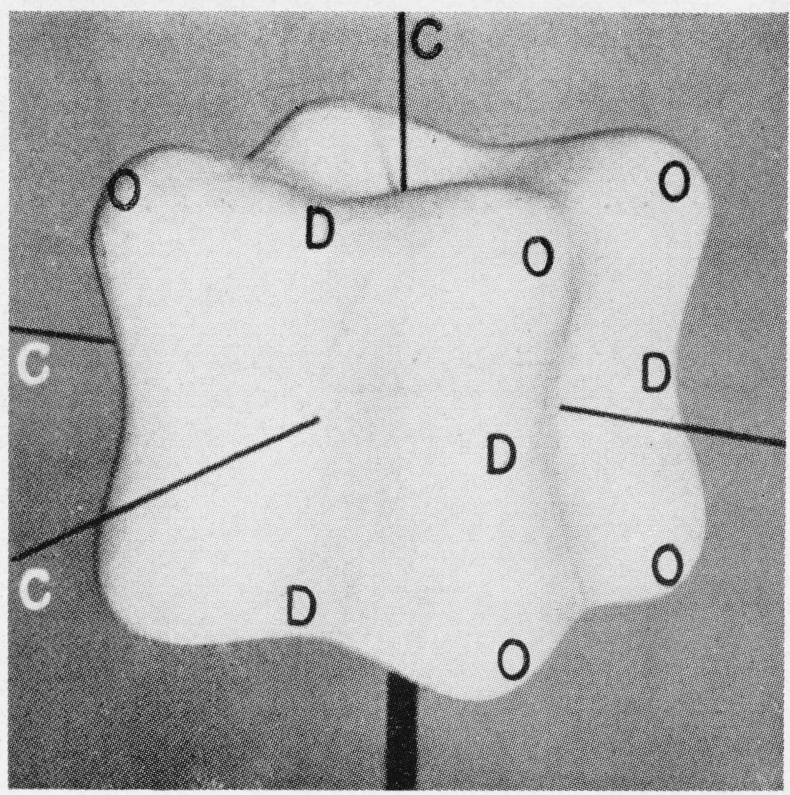

Figure 31.-Directional variation of the tensile modulus of elasticity of a crystal of alpha iron.

$C$, cubic; $O$, octahedral; $D$, dodecahedral.

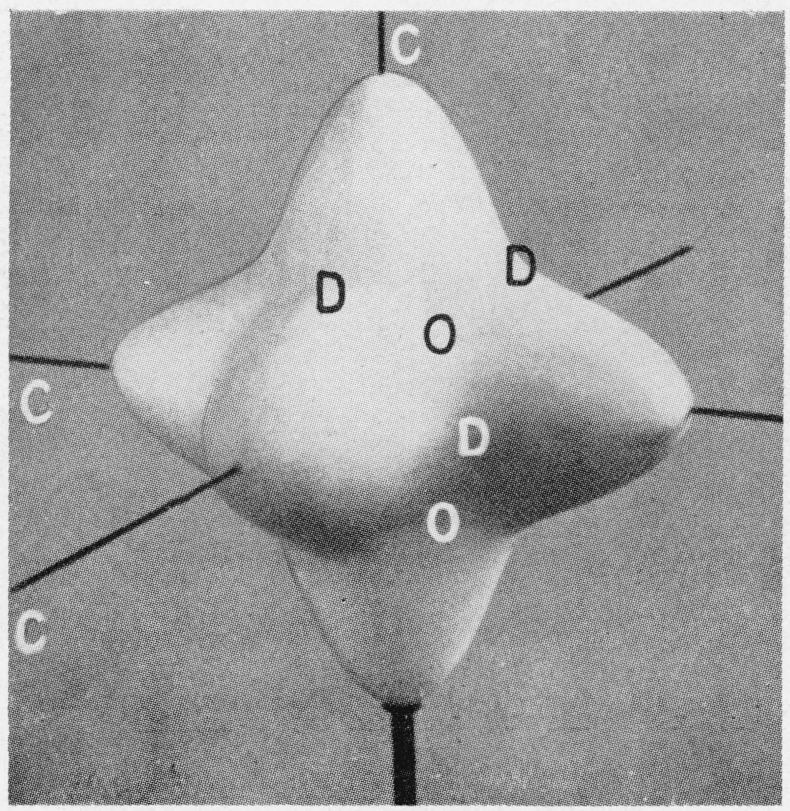

FIGURE 32.-Directional variaiion of the shear modulus of elasticity of a crystal of alpha iron.

$C$, cubic; $O$, octahedral; $D$, dodecahedral. 


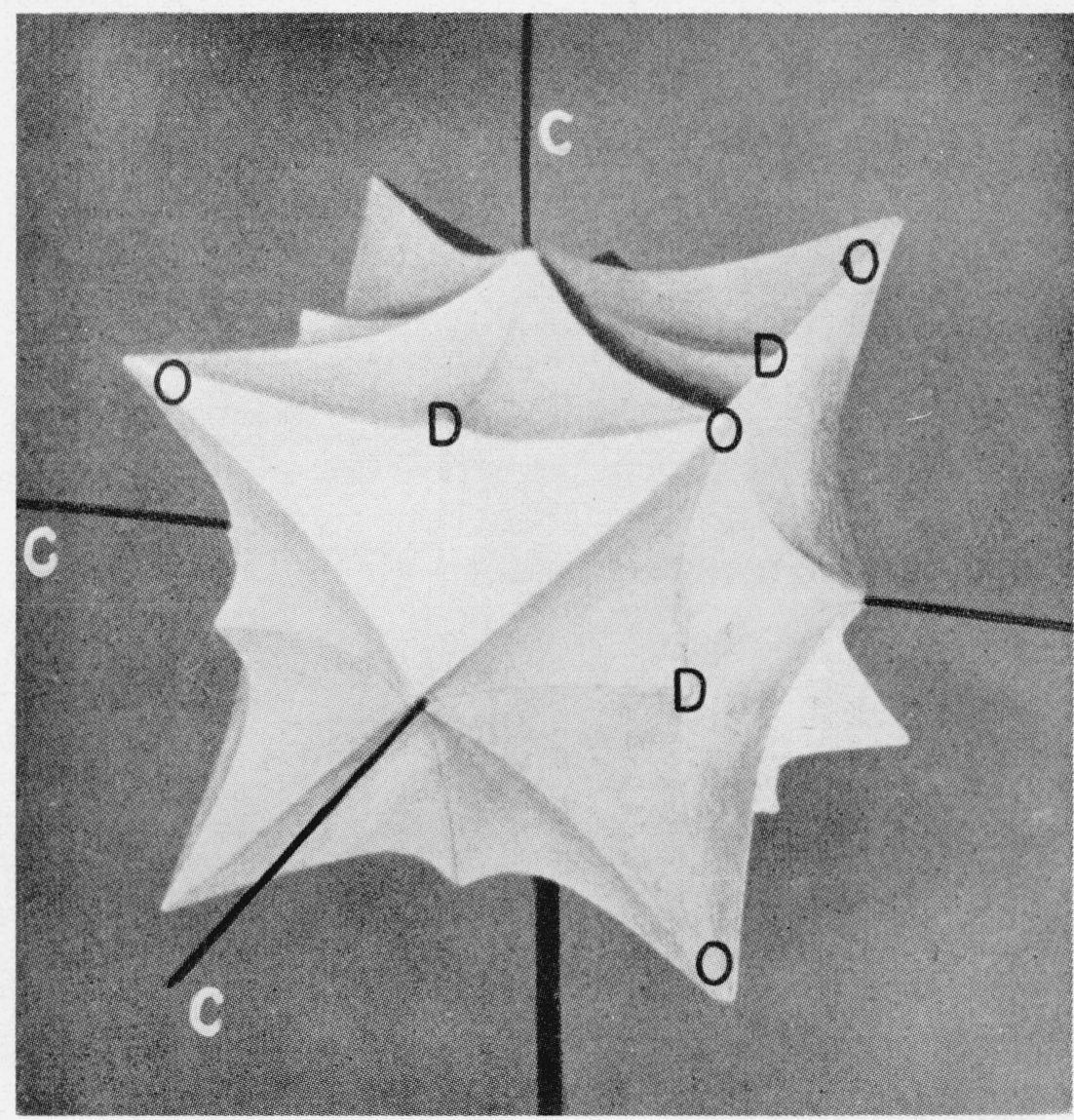

FIGURE 33.-Directional variation of the elastic limit of a face-centered cubic crystal. $C$, cubic; $O$, octahedral; $D$, dodecahedral. 